POSITIVE ADAPTATIONS TO

WEIGHT-LIFTING TRAINING IN THE ELDERLY 


$$
\begin{aligned}
& \text { POSITIVE ADAPTATIONS TO } \\
& \text { WEIGHT-LIFTING TRAINING IN THE ELDERLY }
\end{aligned}
$$

BY

ALLAN BANNERMAN BROWN, B.P.E.

A Thesis

Submitted To The School of Graduate studies

in Partial Fulfilment of The Requirements

for the Degree

Master of science

McMaster University

April 1991 

MASTER OF SCIENCE (1991) MCMASTER UNIVERSITY (Human Biodynamics) Hamilton, Ontario

TITLE: Positive Adaptations To Weight-1ifting Training in the Elderly
AUTHOR: Allan Bannerman Brown, B.P.E. (McMaster University)

SUPERVISOR: Dr. Neil McCartney

NUMBER OF PAGES: 93 


\section{ABBTRACT}

Maximal weight-lifting performance, isometric strength, isokinetic torque, whole muscle and individual fibre cross-sectional areas, and muscle evoked contractile properties were assessed in 14 elderly males before and after 12 weeks of weight-lifting training. Dynamic elbow flexion training of one arm resulted in a significant $48 \%$ mean increase in the maximal load that could be lifted once ( $1 \mathrm{RM}$ ) and a smaller improvement in isokinetic torque (8.8\%) but no change in isometric strength. In the contralateral control arm, 1 RM and isokinetic torque increased by 12.7 and $6.5 \%$, respectively, but isometric strength did not change. The interpolated twitch technique confirmed complete motor unit activation during a maximal isometric contraction of the elbow flexors before and after training. Bilateral leg press training effected mean increases of 17 and $23 \%$ in isokinetic torque and dynamic lifting capacity, respectively. The mean maximal cross-sectional area of the elbow flexors (biceps brachii and brachialis) increased by 17.48 in the trained arm but did not change in the control arm. The increase in the mean area of the Type II fibres in the biceps brachii muscle in the trained arm $(30.2 \%)$ was greater than the corresponding change in the control arm (10.7\%, $\mathrm{P}<0.05)$. The most 
significant change in the the evoked contractile properties of the trained elbow flexors was the increase in twitch half-relaxation time. It is concluded that older individuals retain the potential for significant increases in strength performance and upper limb muscle hypertrophy in response to overload training. 
TO MY MOTHER AND FATHER, WHO TAUGHT THEIR SON TO OPEN WIDE HIS EYES AND WONDER. 


\section{ACKNOWLEDGEMENTS}

\section{A very special thank you to:}

Neil, for sowing the seeds and having the patience to watch them come to fruition.

John and Dianne for keeping me humble.

Joan who is a special person.

Duncan, Audrey and Joe for instructing me in the subtleties of conference attendance.

All of the students and classmates of the Physical Education Department who have given me many happy days in the sun.

And finally to Digby Sale, who sat me down on a slice of the Canadian shield one afternoon and told me what life was all about. 


\section{TABLE OF CONTENTS}

\section{Section}

Abstract

Page

Acknowledgements

viii

Table of Contents ix

List of Tables and Figures xiii

1.0 Background and General Overview 1

1.1 Adaptations to Resistance Training

in Young Adult Muscle

1.1 .1

1.1.2

1.1 .3

Increased Voluntary Strength

Increased Muscle Mass

iv

The effects of Strength Training on

Muscle Morphology.

1.1 .4

Neural Adaptations to Resistance

1.2

1.2 .1

Training.

Age Related Changes in Skeletal Muscle

Decreased Muscular Performance.

Decreases in whole Muscle and Muscle

Fibre Size.

1.2 .3

Previous Training studies in the Elderly.

SUMMARY AND STATEMENT OF PURPOSE

2.1

Methods

subjects

Training and Study Design

Measurement of Voluntary Strength 19

(2.

Weight Lifting strength

2.4. 1

Apparatus

2.6.1 Measurement of Muscle Fibre

2.7.1 Statistics 
Voluntary Strength

Weight Lifting Capacity

Changes in Muscle Performance and Muscle Size.

Voluntary Weight Lifting strength.

\section{REFERENCES}

6.0

A

B

$C(i)$

(iv)

\section{APPENDICES}

Positive Adaptations to Weight-lifting

Training in the Elderly.

The number of repetitions that could be completed by the subjects after the training with a load that corresponded to their pre-training 1 RM.

The maximum weight lifting strength of various muscle groups measured before and after 12 weeks of training.

Maximal Isokinetic Torque of the legs (upper) and arms (lower) before and after training.

The evoked contractile properties of the elbow flexors of both arms recorded at joint angles of 75, 120, and 165 degrees, before and after training.

The maximum isometric strength of various muscle groups before and after 12 weeks of training. 
(v) Mean cross-sectional areas of the arm flexor and extensor compartments before and after training.

(vi) Mean cross-sectional area of the leg flexor and extensor compartments before and after training.

(vii) Mean cross-sectional area of the leg flexor and extensor compartments before and after training.

(viii) Mean cross-sectional areas of Type $I$ and Type II fibres in trained and untrained arms before and after training.

(ix) The mean number of Type I and Type II fibres digitized in both trained and untrained arms before and after training.

(x) Upper Panel-The maximum cross-sectional areas of the elbow flexors and extensors determined by computed tomography in the trained and control arm, before and after training.

Lower Panel- The mean fibre area of the Type I and Type II muscle fibres in the elbow flexors of both arms, before and after the training period.

(xi) Percentage of Type I Fibres.

(xii) ET/ST area ratio of the trained and untrained arms before and after training. $\quad \mathbf{1 0 0}$

(D) Individual subject data. 

Study

\section{Fiqure}

Maximal weight-lifting capacity (1-repetition maximum, 1RM) in trained and untrained arms before (open bars) and after (hatched bars) training. $P<0.05$, change after training and $+P<0.05$, difference between arms.

Maximal (means $\pm S E$ ) weight lifting capacity (1RM) in bench press and bilateral leg press exercises, measured before (open bars) and after (hatched bars) 12 wk of training. " $P<0.001$, increase with training.

Maximal (means $\pm S E$ ) isokinetic leg press torque at $\overline{2}$ angular velocities before and after training." $p<0.0001$, increase with training.

Maximal isokinetic torque during elbow flexion exercise in both arms before (open circles) and after (filled circles) training. " $P<0.01$, overall increase after training. contraction, MVC) during elbow flexion exercise in both arms before lopen circles) and after (filled circles) training. " $P<0.01$, overall increase after training.

Maximal twitch torque during electrically evoked contractions of elbow flexors of both arms before (open circles) and after (filled circles) training. " $P<0.05$, change after training.

Maximal torque-time integral during electrically evoked contractions of elbow flexors of both arms before (open circles) and after (filled circles) training. $p=0.007$, change after training. 
Maximal rates of torque development (MRTD)

during electrically evoked twitch contractions of elbow flexors of both arms before (open circles) and after (filled circles) training. " $P<0.05$, change after training.

Half-relaxation times during electrically evoked twitch contractions of elbow flexors of both arms before (open circles) and after (filled circles) training. " $P<0.05$, change after training.

Maximal rates of torque relaxation (MRTR) during electrically evoked twitch contractions of elbow flexors of both arms before (open circles) and after (filled circles) training. " $P<0.05$, change after training.

11 Contraction time during electrically evoked twitch contractions of elbow flexors of both arms before (open circles) and after (filled circles) training. " $P<0.05$, change after training.

12 Maximal cross-sectional area of elbow flexors in trained and untrained arms before (open bars) and after (hatched bars) training. " $P<0.001$, difference between arms.

Maximal flexor-to-extensor ratio in trained and untrained arms before (open bars) and after (hatched bars) training. " $P<0.05$, change after training and $t P<0.05$, difference between arms.

Mean cross-sectional areas of type II (fasttwitch, ET; top) and I (slow-twitch, 5T; middle fibres and ET-to-ST area ratios (bottom) in biceps brachii muscles of both arms before (open bars) and after (hatched bars) training. " $P<0.05$, change after training (top \& bottom); "p<0.001 and $t P<0.001$, greater increase in $F T$ vs ST fibres in trained are (top). "P<0.01, change after training (middle); $+P<0.05$, difference between arms (bottom). 


\section{CHAPTER 1}

1.0. BACKGROUND AND GENERAL OVERVIEN

1.1. ADAPTATIONS TO REBISTANCE TRAINING IN YOUNG ADULT MUSCLE

1.1.1. INCREASED VOLUNTARY BTRENGTH

Although investigations into strength training had begun as early as the late 19th century, (Lombard, 1892), it was not until Delorme (1945) undertook an investigation of the possible therapeutic applications that the scientific formalizations of weight training was initiated. Using a technique whereby the weight a subject trained with was increased as he/she adapted to the load (called "progressive resistance exercise") DeLorme found that exercising with a small number of repetitions and a heavy weight effected large gains in strength, whereas performing more repetitions with a lighter load enhanced muscular endurance. since then, many investigators have reported that resistance training in young subjects increases strength of the upper and lower limbs, (Atha, 1981; McDonagh \& Davies, 1983; Jones et al., 1989). 
Individual responses to training are influenced by many factors including: the subject's age; level of training; genetic potential; the muscle being trained; and the type, frequency and duration of the training. Isometric strength has been shown to increase from 0.5 to 2\% per day in response to isometric resistance training (McDonaugh \& Davies, 1984), whereas most short-term weightlifting studies of 8 to 12 weeks duration have demonstrated gains of 25 to $30 \%$ in the maximum weight that could be lifted once (1RM) (Wilmore, 1974; Thorstenson et al., 1976, Wilmore et al., 1978; Jones et a]., 1989)

\subsubsection{INCREASED MUSCLE MASS}

Increases in strength which result from resistance training may often be attributed in part to increases in muscle mass. When limb girth measurements have been used to reflect gains in muscle mass after training, increases have been documented in both the upper and lower limbs, (Wilmore, 1974; MacDougall et al., 1977; Wilmore et al., 1978; Moritani \& de Vries, 1979; Hakkinen et al., 1985). The theory behind this technique is that muscle cross-sectional area can be estimated by correcting the overall limb girth measurements for skinfold thickness and subcutaneous fat deposits. Although the absolute magnitude of muscle cross-sectional 
area may only be approximated using this technique, relative changes brought about by training should be measurable by a skilled investigator.

Another indirect method that has been used to determine increases in muscle mass is to measure body weight and body fat. Increases in body weight with concurrent decreases in overall body fat, results in an increased total lean body mass, most likely because of gains in muscle mass, (Wilmore,1974; Brown \& Wilmore, 1974 ; Wilmore et al., 1978).

The development of computerized axial tomography (CAT) and ultrasound techniques have enabled researchers to make more accurate measurements of the cross-sectional area of individual muscles. Studies have compared cross-sectional areas of muscles from subjects with dissimilar training backgrounds, (Schantz et al., 1983; Sale et al., 1987). Sale et al. (1987) found the cross-sectional area of the elbow flexors of bodybuilders to be $60 \%$ greater than that of untrained males, while Schantz et al. (1983) found the knee extensors of another group of bodybuilders to be approximately $40 z$ greater in area than those of age matched physical education students. Longitudinal training studies are superior to cross-sectional studies because the effects of training upon muscle size can be demonstrated over time in the 
same individual(s). Such studies have shown increases in muscle cross-sectional area of $23 \%$ (elbow flexors, ultrasound measures) after 100 days of training (Ikai \& Fukanaga, 1970), $16 \%$ and $23 \%$ (elbow flexors, males and females respectively, CAT scans) after 16 weeks of training and $6 \%$ (quadriceps) after 15 training sessions (Young et al. 1983). Recently Narici et al. (1989) and Sale et al. (1990), have reported increases of up to $8.5 \%$ and $21 \%$ respectively in the cross-sectional area of knee extensor muscles as measured by computed tomographic scans after 60 days and 22 weeks of training.

Increases in muscle cross-sectional area may theoretically result from increases in the size of individual muscle fibres, from increases in muscle fibre number or from the proliferation of connective tissue.

1.1.3. THE EFFECTS OF STRENGTH TRAINING ON YUSCLE MORPHOLOGY

The stimulus of progressive resistance exercise to induce muscle hypertrophy is potent and has been demonstrated in animals undergoing a net weight loss, in the absence of endocrine signals for hypertrophy and even in the presence of endocrine signals for muscle depletion. (Goldberg et al., 1975; MacDougall, 1986) 
All muscle fibre types have been shown to increase in cross-sectional area in response to training, with greater hypertrophy occurring in the Type II fibres (Thorstensson, 1976; MacDougall et a1., 1980.). The magnitude of this increase may be up to $39 \%$ and $31 \%$ in Type II and Type I fibres respectively, following 5-6 months of heavy weightlifting training (MacDougall et al., 1980).

A muscle fibre's cross-sectional area is increased after strength training by the addition of actin and myosin filaments to the myofibrils, though filament packing density does not change (MacDougall, 1986). Increases in fibre size are also accompanied by increases in connective tissue. The absolute amount of connective tissue in the muscle increases, but the relative amount decreases (Sale et al., 1987).

It has been argued that increases in muscle cross-sectional area may be the result of not only increases in muscle fibre size but also in fibre number. Such hyperplasia has been demonstrated in some animal studies, (Gonyea et al., 1977; Gonyea, 1980), but others (Gollnick et al., 1981; Gollnick et al., 1983), have failed to confirm these observations and have criticized the previous authors work for having methodological errors. Exact counts of fibre numbers in humans engaged 
in training studies are not possible as such research necessitates the surgical removal of the muscle. However, estimates of muscle fibre numbers may be determined from CAT measures of muscle cross-sectional areas, which are corrected for connective tissue content and then divided by mean fibre areas determined from needle biopsy samples. Such studies have shown that elite and intermediate male bodybuilders have similar numbers of fibres in the biceps brachii as untrained males, indicating that in humans hyperplasia probably does not occur (MacDougall et al., 1982). This same research group reported that elite bodybuilders possessed more muscle fibres in the triceps brachi than a group of trained controls, but since they found individuals who were equally as well trained as the bodybuilders but with fewer than normal fibre numbers, they concluded that the bodybuilders may have been genetically endowed with more fibres at birth rather than developing them through training (MacDougall et al., 1982).

1.1.4. NEURAL ADAPTATIONS TO RESISTANCE TRAINING

As well as increasing contractile mass, it is possible to increase strength through the recruitment of synergistic muscles and by enhanced control of motor units (Gonyea and Sale 1982; Sale, 1988; Enoka, 1988; 
Jones et al., 1989). During the early stages of training the majority of adaptations are thought to be neural. Up to $80 \%$ of strength gains after two weeks of training can be attributed to neural factors (Moritani \& de Vries, 1979). Similarily, voluntary strength can be increased in the absence of muscle hypertrophy in short term training studies of less than 8 weeks (Thorstensson, 1976; Moritani \& de Vries, 1979). Moreover, when increases in whole muscle, or muscle fibre size do occur, they are much less than the increases in voluntary strength. For example, Ikai and Fukanaga (1970) found a 928 increase in voluntary strength after 100 days of training, but only a $23 \%$ increase in the cross-sectional area of the elbow flexors.

Up to the 5th week of training increases in maximal voluntary contractions of $20 \%$ (McDonaugh et al., 1983) and 30\% (Davies and Young, 1983), have been reported without a corresponding increase in evoked twitch or tetanic tensions. If hypertrophy were responsible for the increases in voluntary strength one would expect to see similar increases in evoked contraction strength, as the subjects would have more contractile machinery rather than just an enhanced ability to utilize what they already have to greater advantage. 
Strength training also results in an increased integrated electromyogram (IEMG), indicating an increase in the number of active motor units and/or an increase in their firing frequency (Hakkinen Komi, 1983) with most of this change occurring in the first 3-4 weeks of training (Moritani \& de Vries, 1979).

Finally, strength training of one limb has been shown to increase the strength of an untrained contralateral limb. Ikai and Fukanaga (1970) found a $30 \%$ increase in the strength of an untrained contralateral limb with no increase in the cross-sectional area and suggested that the strength gain was brought about through enhanced motor unit control.

\subsection{AGE RELATED CHANGeS IN SRELETAL MUSCLE}

1.2.1. DECREASED MUSCULAR PERFORMANCE

Age related changes in various parameters of human skeletal muscle have been well documented. For example, aging is associated with general decreases in strength (Vandervoort et al., 1986; Gerdle \& Fugl-Meyer, 1985; Murray et a1., 1980; Young, 1985; Essen-Gustavssen \& Borges, 1986). Isometric and dynamic strength have been found to increase in individuals up to the age of 30, change very little up to the age of 50 and then to slowly decline thereafter (Montoye \& Lamphiear, 1977; 
Larsson et al., 1979). The decrease in strength has been noted in both the upper (Moritani \& de Vries, 1980) and lower limbs (Murray et al., 1985). On the basis of electrophysiological techniques, Campbell et al. (1973) suggested that one factor contributing to the weakening of aging muscle is a reduction in the number of functioning motor units, particularly the type II moiety; the fibre type grouping and enclosed fibres that are seen in histological sections of older muscles lend support to this finding (Grimby et al., 1982). Although changes in connective tissue and fat content of older muscle have been noted (Tzankoff et al., 1977; Borkan et al., 1983), aged muscle has been found to have similar enzymatic and capillary supplies as young muscle (Orlander et al., 1978). In addition it has been demonstrated that while older individuals may exhibit a weaker and prolonged evoked twitch contraction response, they show no evidence of decreased motor unit activation (Vandervoort \& McComas, 1986) and so it has been suggested that decreases in muscle performance that occur with advancing age are the result of quantitative rather than qualitative differences within the muscle (Grimby \& saltin, 1983). It has also been suggested that inactivity may be a major contributor to muscle wasting and weakness (Campbell et al., 1973; Lexell, 1986). 
1.2.2. DECREASES IN WHOLE MUSCLE AND MUSCLE FIBRE SIZE Advancing age appears to be associated with decreases in lean tissue mass and a redistribution of subcutaneous and intra-abdominal fat stores (Borkan et al. 1983). Studies using computerized x-ray tomography (Immamura et al., 1983) have indicated that much of the reduction in lean tissue is because muscle size decreases with age; as much as $25 \%$ in the maximum cross-sectional area of the quadriceps between the third and eighth decade of life (Young et al., 1985).

Decreases in muscle mass and cross-sectional area can result from decreases in muscle fibre number (Lexell et al., 1986), muscle fibre size (EssenGustavssen \& Borges, 1986) or a combination of the two. The majority of the evidence suggests that it is the Type II fibres which seem most affected, fibre cross-sectional areas decreasing by 5-10\% in subjects over sixty years of age (Grimby \& Saltin, 1983) and their relative distribution diminishing from $60 \%$ at age 30 , to only $45 \%$ at age 70, (Larsson et al., 1978, 1979, 1983). Evidence from electrophysiological studies indicates that the loss of Type II fibres is secondary to motoneuron cell death (Campbell et al., 1973). 
It has been demonstrated (Davies \& White, 1983; Vandervoort \& McComas, 1986) that, when compared to young muscle, elderly muscle is slower contracting and weaker, producing significantly lower maximal twitch torques, increased times to peak twitch tension and slower half relaxation times. Sica and Mccomas (1971), however, found no such relationship between age and contraction time, but on the basis of relaxation-time data have speculated that the series elastic element of elderly muscle may be decreased. In contrast to the decreases in muscle size and contractile properties in aging muscle, there appears to be little deterioration in metabolic capacity (Essen-Gustavssen \& Borges, 1986). Taking this into consideration, and based on the similar reductions in muscle mass and strength with aging, and evidence for the preservation of specific tension, Grimby and saltin (1983) have suggested that it is quantitative rather than qualitative changes within muscles which account for most of the age related strength loss.

\subsubsection{PREVIOUS TRAINING STUDIES IN THE ELDERLY}

It has been suggested that declining physical activity may contribute to age related strength loss (Aniansson et al., 1983). If this is so, progressive resistance strength training may serve to decrease or 
reverse the rate of strength decline in the elderly. To date, few strength training studies in the elderly have been published, and the majority of these have not used progressive resistance models, but rather have involved the use of isometric training (Kaufman, 1985), calisthenics and elastic bands, (Aniansson \& Gustavsson, 1981; Aniansson et al., 1984), or have dealt with very small muscle groups such as the index finger (Chapman et al., 1972) or the abductor digiti minimi (Kaufman, 1985). Though subjects have increased strength in all of the above studies, the degree of increase has varied. Those studies employing calisthenics or elastic bands as the training stimulus have shown strength increases of only 9-22\% (Aniansson \& Gustaffsson, 1981) and 7-11\% (Aniansson et al., 1984). Isometric training increased plantarflexion and knee and hip extension strength from 29-57\% (Perkins \& Kaiser, 1961), and little finger adduction strength by 728 (Kaufman, 1985). This latter figure probably reflects more upon the peculiar nature of the movement involved rather than the efficacy of the training protocol. Dynamic training studies have produced increases in plantarflexion and knee and hip extension strength from 41-648 (Perkins \& Kaiser, 1961), index finger flexion strength of $33 \%$ (Chapman et al., 1972) and elbow flexor strength of 238 (Moritani \& de 
Vries, 1980). Recently, Frontera et al. (1988) have published increases of 107 and $227 \%$ in the strength of elderly subjects' knee extensors and flexors respectively after 12 weeks of dynamic resistance training. Again, such striking increases may perhaps be attributed to the nature of the exercise involved in the training and measurement of knee extension and flexion strength.

In those studies which have used untrained contralateral limbs as controls, cross-training effects have been observed and these increases in strength of an untrained limb occurring in the absence of hypertrophy, as well as the relatively rapid increases in strength, have led researchers to conclude that much of their subjects' improvements have been due to neural factors (Perkins \& Kaiser, 1961; Chapman et al., 1972; Kaufman, 1985). However, it may be that such conclusions have been drawn as a result of training protocols insufficiently intense or long enough to produce hypertrophy, or the use of testing methods incapable of accurately detecting it. Moritani and de vries (1980) felt that their elderly subjects increased strength after training because of neural adaptations, indicated by increases in maximal IEMG in the absence of hypertrophy. However, their study was of only 8 weeks duration, subjects trained with a load corresponding to only $66 \%$ of 
their 1 RM and muscle cross-sectional area was determined from limb girth measurements corrected for skinfold thickness.

Recently CT scans have been used to determine muscle cross-sectional areas in combination with a strenuous progressive resistance training protocol (Frontera et al., 1988). In this group, after 12 weeks of training, subjects were found to have an $11.4 \%$ increase in total muscle area of the thighs, including a 9.3\% increase in the area of the quadriceps. These findings were supported by increased muscle fibre areas of $33.5 \%$ and $a 27.6 \%$ in the Type I and II fibres respectively, and by increased myofibrillar protein turnover, suggesting that hypertrophy can occur in an older population in response to training. While other studies have found similar increases in fibre areas in response to training in the elderly, (Larsson et al., 1982), it should be noted that there are reports of strength gains accompanied by only 5-9\% (NS) increases in fibre area (Aniansson \& Gustafsson, 1981). 


\section{SUMMARY AMD STATEMENT OF RURPOSE}

The practical implications of any study into the effects of strength training in an older population are to improve the quality of life of the elderly. The well documented substantial deterioration of muscle mass and fibre number with advancing years, with the associated decrease in muscular strength, results in a reduced functional capacity, often resulting in dependency and institutionalization. If it is possible to increase the strength of elderly individuals through resistance training, this may translate into an improved ability to perform many of the activities of daily living, thereby making older individuals better able to look after themselves and decreasing the need for geriatric support facilities.

Studies in this area utilizing calisthenics and rubber bands as resistance have yielded encouraging but inconclusive results. Few studies have utilized progressive resistance weight training programs for their subjects, but such models seem ideal for improving the performance of subjects in activities of daily living because they yield large increases in dynamic strength which may conceivably carry over to many daily tasks. The benefits of isometric training programs are considerably more restricted and limited to the joint 
angles trained at. Many studies which have employed progressive weight training models have examined obscure muscle groups such as the finger flexors and abductors and findings from them cannot be extrapolated to the larger muscles of the body.

The purpose of this study was to investigate the adaptations to strength training in a group of 60-70 year old men, utilizing a unilateral arm training model in which one arm served as a within subject control. Electrophysiological techniques, including the interpolated twitch method were employed in combination with measures of muscle and muscle fibre cross-sectional areas determined from CT scans and needle biopsy samples. In this way it could be determined if increases in muscle cross sectional areas would translate into increases in twitch torques, rates of torque development and half relaxation time, providing evidence of increases in intrinsic strength independent of volition. To date no other such study has been undertaken. 


\section{CHAPTER 2}

METHODS

2.1.1. SUBJECTs

Fourteen male volunteers aged 60 - 70 (mean 62.8), took part in the study. All subjects participated with their own informed consent in accordance with the policies of the McMaster University President's Committee on Ethics of Research on Human Subjects. Prior to acceptance into the study, subjects performed a progressive incremental cycle ergometer test to detect any signs of latent heart disease or pulmonary impairment; such individuals were excluded from the study.

2.2.1. TRAINING AND STUDY DESIGN

strength training was done 3 alternate days per week for 12 weeks. Bilateral leg press, supine bench press and seated dead lift exercises were done on a multistation weight training machine (Global Gym Inc., Downsview ont., Canada); bent leg abdominal curls were done on a padded station on the floor. Dead-lift and abdominal curl exercises were included in the study to provide the subjects with a well rounded training program; however, no measures of performance were made on 
these exercises. Subjects trained the elbow flexors of one arm only, on a custom-built weight lifting apparatus (Rubicon Industries, stony creek, ontario); the arm to be trained was selected randomly, the non-trained arm serving as a within subject control. Exercises were done in a circuit set system with no more than 2 min rest between sets. Subjects performed 10 repetitions per set of bench press and arm curl exercises, 15 repetitions per set of leg presses and 12-20 repetitions of dead-lift and abdominal curls. Although only one arm performed the arm curl exercise, the elbow flexors of both arms probably received a moderate stimulus from the bench press and dead-lift exercises. Subjects progressed from performing 2 sets of each exercise at 50\% of their initial 1 RM, (1 repetition maximum, the heaviest weight lifted for one repetition), to 4 sets at 70-908 of their initial 1RM, over the course of the study (Table 1). 


\subsection{MEASUREMENT OF VOLUNTARY BTRENGTH}

2.3.1. WEIGHT IIFTING STRENGTH

Weight lifting strength was measured as the

highest $1 \mathrm{RM}$ achieved on the training apparatus over two separate days of testing. After a suitable warm-up subjects performed single repetitions with progressively heavier weights, resting $2-3$ min between attempts. The heaviest weight that subjects could lift once in this manner was determined to be their $1 \mathrm{RM}$ for that exercise. The movements tested included: 1) elbow flexion of each arm separately on a custom-made weight lifting device; 2) bilateral leg press (hip and knee extension, ankle plantarflexion); 3) bench press. The latter two movements were tested on a multistation weight-training apparatus. In addition, after training, endurance was measured as the number of repetitions done in each exercise with the pre-training $1 \mathrm{RM}$.

\subsubsection{ISOKINETIC CONTRACTION STRENGTH}

Isokinetic, concentric contraction strength during leg press and elbow flexion movements was measured as peak torque on a cybex dynamometer (Lumex, Inc., Ronkonkoma, New York) . Elbow flexion of each arm was tested separately. A series of 3 maximal voluntary contractions (MVCs) was performed in a random order at 


\section{TABLE 1}

The circuit training scheme employed in this study. The progression in the left panel was employed for the bench press (10 reps), double leg press (15 reps) and single arm curl (10 reps) exercises. The progression in the right panel was followed for abdominal curl exercise and seated dead lift at a constant weight of $25 \mathrm{~kg}$.

\section{WEEK}

1

2

3

4

5

6

7

8

9

10

11

12
Sets and $\%$

of initial 1RM

$50 \quad 50$

$50 \quad 70 \quad 70$

$50 \quad 70 \quad 70$

$60 \quad 70 \quad 80$

$\begin{array}{llll}60 & 70 & 70 & 80\end{array}$

$\begin{array}{llll}60 & 70 & 70 & 80\end{array}$

$\begin{array}{llll}60 & 70 & 70 & 80\end{array}$

$\begin{array}{llll}60 & 70 & 70 & 85\end{array}$

$\begin{array}{llll}60 & 70 & 75 & 85\end{array}$

$\begin{array}{llll}70 & 70 & 75 & 85\end{array}$

$\begin{array}{llll}70 & 70 & 80 & 90\end{array}$

$\begin{array}{llll}70 & 80 & 90 & 90\end{array}$

\section{Sets and}

\# of reps

$12 \quad 12$

$\begin{array}{lll}12 & 12 & 12\end{array}$

$\begin{array}{lll}12 & 12 & 12\end{array}$

$\begin{array}{llll}12 & 12 & 12 & 12\end{array}$

$\begin{array}{llll}12 & 12 & 12 & 12\end{array}$

$\begin{array}{llll}12 & 12 & 12 & 12\end{array}$

$\begin{array}{llll}12 & 12 & 12 & 12\end{array}$

$\begin{array}{llll}15 & 15 & 15 & 15\end{array}$

$\begin{array}{llll}15 & 15 & 15 & 15\end{array}$

$20 \quad 20 \quad 20 \quad 20$

$\begin{array}{llll}20 & 20 & 20 & 20\end{array}$

$20 \quad 20 \quad 20 \quad 20$

Note: From the sixth week of training on, subjects trained at 10 12 repetitions to failure after an initial warm up set. The percentages of initial 1RM listed here are therefore approximations based upon the weights the subjects were able to train with. 
angular velocities of $30,120,180,240$ and $300 \%$ s. since the elbow joint was aligned with the axis of rotation of the cybex, the arm velocity measured at the elbow corresponded to the lever arm velocity of the machine. The best of the three trials at each velocity was taken as the pre-training value. Isokinetic bilateral leg press strength was measured on a leg press apparatus coupled to the cybex dynamometer (Vandervoort et al., 1984). This apparatus, by means of a 4:1 gear reduction mechanism, enables the cybex to accommodate the potentially large torques which can be generated during a leg press manoeuvre. Such a mechanisn not only reduces the torque registered by the cybex to one fourth of that produced by the subject, (the subject's torque is then multiplied by 4 to obtain his actual value), but also reduces the set lever arm velocity of the cybex by a similar magnitude. As a result, if the velocity selected on the Cybex dial was $60 \%$, the true velocity of the Cybex lever arm would be $15 \% / \mathrm{s}$. While subjects were actually tested throughout the velocity range of the instrument, the highest velocity was limited to $75 \% / \mathrm{s}$. Thus, three trials were done at lever arm velocities of 15 and $75 \%$. The peak torque of the best of the three trials was taken as the pre-training value. 
Maximal voluntary isometric strength was measured on a custom-built apparatus (described in detail in section 2.4.2.). Maximal voluntary elbow flexion strength of each arm was tested separately by having subjects perform 2 MVCs interspersed with $2 \mathrm{~min}$ of rest at randomly selected joint angles of 75,120 and $165^{\circ}$; the higher of the 2 peak torques being taken as the pre-training value. The extent of motor unit activation during the maximal voluntary contractions (MVCs) was assessed using the interpolated twitch technique (Belanger \& McComas, 1981), described in detail in section 2.4.3.

2.4. MEASUREMENT OF EVOKED CONTRACTILE PROPERTIES 2.4.1. APPARATUS

A custom-built device comprised of two aluminum plates hinged together was used to secure subjects' elbows at angles of 75,120 and $165^{\circ}$ for the measurement of voluntary and evoked torque. One plate, on which the subject's upper arm rested, remained secured in the horizontal position to a wooden bench. The second plate, to which the subject's forearm was attached in the supinated position by means of velcro straps, could move freely. The subject's elbow was aligned with the device's axis of rotation and could be fixed at the desired joint angle determined from a scale located on 
the side of the apparatus. A clamp secured the device at the desired angle and torque was measured with a strain gauge located on the shaft linking the two plates together. The signal from the strain gauge was relayed through an amplifier to a storage oscilloscope (HP 120 1B) and a computer (PDP 1103 Digital Equip. Corp.) where it was analyzed on line.

\subsubsection{TESTING PROCEDURE}

Subjects were seated in a chair with the bench and the arm apparatus located in front of them. The upper arm was positioned horizontally on the stationary plate and the forearm was secured to the second plate. Since MVC's can potentiate twitch responses, (Vandervoort et al., 1983), twitch contractions were evoked prior to voluntary contractions. Lead plate electrodes, wrapped in gauze soaked with conductive cream, were attached to the palmar surface of the forearm and the belly of the biceps. Twitches were elicited using rectangular voltage pulses of $50 \mu s$ duration from a Devices, (Medical Systems Corp.) stimulator. Torque was read from the storage oscilloscope, and when no further increase in torque was noted with increases in stimulating voltage it was assumed that the muscle was maximally stimulated. After the twitches, subjects were given two attempts at each 
angle to perform an MVC of the elbow flexors, the highest of the scores being used for analysis. Twitch and maximal voluntary torque were measured at angles of 75 , 120 , and $165^{\circ}$ in a randomized order. Computer analysis of the twitches yielded the following measures: peak torque (N.m), time to peak torque (ms), half-relaxation time (ms), maximum rate of torque development (N.m/s), maximum rate of torque relaxation (N.m/s), and torquetime integral (N.m.s).

\subsubsection{INTERPOLATED TNITCH TESTING}

During MVC testing, interpolated twitch contractions were used to determine the extent of motor unit activation (Belanger \&cComas, 1981). While subjects performed maximal voluntary contractions, peak torque production was determined from a storage oscilloscope. When subjects were determined to be generating peak torque with their elbow flexors a supramaximal stimulus was delivered to the elbow flexor muscles using the technique described above. Any motor units that had not been recruited during the MVC or were not firing at their optimal frequencies, should produce a detectable twitch response after being stimulated in this manner. 
2.5.1. MEASUREMENT OF MUSCLE CROSS-SECTIONAL AREA

The cross-sectional area $\left(\mathrm{cm}^{2}\right)$ of the flexors and extensors of the elbows and knees as well as the area of the humerus and femur was determined using computerized tomographic scans (Model 20-30, Ohio Nuclear) pre- and post-training. The two legs were scanned simultaneously through a point corresponding to $50 \%$ of the upper leg length as measured from the head of the fibula to the greater trochanter of the femur while the subjects lay in a supine position. The arms were scanned individually while abducted $90^{\circ}$, with the elbow fully extended, through a point corresponding to $40 \%$ of the upper arm length as measured from the lateral epicondyle of the humerus to the acromion process of the scapula. Slide photographs taken of the scan images were projected on to blank paper and tracings made of the flexor, extensor and bone compartments to be studied. Compartment areas were measured using a computerized digitizing platform (Compucolour Inc.).

2.6.1. MEASUREMENT OF MUSCLE FIBRE CHARACTERISTICS Muscle fibre characteristics of the biceps brachii in trained and untrained arms were determined from needle biopsy samples. After being oriented under 
a dissecting microscope, muscle tissue samples were secured in Tissue Tek OCT embedding medium, frozen in isopentane which had been pre-cooled in liquid nitrogen, and then stored in a freezer at $-50^{\circ} \mathrm{C}$. Sections $10 \mu \mathrm{m}$ thick were taken from the samples and mounted on slides. Fibre type was determined using the method of Padykula and Herman (1955) at a pre-incubation $\mathrm{pH}$ of 10.0 .

From a single stained section of muscle tissue, photomicrographic slides with non-overlapping fields were taken on an Olympus BHA microscope at a magnification of 10X with an olympus photo-micrographic camera (model PM10A). These slides were then projected onto a computerized digitizing platform (Compucolour Inc.) for fibre area analysis. Measurements included crosssectional areas of both Type I and II fibres and fibre type distribution. An average of 100 type I and II fibres per subject pre-training and 78 type $I$ and 88 type II fibres per subject post-training were used for fibre area analysis. For muscle fibre distribution measures, all fibres visible on the slides, whether partial or whole were counted.

2.7.1. STATISTICS

Descriptive statistics included mean and standard error. Training effects were evaluated using 
between and within split plot ANOVA's with one between subject factor. Factors for these analyses included; arm, angle, velocity and time with repeated measures on the time factor. 1 RM results for bench press and leg press were analyzed using one way ANOVA's. Post hoc mean comparisons were examined using the Tukey "A" test. Statistical significance was accepted at $p \leq .05$. 


\section{CHAPTER 3}

\section{RESULTS}

All subjects were able to successfully complete the study and no injuries were sustained as a result of training.

\subsection{VOLUNTARY STRENGTH}

\subsubsection{NEIGHTIFTING CAPACITY}

The 1 RM values for all three weightlifting exercises increased significantly $(p<0.001)$ following training (Fig. $1 \& 2$ ). The improvement in the single arm curl 1RM in the trained $\operatorname{arm}(48.48,11.2$ to $16.7 \mathrm{~kg})$ was greater than in the control arm $(12.7 \%, 11.9$ to $13.4 \mathrm{~kg}$; $\mathrm{p}<0.05)$. In addition, after the training period subjects were able to perform an average of from 7-19 repetitions (Table 2, Appendix B) with a weight corresponding to their pre-training $1 \mathrm{RM}$.

\subsubsection{ISOKINETIC STRENGTH}

Maximum isokinetic strength in the bilateral leg press manoeuvre improved by $18 \%(201$ to $237 \mathrm{~N} . \mathrm{m}$ ) at $.26 \mathrm{rad} / \mathrm{s}\left(15^{\circ} / \mathrm{s}\right)$ and $17 \%(135$ to $158 \mathrm{~N} . \mathrm{m})$ at $1.31 \mathrm{rad} / \mathrm{s}$ $(75 \% / s)$ following training ( $p<0.001)$ (Fig.3). During isokinetic elbow flexion exercise at the 5 angular 

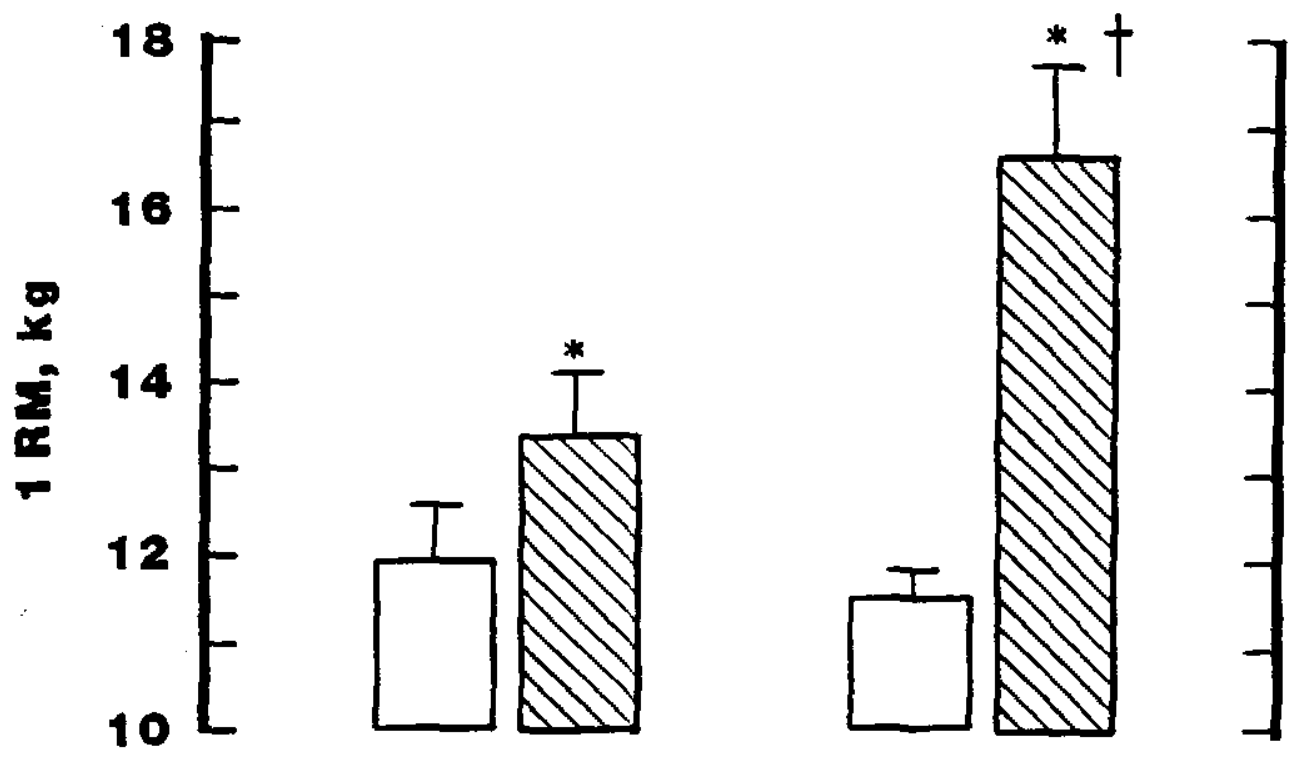

EIG. 1. Maximal weight-lifting capacity (1-repetition maximum, IRM) in trained and untrained arms before (open bars) and after (hatched bars) training. " $p<0.05$, change after training and $\dagger P<0.05$, difference between arms. 


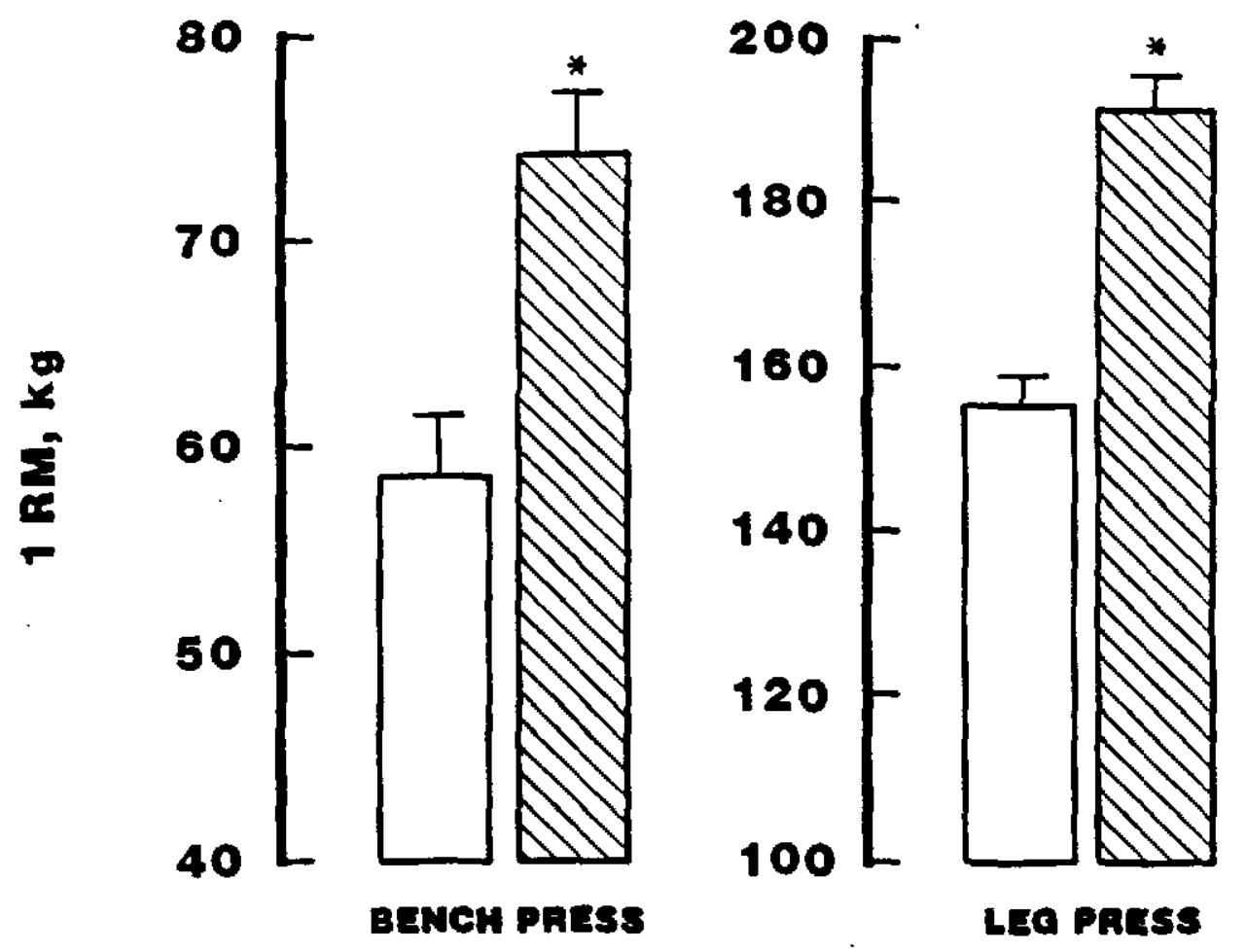

FIG. 2. Maximal (means $\pm S E$ ) weight lifting capacity (1RM) in bench press and bilateral leg press exercises, measured before (open bars) and after (hatched bars) 12 wk of training." $P<0.001$, increase with training. 


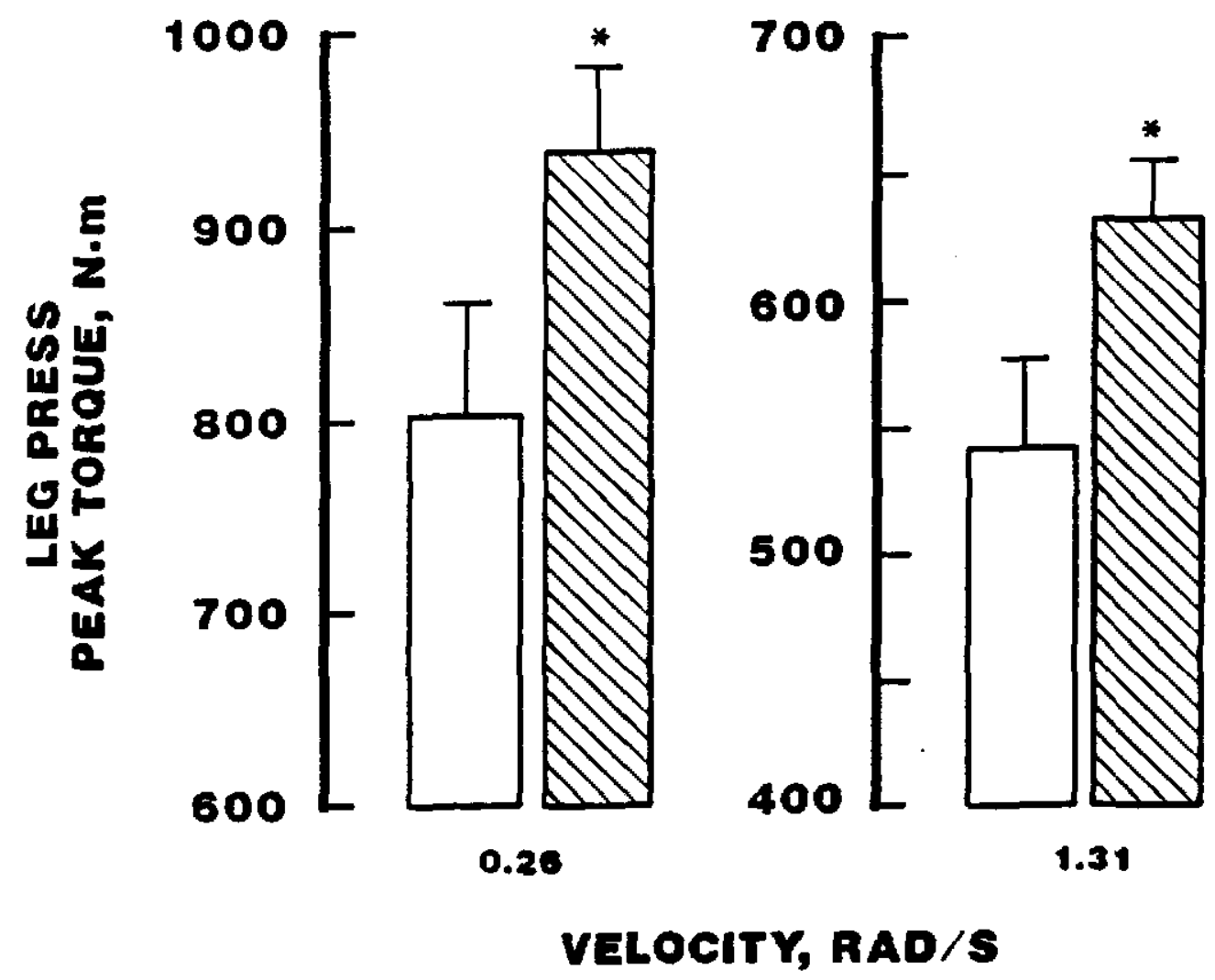

FIG. 3. Maximal (means $\pm S E$ ) isokinetic leg press torque at 2 angular velocities before and after training. " $P<0.0001$, increase with training. 


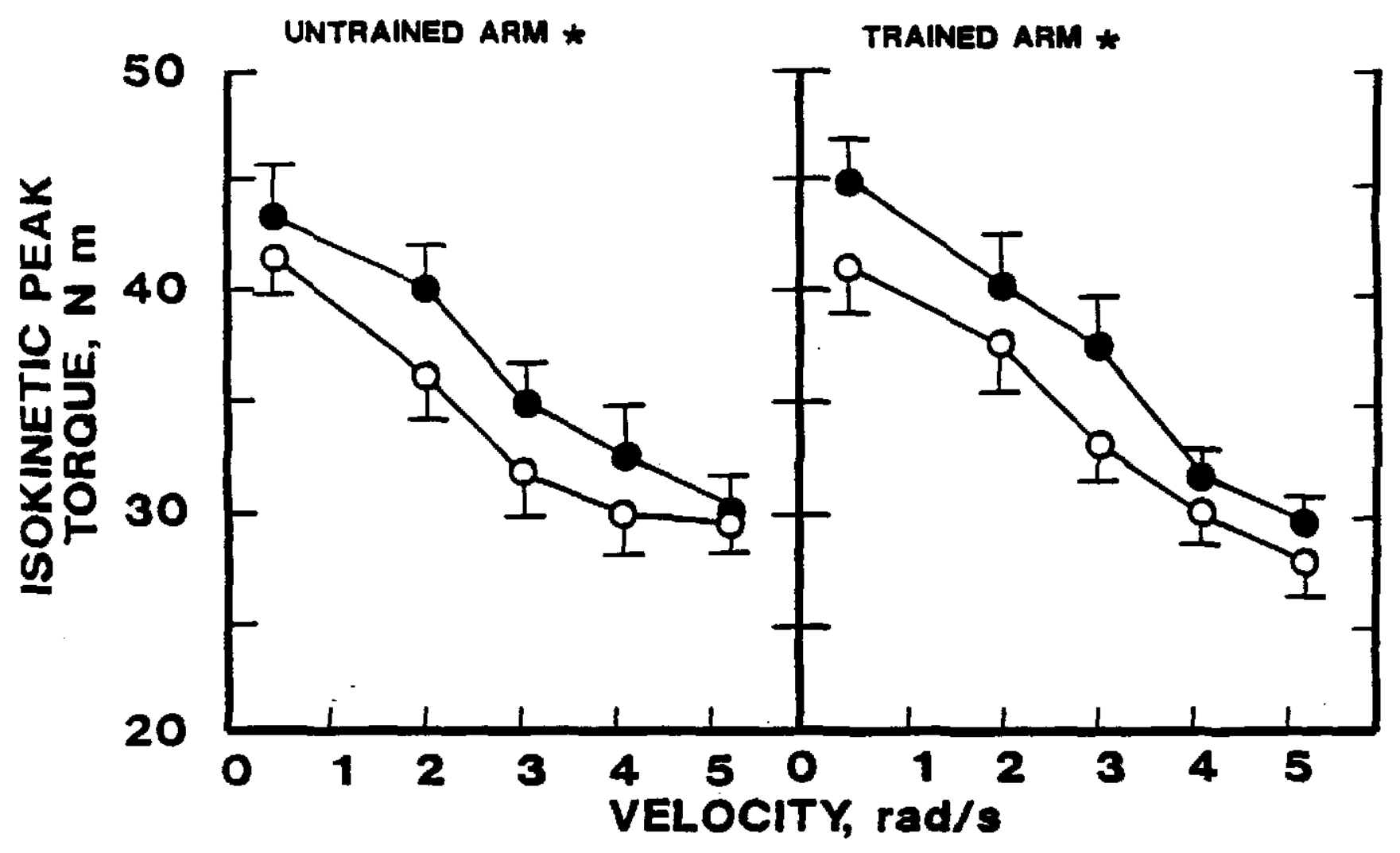

FIG. 4. Maximal isokinetic torque during elbow flexion exercise in both arms before (open circles) and after (filled circles) training. " $p<0.01$, overall increase after training. 
velocities, the mean increases in the trained arm $18.8 \%$; $p<0.01)$ were similar to those in the control arm (6.5\%) (Fig. 4).

3.1.3. ISOMETRIC STRENGTH

Peak elbow flexion torque varied with joint angle, but there was no significant increase in torque in either arm after training (Fig.5). The absence of additional isometric tension in response to an interpolated stimulus confirmed that the subjects were able to achieve almost complete motor unit activation prior to (97.5\%) and following (988) the weight training.

\subsubsection{EWOKED MUSCLE CONTRACTILE PROPERTIES}

Training increased the maximum evoked twitch torque at joint angles of $2.04 \mathrm{rad}\left(120^{\circ}\right)(9.18,7.5$ to $8.2 \mathrm{~N} . \mathrm{m})$ and $2.81 \mathrm{rad}\left(165^{\circ}\right)(11.68,7.5$ to $8.4 \mathrm{~N} . \mathrm{m})$ in the trained $\mathrm{arm}$, and at an angle of $2.81 \mathrm{rad}\left(165^{\circ}\right)$ $(11.98,7.3$ to $8.2 \mathrm{~N} . \mathrm{m})$ in the untrained arm $(p<0.05)$ (Fig. 6). There was also a significant decrease $(p<0.05)$ in the twitch torque of the untrained arm at $2.04 \mathrm{rad}$ $\left(120^{\circ}\right)(11.28,7.7$ to $6.8 \mathrm{~N} . \mathrm{m})$. The twitch torque-time integral increased significantly $(p=0.007)$ in the trained arm at elbow joint angles of 2.04 and $2.81 \mathrm{rad}(120$ and $165^{\circ}$ ), but there was no change in the control axm (Fig. 


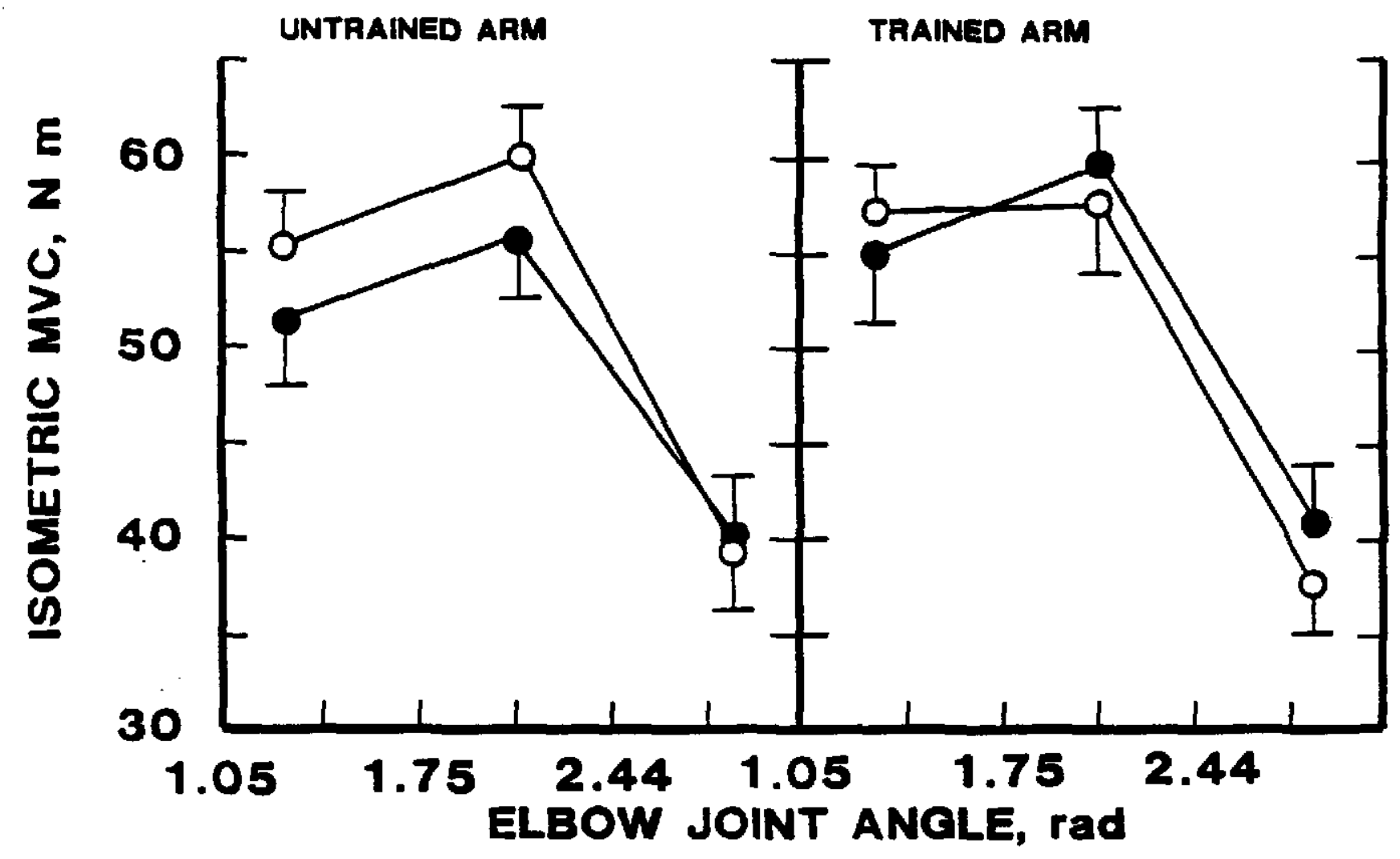

FIG. 5. Maximal isometric torque (maximum voluntary contraction, MVC) during elbow flexion exercise in both arms before (open circles) and after (filled circles training. 
UNTRAINED ARM

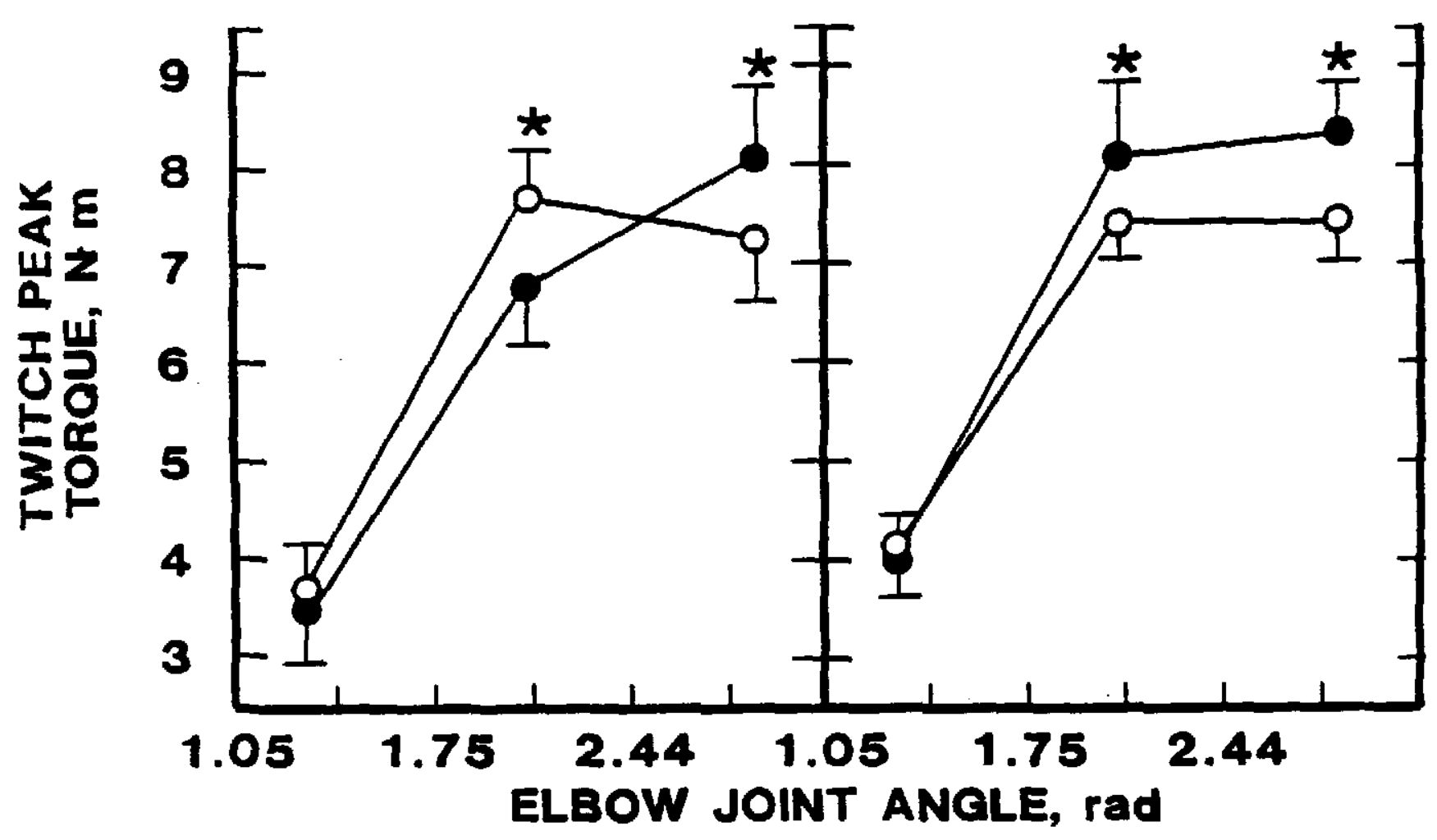

FIG. 6. Maximal twitch torque during electrically evoked contractions of elbow flexors of both arms before (open circles) and after (filled circles) training. " $P<0.05$, change after training. 


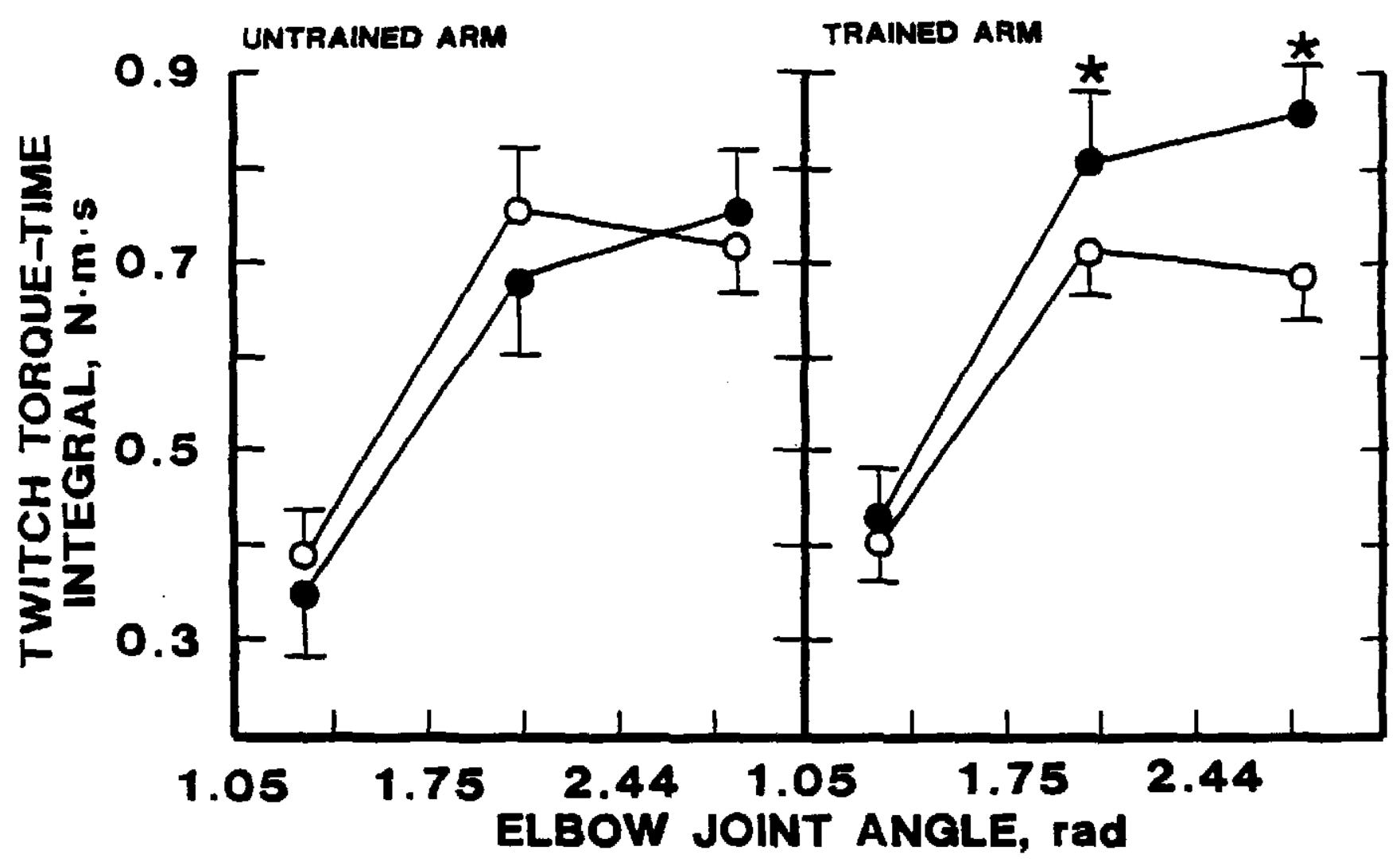

FIG. 7. Maximal torque-time integral during electrically evoked contractions of elbow flexors of both arms before (open circles) and after (filled circles) training. " $p=0.007$, change after training. 
7). The maximum rate of torque development decreased significantly $(p<0.05)$ in the untrained arm at $2.04 \mathrm{rad}$ $\left(120^{\circ}\right)(229.6$ to $204.8 \mathrm{~N} . \mathrm{m} / \mathrm{s})$ and increased significantly in both arms at an angle of $2.81 \mathrm{rad}\left(165^{\circ}\right)(211.9$ to 237.8 and 202.7 to $232.5 \mathrm{~N} . \mathrm{m} / \mathrm{s}$, trained and untrained arms respectively; $p<0.05)$, but not at the other joint positions (Fig. 8). The half-relaxation times were prolonged in the trained arm at all joint angles following training $(p<0.05)$, but were unchanged in the control arm (Fig. 9). No differences were seen in time to peak twitch torque or maximum rate of torque relaxation in either arm before or after training (Figs $10 \& 11)$.

3.3.1 MUSCLE CROSS-SECTIONAL AREA

During the course of the study there was a significant $(p<0.001)$ increase in cross-sectional area (CSA) of the elbow flexors of the trained arm (16.7 to $19.6 \mathrm{~cm}^{2}, 17.48$ ) (Fig. 12), but no change in the control arm. In contrast, in the control arm there was a small but significant $(p=.035)$ increase in the mean maximum cross-sectional area of the elbow extensors (triceps brachii) (22.1 to $23.7 \mathrm{~cm}^{2}$ ), but no significant change in the trained limb. It should be noted that the terms "trained" and "untrained" refer only to the elbow flexors 


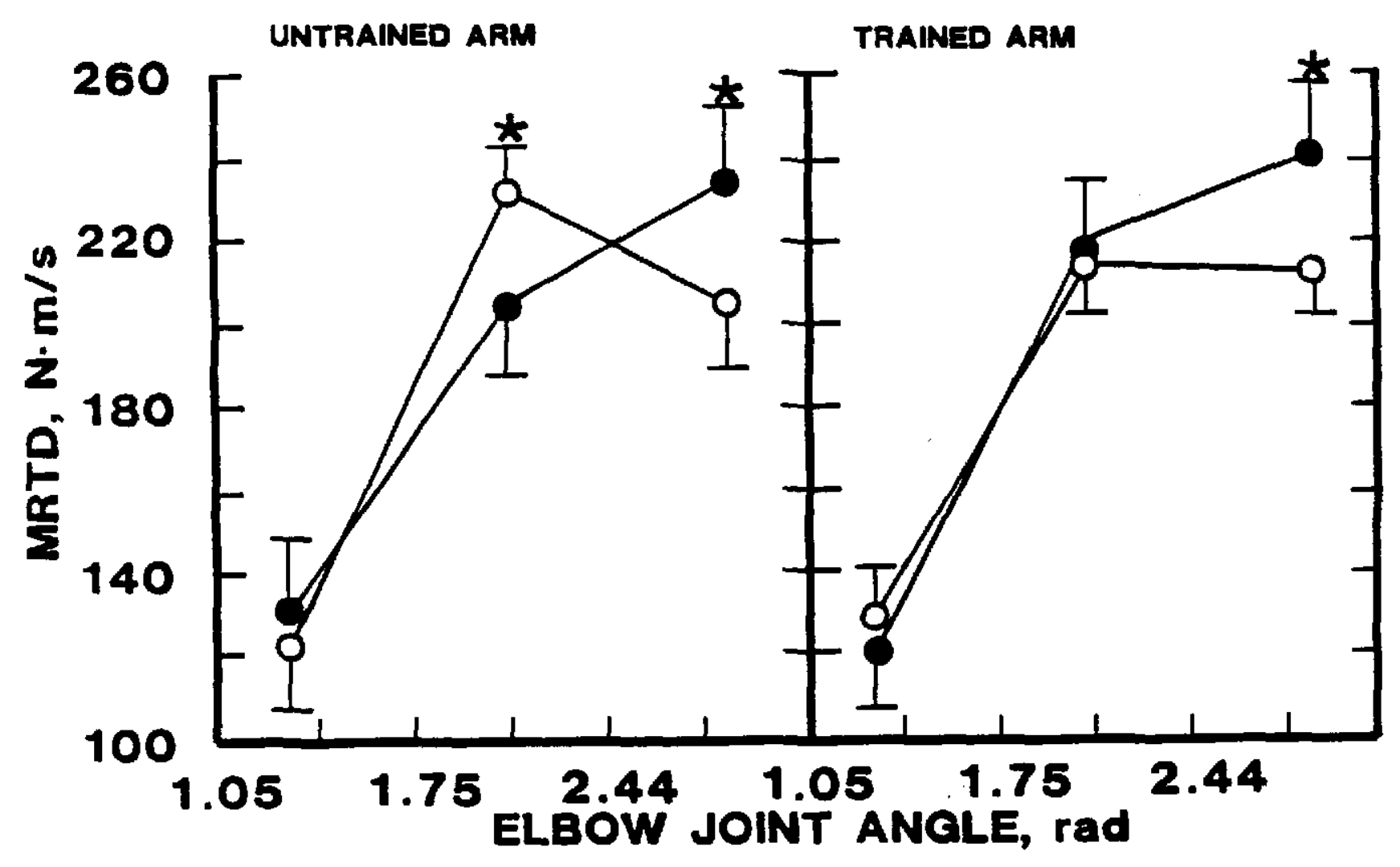

FIG. 8. Maximal rates of torque development (MRTD) during electricaliy evoked twitch contractions of elbow flexors of both arms before (open circles) and after (filled circles) training. " $P<0.05$, change after training. 


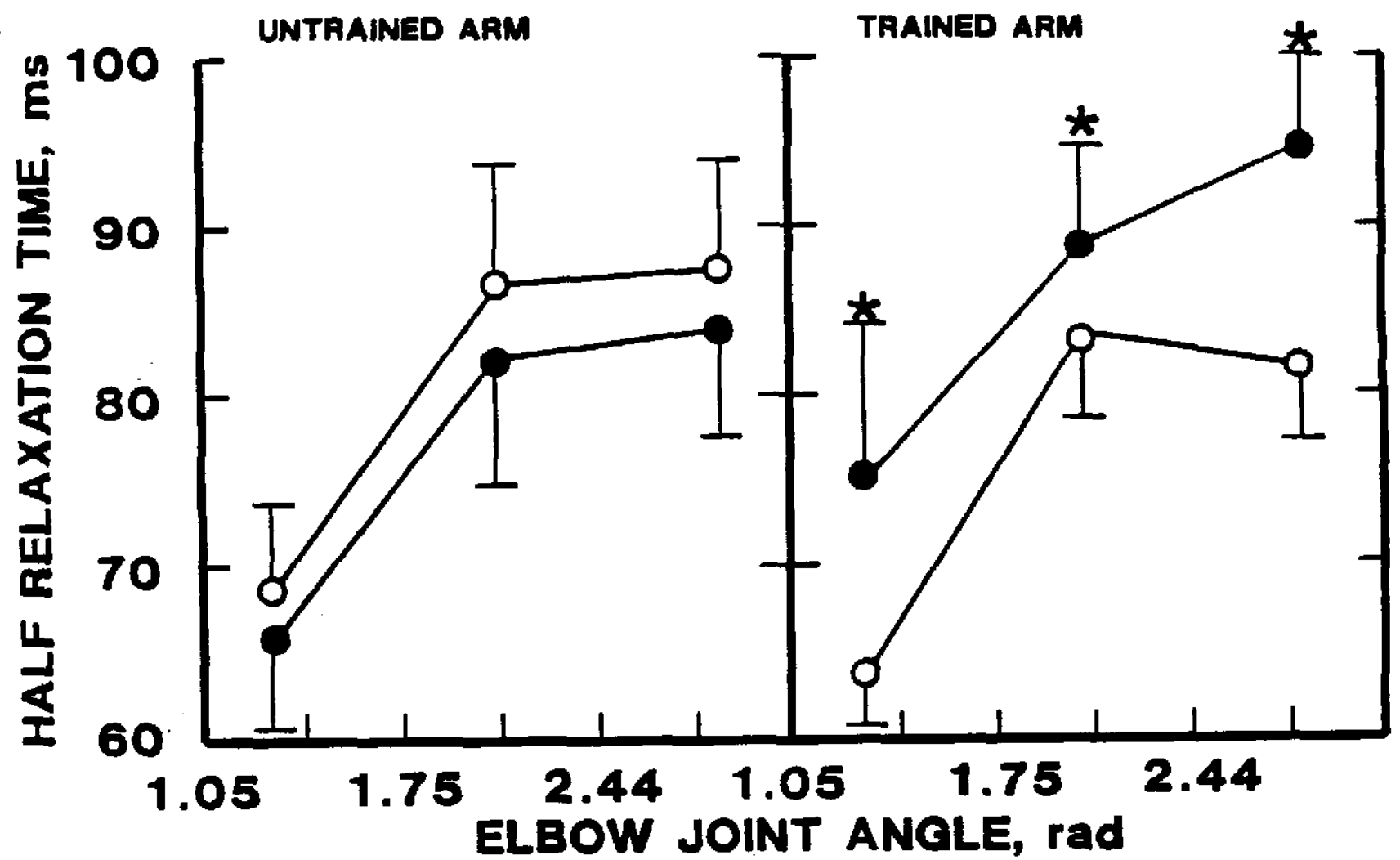

EIG. 9. Half-relaxation times during electrically evoked twitch contractions of elbow flexors of both arms before (open circles) and after (filled circles) training. " $P<0.05$, change after training. 


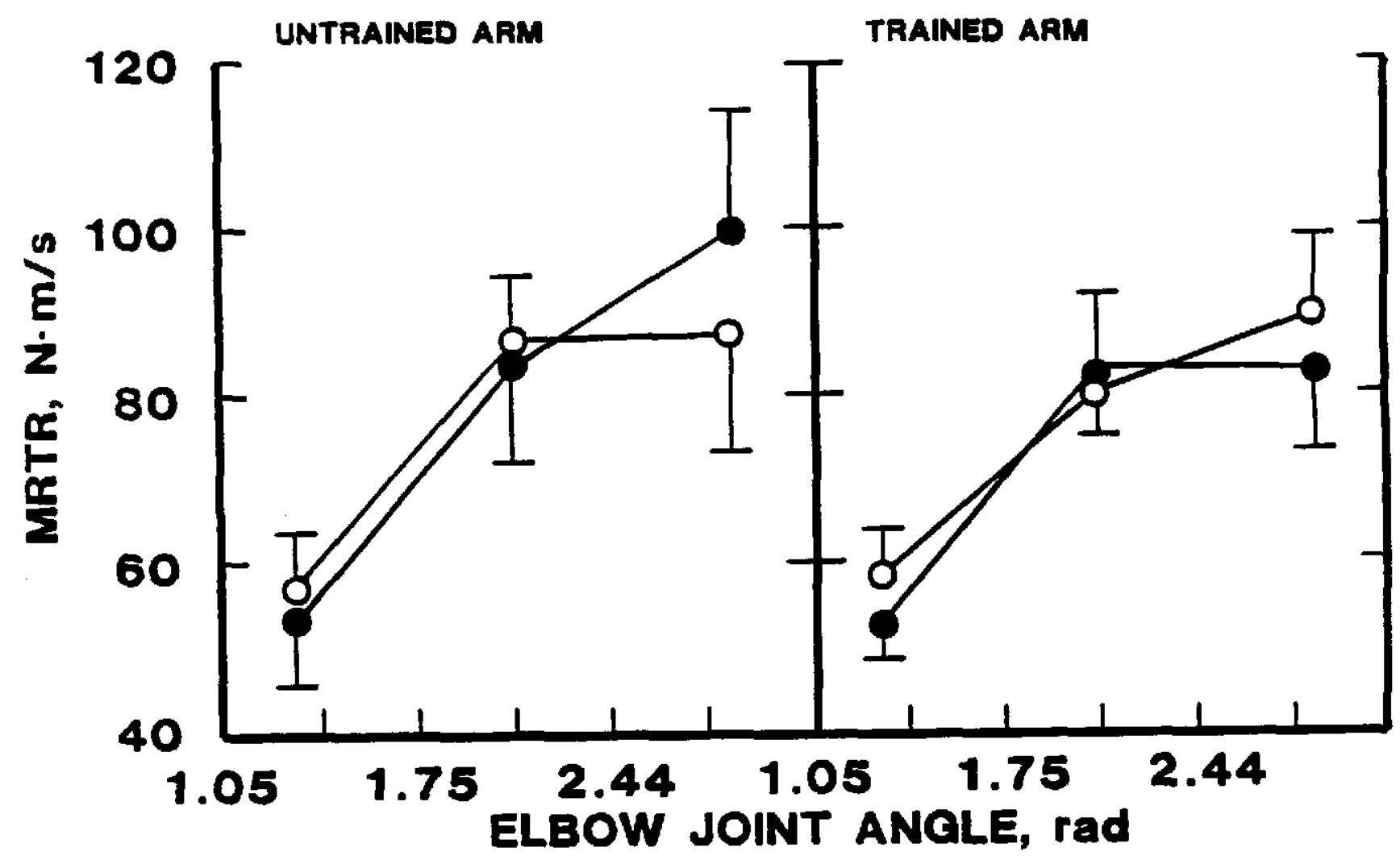

IIG. 10. Maximal rates of torque relaxation (MRTR) during electrically evoked twitch contractions of elbow flexors of both arms before (open circles) and after (filled circles) training. ? $p<0.05$, change after training. 


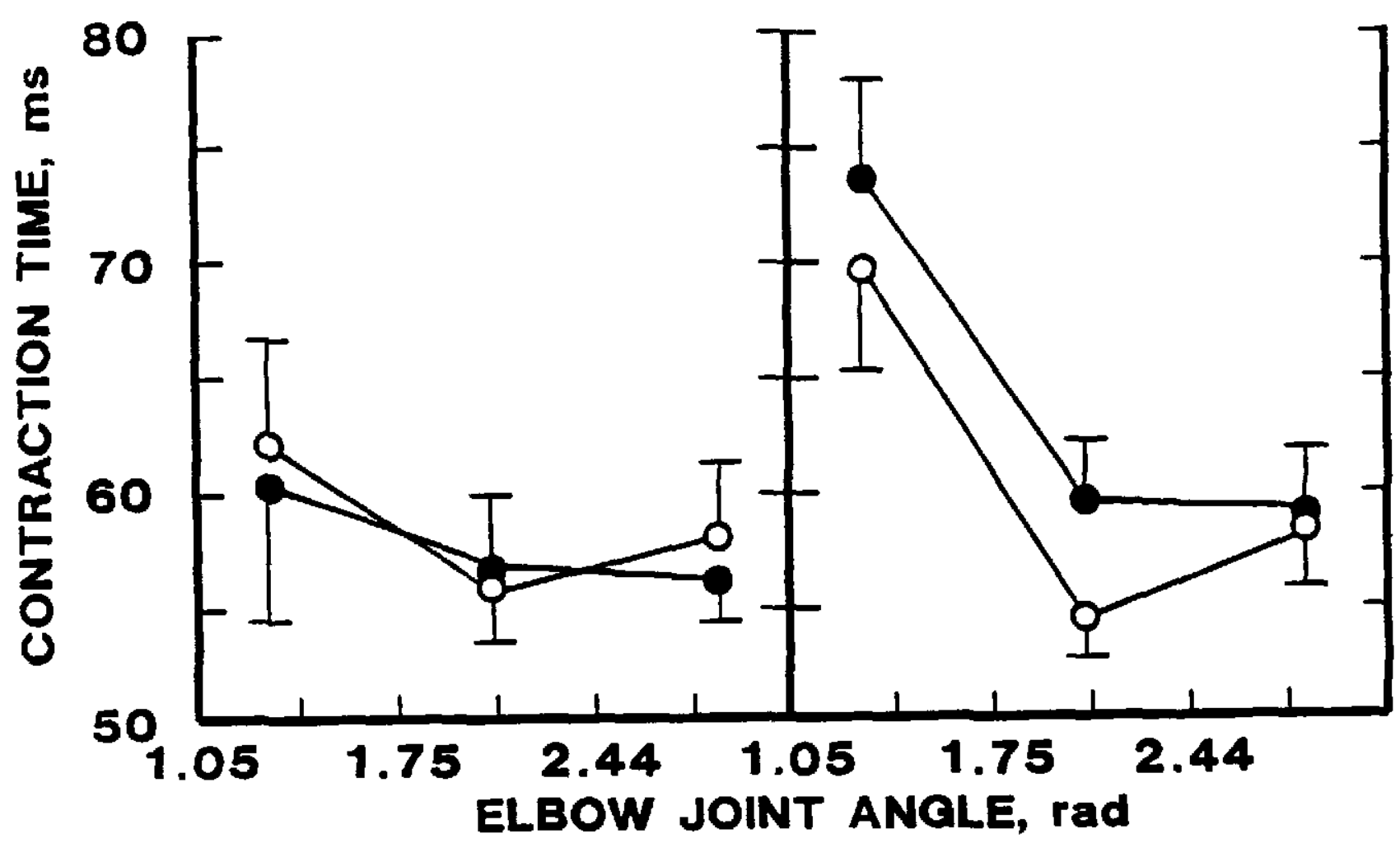

FIG.11. Contraction time during electrically evoked twitch contractions of elbow flexors of both arms before (open circles) and after (filled circles) training. " $p<0.05$, change after training. 

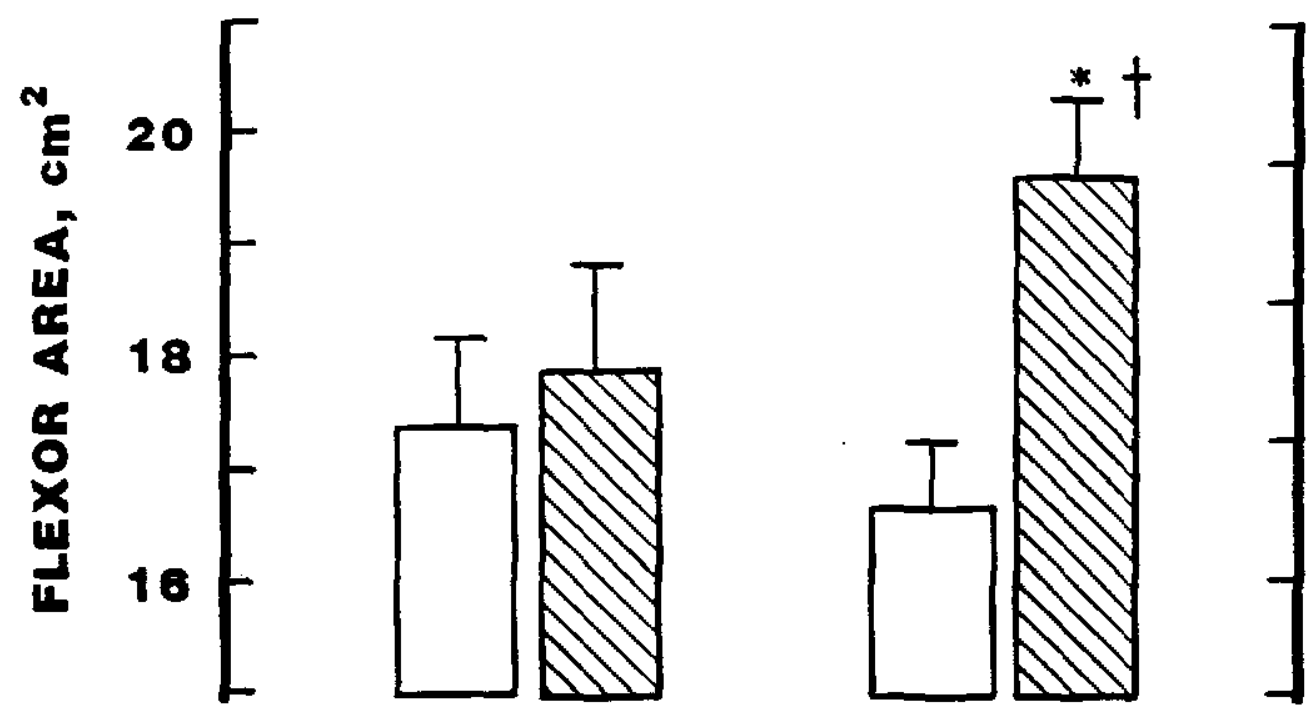

FIG.12. Maximal cross-sectional area of elbow flexors in trained and untrained arms before (open bars) and after (hatched bars) training. " $P<0.001$, difference between arms. 
and that the extensors of both arms were trained during the bench press exercise. The cross-sectional area of the humerus did not change after training.

The flexor/extensor area ratio calculated for the arms did not change significantly during the investigation period even though the trained arm had a higher ratio than the untrained arm post training (.89 vs $.76),(p=.042)$ whereas prior to training it did not (.79 vs . 80) (Fig. 13).

significant $(p<0.01)$ increases in the crosssectional area of the flexors $\left(3.62 \mathrm{~cm}^{2}, 4.48\right)$ and the extensors $\left(6.9 \mathrm{~cm}^{2}, 9.98\right)$ of the right leg but not the left leg were observed over the course of the study (Table vi, appendix $c$ ), despite the fact that both legs were trained simultaneously. A significant $(p<0.01)$ increase in the area of the right femur was also noted.

\subsubsection{MUSCLE FIBRE CHARACTERISTICS}

In both arms type I and type II fibre area increased after training ( $p<0.005)$ (Fig.14). The type II fibre area increase in the trained arm (30.22\%, $\left.5617.0-7311.0 \mu \mathrm{m}^{2}\right)$ was significantly $(p<0.05)$ greater than in the control arm (10.7\%, 5609.0-6209.0 $\left.\mu \mathrm{m}^{2}\right)$. Type II fibre area increased more than type $I$, as indicated by a significant increase $(p<0.05)$ in the FT/ST (II/I) area 
ratio of the trained arm (1.13 to 1.29) (Fig.14); there was no change in the control arm. The percentage of type I fibres in the trained arm was found to be initially different from that of the untrained arm (39.5\% vs $45 \%$ respectively; $\mathrm{p}<.035)$, but this difference was not altered by training.

The relative ( 8 ) increases in elbow flexor $1 \mathrm{RM}$ capacity did not correlate significantly with either muscle ( $r=.0265$ ) or muscle fibre (type I $r=-.1438$, type II $r=-.2635$ ) hypertrophy. 

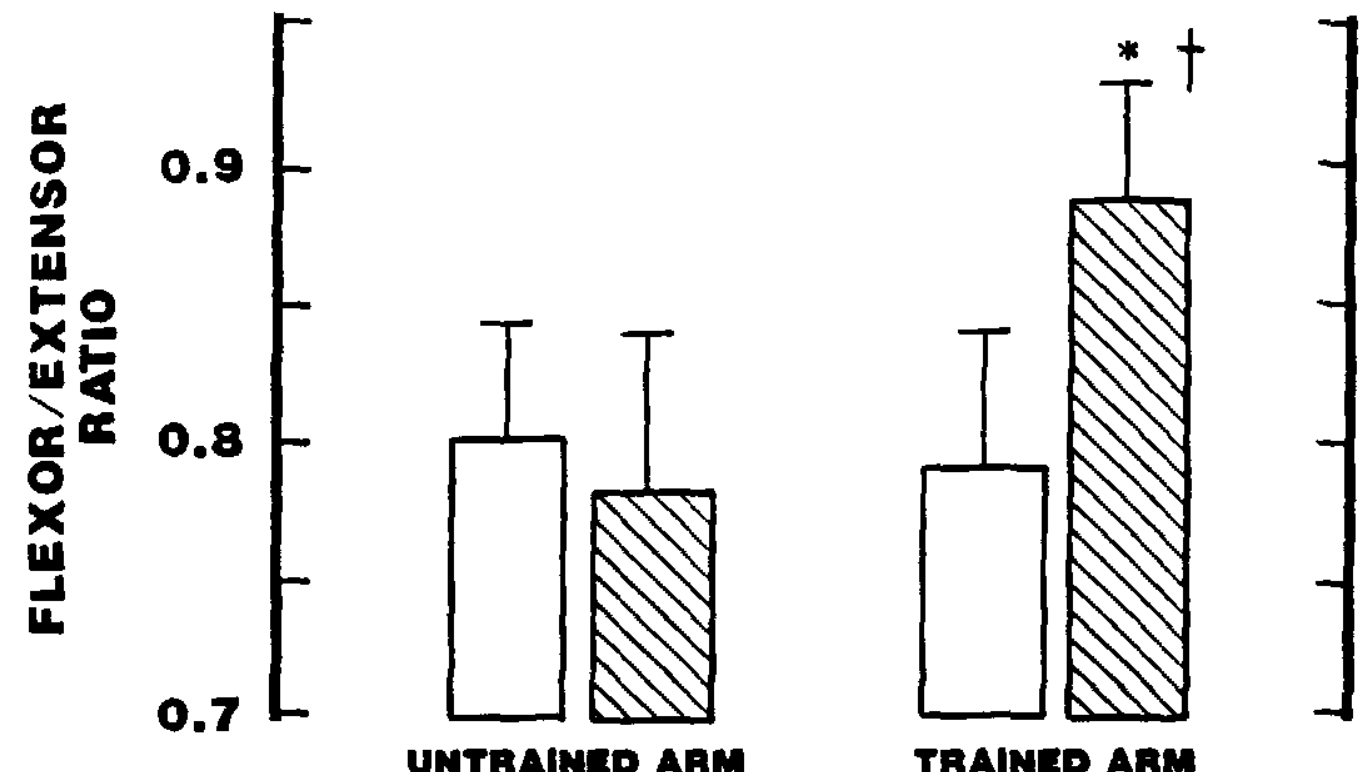

FIG. 13. Maximal flexor-to-extensor ratio in trained and untrained arms before (open bars) and after (hatched bars) training. $" P<0.05$, change after training and $+P<0.05$, difference between arms. 

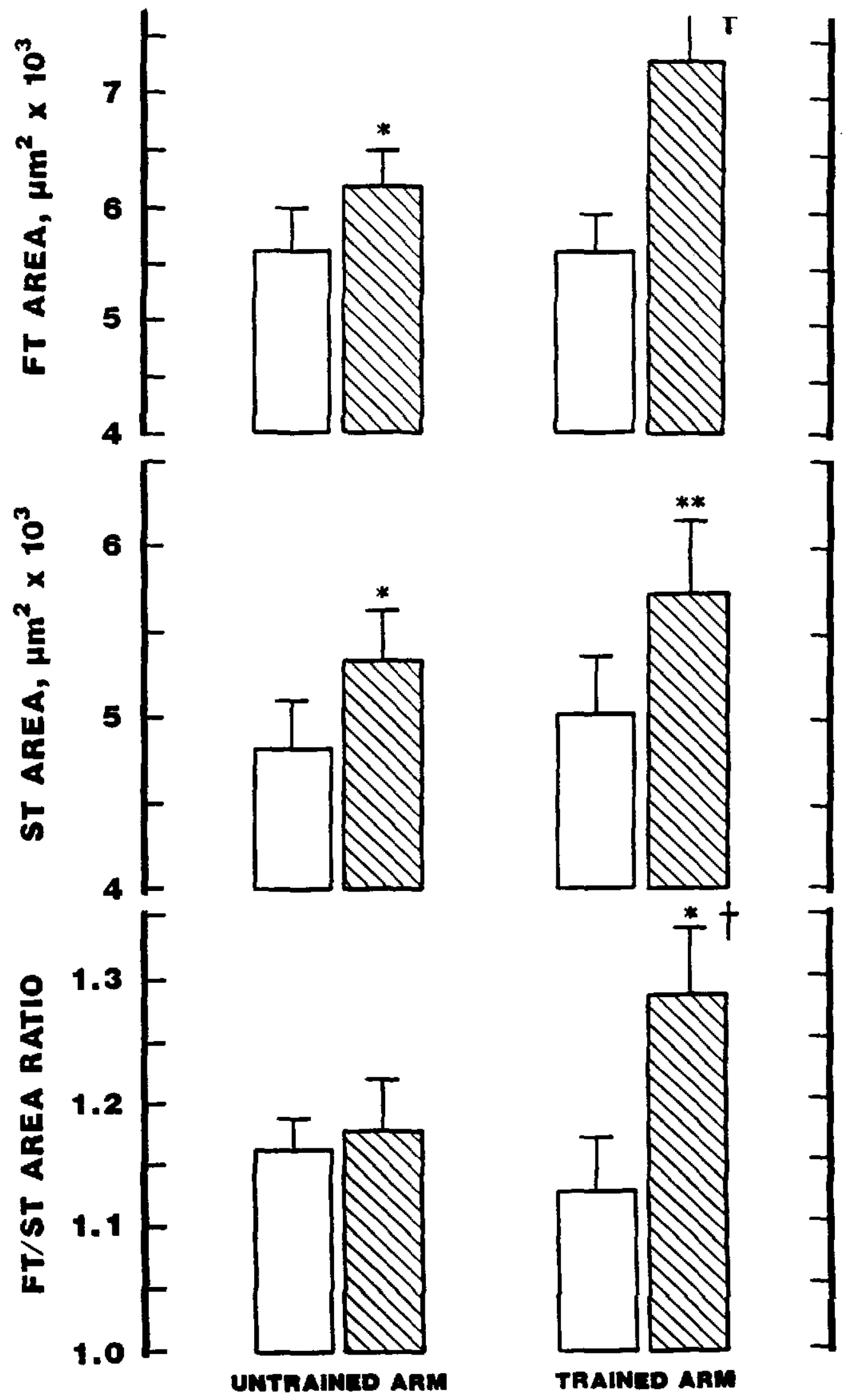

II0. 14. Mean cross-sectional areas of type II (fast-twitch, ET; top) and I (slow-twitch, 5T; middle) fibres and ET-to-ST area ratios (bottom) in biceps brachii muscles of both arms before (open bars) and after (hatched bars) traini:g. " $P<0.05$, change after training (top \& bottom); " $\mathrm{p}<0.001$ and $t p<0.001$, greater increase in ET VS ST fibres in trained are (top). " $p<0.01$, change after training (middle); $+P<0.05$, difference between arms (bottom). 


\section{CHAPTER 4}

\section{DIscussion}

All subjects were able to successfully complete the training without injury. Compliance was excellent; one subject missed a single session because of a prior commitment and another missed two sessions due to minor back pain sustained outside of training. Kaufman (1985), as part of his rationale for selecting the adductor digiti minimi as the muscle his subjects trained, cited the fact that older subjects find strength training more uncomfortable than young people. This was not the experience in this investigation as the subjects appeared to experience no greater discomfort than university aged subjects trained in a similar manner. It is encouraging that a training program involving large muscle groups is indeed viable and can be completed successfully by the elderly.

4.1.

CHANGES IN MUSCLE PERFORMANCE AND MUSCLE SIZE The major finding in the present study was that older men responded to weightlifting training in a qualitatively similar manner as young men, with large increases in the maximal load that could be lifted and accompanying enlargement of whole muscle and muscle fibre areas. 
4.2.1. VOLUNTARY WEIGHTLIETING STRENGTH

The pre-training $1 \mathrm{RM}$ values were lower in the elderly subjects than the values recorded in a previous study in this laboratory involving untrained university males: (Bench Press (BP), 76\%; Leg Press (LP), 868; Arm Curl (AC), 62\%; elderly subjects 1 RM values expressed as a percentage of the young subjects values,) but posttraining the elderly subjects' 1 RM values were comparable to the initial levels of the young subjects (BP 97\%, LP 106\% and AC 89\%) (unpublished data).

The improvement in dynamic strength represents a major finding of this study. Increases in BP (27\%), LP (23\%) and AC (49\%) were equal to or greater than those reported in 19-21 yr old males following 10 weeks of strength training, (BP 16.5\%, LP 23\%, and AC 18.9\%, Wilmore, 1974). Moritani and de Vries (1980) reported an increase in the weightlifting capacity of elderly subjects' elbow flexors of $23 \%$ after 8 weeks of progressive weightlifting exercise and Aniansson and Gustafsson (1981) reported similar increases in the isokinetic torque of the knee extensors of elderly subjects after 12 weeks of training using body weight as resistance. A recent study by Frontera et al. (1988) provided the first evidence that older muscles could respond to intense resistance training with large 
increases in I RM performance concurrent with substantial whole muscle and individual muscle fibre hypertrophy. Data from the present study is in broad agreement with these findings, but the gains in muscle performance in this investigation were less for a greater degree of hypertrophy. (For a more complete discussion of hypertrophy see sections 4.3 and 4.4.) Frontera et al. (1988) reported an improvement of $107 \%$ in knee extensor $1 \mathrm{RM}$ and $227 \%$ in the leg flexor $1 \mathrm{RM}$ after 36 training sessions. These increases in lower limb voluntary strength are substantially greater than our increases in upper limb (BP, 27\%, AC 49\%) and lower limb strength (23\%).

One possible explanation for the different findings is that leg extension and flexion exercises may not be as familiar to, or as comfortable for, the subjects to perform, as the leg press exercises, and as a result initial strength measures may be depressed due to discomfort or inhibition (Perrine \& Edgerton, 1978). This may result in apparently large performance improvements as the subjects become familiar with the exercises through training. The $49 \%$ increase in AC strength in the present study was potentially inflated for similar reasons due to the nature of the arm curl training and testing device. The device had an unusual 
"sticking point" which possibly deflated pre-training values. With training, the subjects became accustomed to the leverage mechanism of the machine and this may have been reflected in the large increases in strength.

In addition to the substantial gains in the maximal weight lifting capacity in this study, there was a notable improvement in muscular endurance during repeated lifting. After training, subjects were able to lift their pre-training $1 \mathrm{RM}$ from (range) 4 to 34 times in the trained arm and from 1 to 16 times in the untrained arm. By the seventh decade of life losses in strength and power often interfere with many common activities of daily living such as lifting and carrying, raising and lowering body weight and walking. It seems likely that increases in muscular endurance of the type reported here might enable seniors to accomplish certain tasks which may otherwise prove to be impossible or extremely fatiguing.

\subsubsection{ISORINETIC AND ISOMETRIC STRENGTH}

The benefits of training were somewhat specific to the mode of exercise employed as strength performance measured on the training device increased far more than in the less familiar isometric and isokinetic tests. While there were no increases in isometric elbow flexor 
strength post training at any measured joint angle, there were significant increases in isokinetic bilateral leg press and unilateral arm flexion torque at all velocities tested. Most studies involving isokinetic measures have examined knee extension, and increases of $7-22 \%$ after a short period of training have been reported (Aniansson \& Gustafsson, 1981, Aniansson et al., 1984). Similar increases of $17-18 \%$ were observed in the present study in which subjects trained using a bilateral leg press manoeuvre. As with the 1 RM measures, isokinetic strength gains were seen in both the trained and untrained arms. This was perhaps due to a neural transfer effect; for example, an enhanced ability of the central nervous system to recruit the motor units of the untrained arm as a result of the neural adaptations occurring in response to training in the trained arm. It is also possible that the elbow flexors of both arms received a moderate stimulus during the seated dead lift and bench press exercises.

The observed specificity points to the important role of nervous system adaptations in the response to strength training, in particular the role of learning and coordination (Rutherford \& Jones, 1986).

- The implication for the design of strength training programs for the elderly is that the strength training 
exercises should simulate as closely as possible the most common strength-requiring tasks likely to be encountered by this population. such an approach will ensure the best possible return on the training investment.

The lack of a significantly greater increase in isometric and isokinetic performance in the trained vs. the untrained arm was a puzzling finding, particularly in view of the fact that the trained arm underwent the greatest increase in muscle and muscle fibre crosssectional area. A greater increase in strength would be expected to accompany a greater increase in muscle mass. such a finding is not unique to the present study however. Frontera et al. (1988), found that right knee extensor muscles failed to increase in isometric strength despite àn 11.98 increase in muscle cross-sectional area. In the left knee extensors the increase in isometric strength (7.7\%) was slightly less than the increase in muscle size (9.38). In other work by Dons et al. (1979), weight training in young men caused a greater increase in muscle cross-sectional area $(10-17 \%)$ than isometric strength $(4-5 \%)$. The authors also reported that weightlifting performance increased $24-42 \%$. In a previous study in this laboratory (unpublished observations) a significant increase was not found in isometric strength after 5 months of weight training by young men despite 
significant increases in weight-lifting performance and muscle cross-sectional area. In addition, in a recent study no increase was found in the peak isometric force of overloaded rat soleus despite significant increases in muscle mass and muscle fibre area (Kandarian \& White, 1989).

It is difficult to explain why any measure of strength would not increase if muscle size increased. Perhaps in the present study training caused a "negative" neural adaptation, which took the form of inhibition of the elbow flexors during isometric contractions, thereby preventing increased force despite hypertrophy. This explanation can be excluded because motor unit activation in the flexors was near maximal and similar before and after training. A counterproductive neural adaptation might have taken the form of increased co-contraction of antagonists; thus, increased cocontraction of triceps in the less familiar isometric task may have offset the increased contractile force of the agonists (elbow flexors). The present investigation has no data related to this possibility, but there is one report in the literature of greater co-contraction in the leg muscles of trained power athletes than endurance athletes (osternig et al., 1986). In view of the many ways in which the muscles acting at the elbow joint can be 
activated and coordinated(Buchanan et al.,1989), such seemingly counterproductive adaptations cannot be ruled out.

Perhaps the observed hypertrophy did not increase the intrinsic force-generating capacity of the muscle. It cannot be argued that hypertrophy in these older muscles was entirely the result of connective tissue proliferation, because the increase in fibre size was at least equivalent to that of the whole muscle. Furthermore, the greatly hypertrophied muscle of bodybuilders shows no evidence of connective tissue proliferation (sale et al,,1987). In the previously cited study of rat soleus (Kandarian \& White, 1989), hypertrophy after 30 days of overload was not associated with connective tissue proliferation, an increase of interstitial fluid volume, or a decrease in protein content. These authors suggested that ultrastructural examination of the myofibrils and cytoarchitecture and assessment of possible alterations in the excitationcontraction coupling might help uncover the mechanisms responsible for the decrease in specific tension (i.e., the force developed per unit muscle cross-sectional area) that can accompany hypertrophy. Whatever the mechanisms, they may account for the pattern of results found in the present study. 
A third possible explanation of these results involves the orientation of the arms during training and testing. The training of the elbow flexors was carried out with the humerus flexed at $45^{\circ}$ into the frontal plane on a preacher style bench. Testing of the elbow flexors for 1 RM strength was carried out on the same apparatus, but for isometric MVC, interpolated twitch, electrophysiology and isokinetic testing the humerus was flexed $90^{\circ}$ into the frontal plane. It could be that the change in the orientation of the arm during the testing of these latter measures from the position at which it was trained, may have been responsible for some of our findings or the lack thereof.

\subsection{MUSCLE CROSS-8ECTIONAL AREA}

Voluntary strength gains were accompanied by increases in muscle cross-sectional area. The elbow flexor area of the trained arm in our subjects increased $17 \%$ in response to training after 12 weeks. Ikai and Fukanaga (1970) utilizing ultrasonic measuring devices to study the effects of 100 days of isometric training on muscle cross-sectional areas in young males reported increases of up to 23\%. Though the increase in muscle cross-sectional area was smaller in the present investigation, the subjects trained for 36 as opposed to 
100 sessions. Moritani and de Vries (1980) reported only a $1.5 \%$ increase in elbow flexor area in their $67-72$ year old subjects following 8 weeks of progressive resistance training. These authors employed a 4 site skinfold technique to estimate muscle area which assumes that no decreases in intramuscular fat deposits or changes in connective tissue result from training. Such changes occurring in combination with muscle fibre hypertrophy could result in increases of muscle cross-sectional area undetected by this technique.

Recently Frontera et al. (1988) found a 10 11\% increase in quadriceps cross-sectional area in response to heavy resistance training in older males and while this represents a smaller increase than found in the present investigation, this may simply reflect the greater hypertrophy potential of the arms versus the legs. Previous investigations from this laboratory in experienced weight-trainers suggest that the arms possess a significantly greater potential for hypertrophy than the legs (Sale \& MacDougall, 1984). The lesser overall hypertrophy of the knee extensors in the present study (1.5 to 9.98 ) compared to the arms seems to support this hypothesis.

A notable observation in the present study is that muscle size increased significantly only in the 
right knee extensors and flexors even though both legs were trained simultaneously in a bilateral leg press movement. Perhaps most of the subjects were right limb dominant and unintentionally favored this limb during training. Leg extensor muscle CSA increases of $9.9 \%$ are comparable to extensor muscle increases noted by Frontera et al. (1988).

4.4. MUSCLE FIBRE CROSS-SECTIONAL AREA

In the present study, increases in the crosssectional area of the elbow flexors were associated with corresponding muscle fibre area increases. While type I and II fibres from both arms increased signifcantly, the substantial $30 \%$ increase of type II fibres in the trained arm is of particular note and may perhaps account in large part for the strength gains in that arm. In addition, the increase in the maximal evoked elbow flexor torque seen post training could also be explained by the fibre hypertrophy. Fibre area increases in this study were greater than those reported by Aniansson and Gustafsson (1980) (5 - 9\%, not significant) in the vastus lateralis of 69 - 74 year old men after 12 weeks of training, but not as great as those reported by Larson (1982) (38 - 518) utilizing the "lesser fibre diameter" method. Frontera et al. (1988) found comparable 
increases of $27.5 \%$ in type II fibre areas but larger increases in type $I$ area (33.5 vs $13.7 \%$ ) than in the present study. Fibre type distribution was not affected by training.

Moritani and deVries (1980), based on muscle cross-sectional area estimates and IEMG data, concluded that the increases in strength displayed by the elderly in response to training are the result of neural factors. In the present study, the significant increases in muscle and muscle fibre areas, together with the impressive gains in voluntary strength measures indicate that hypertrophy as well as neural factors can contribute to enhanced strength in the elderly.

4.5. ELECTROPHYSIOLOGICAL PROPERTIES

4.5.1. PEAR TWITCH TORQUE

An increase in muscle cross-sectional area after training should theoretically result in a greater force production during electrically evoked activation. Bodybuilders and weightlifters do have greater evoked twitch force than untrained men (Sale et al.,1983); however, short term studies of strength training in young subjects have noted gains in maximum voluntary strength with no corresponding increases in the evoked maximal twitch and tetanic tensions (Davies \& Young, 1983; 
McDonagh et al., 1983). Cross-sectional studies of the ankle plantarflexors in men aged 69-100 years have reported age-associated reductions in maximum twitch torque and in the rate of torque development (Davies \& White, 1983; Vandervoort \& McComas, 1986), but the effects of strength training on muscle contractile properties in the elderly have not been investigated.

In the present work, significant increases in peak twitch torque were seen at elbow joint angles of 120 and $165^{\circ}$ in the trained arm. This is consistent with the finding of increased muscle and muscle fibre crosssectional area. Although there was an increased torque at the greater joint angles, there was no change at $75^{\circ}$. It could be that because of the short duration of the twitch contraction, the relatively greater amount of series elasticity that exists at the smaller joint angles cannot be taken up quickly enough to enable the muscle to achieve its full contractile tension. As a result, it may be possible for a muscle to become stronger as a result of training, but not display any greater evoked torque production at smaller joint angles.

In the untrained arm an increase in twitch torque was noted at an angle of $165^{\circ}$. This was unexpected since the arm was not trained; however, an increase in muscle fibre cross-sectional area was noted 
and this may perhaps account for the increased twitch torque. However, if this significant increase in fibre area was the mechanism responsible for increased twitch torque at $165^{\circ}$ then a similar type of increase in twitch torque would be expected at a joint angle of $120^{\circ}$. This did not occur and in fact significant decreases in twitch torque were noted at this angle post-training. Since the other electrophysiological measures were based upon the same twitch contractions as these torque measurements and were also a result of them, (that is, a decreased twitch torque would ordinarily result in a decrease in the time to peak torque, half relaxation time and decreased rates of torque production), the results in these other parameters are similarily affected at this joint angle. No change was noted in twitch torque at a joint angle of $75^{\circ}$

Since twitch torque increased in the trained arm at two of three joint angles tested and also at one of the joint angles in the untrained arm, no convincing evidence exists of a systematically greater increase in twitch torque in the trained arm. These results are consistent with the lack of a greater voluntary isometric strength increase in the trained arm. of the previously discussed mechanisms that might account for the failure of voluntary isometric strength to increase despite 
hypertrophy, only the possible decrease in specific tension can be offered to explain the failure of twitch torque to increase more in the more hypertrophied trained arm. A greater degree of hypertrophy than that observed in the present study may be necessary before absolute muscle force begins to increase.

\subsubsection{MAXIMUM RATE OF TORQUE DEVELOPMENT}

The maximum rate of torque development was significantly higher in the trained arm at a joint angle of $165^{\circ}$ post-training. As there was no change in the time to peak torque, the maximum rate of torque production must increase if peak torque increases.

An increased maximum rate of torque production may also suggest that strength training, by causing the selective hypertrophy of fast twitch muscle fibres, produced a faster contracting muscle. If this was the case, similar increases in rates of torque production should have been noted at the other joint angles, which it was not. It may be that by extending the arm to $165^{\circ}$, the series-elastic component of the muscle is taken up to such an extent that the muscles rate of torque development is increased and this, combined with a possibly stiffer muscle post training, produces a quicker contraction in response to the twitch stimulus. 
4.5.3. HALF RELAXATION TIME.

There was a significant increase in halfrelaxation time in the trained arm at all joint angles tested post training and this is in agreement with similar observations in young adults after strength training (Kitai \& Sale, 1989). The increase in halfrelaxation time contributed to the increase in the torque-time integral. The prolongation of the twitch contraction would shift the force-frequency relation to the left, thereby allowing maximal tetanic tension to be achieved at a lower motor unit firing frequency. This adaptation coupled with the already observed slowing of older muscles even without training (Vandervoort \& McComas, 1986) should allow strength-trained seniors to achieve maximal force at lower motor unit firing rates than their younger counterparts. Lower firing rates might also increase resistance to fatigue.

4.6. MECHANISMS FOR INCREASES IN MUSCLE PERFORMANCE Despite the evidence for hypertrophy in the present study, it is unlikely that all of the gains in voluntary performance could be attributed to that mechanism. In agreement with the work of others (Rutherford \& Jones, 1986), the greatest gains were manifest on the training apparatus, indicating a 
specificity effect. During elbow flexion with the trained arm, the $48 \%$ improvement in 1 RM load was accompanied by a corresponding average increase in isokinetic torque at the five angular velocities of only 8.8\% and there was no change in isometric MVC. This variability resulted in the maximal force per unit crosssectional area increasing by $27 \%$ in dynamic exercise, but decreasing by $7 \%$ and $13 \%$ in isokinetic and isometric tests respectively. Many other investigators have reported training-induced alterations in muscle performance which could not be explained by accompanying changes in muscle area (Ikai \& Fukunaga, 1970; Komi et al., 1978; Costill et al., 1979; Dons et al., 1979; Moritani \& devries, 1980; Young et al., 1983; Jones \& Rutherford, 1987).

The most likely explanation for the largest increases occurring during testing on the training apparatus is that some of the improvement was due to a learning effect, or to neural adaptations which optimized force generation. In a study by Rutherford and Jones (1986), weightlifting training resulted in a 2008 increase in training weights but only a 15 to $20 \%$ gain in isometric strength. It was concluded that much of the improvement in dynamic lifting could be attributed to an enhanced contribution of other muscle groups involved in 
the activity. other workers have postulated that strength gains in the absence of hypertrophy and increases in the strength of the control limb are evidence for neural adaptations to resistance training (Moritani \& devries, 1980). Some of these observations may help to explain the variable increases in performance in the present study. That subjects become more comfortable with the training apparatus over the course of the study is very probable; a $12.7 \%$ increase in the 1 RM capacity of the control arm was observed. One somewhat puzzling observation, however, was that substantial muscle hypertrophy without a significant increase in evoked twitch torque was noted in the subjects, even though their ability to recruit motor units was apparently maximal both before and after training, at least in the isometric test. Despite this, subjects demonstrated minimal increases in performance except on the training apparatus. This finding has important implications for health care practitioners involved in therapeutic exercise programmes. It may be incorrect to assume that gains in muscle strength and size will translate into improved function in the physically arduous tasks of daily living. The best results would probably be obtained from training programmes that mimicked actual activities as closely as possible. 


\section{SUMMARY AND CONCLUSIONS}

In summary, this work has demonstrated that aging muscle is able to respond to progressive overload weight lifting training in a qualitatively similar manner as the muscles of young healthy individuals. Large increases in strength are mediated by an increased whole muscle cross-sectional area, particularly the area of the type II fibres. The effects of weight lifting training carry over somewhat to isokinetic power production, but do not result in an enhancement of isometric strength. An additional important finding was that following the training, subjects were able to perform many repetitions of an exercise with a load that corresponded to their initial $1 \mathrm{RM}$; thus there were major improvements in high strength endurance capacity. It seems likely that such notable gains in strength, power and endurance in seniors would translate into an improved function in many activities of daily living which may otherwise prove difficult.

These findings suggest that exercise practitioners should utilize weight lifting as a recommended mode of training in older subjects. It must be remembered however that many of the middle-aged and elderly have covert heart disease and hypertension on 
exercise. Further study is needed to investigate the safety of weight lifting training in seniors. Until such time as the results become available, exercise practitioners must insist on a rigorous physical examination of any older individual who wishes to engage in a weight lifting programme, and carefully monitor heart rate, heart rhythm and arterial blood pressure during the activity. 


\section{REFERENCES}

An K.N., Hui F.C., Morrey B.F., Linscheid R.L., Chao E.Y. (1981) Muscles across the elbow joint: a biomechanical analysis. J. Biomech, 14:659-669.

Aniansson, A., sperling, L., Rundgren, A., Lehnberg, E. (1983) Muscle function in 75-year-old men and women, a longitudinal study. Scand. J. Rehab. Med.L (suppl).9:92-102.

Aniansson, A., Gustafsson, E. (1981) Physical training in elderly men with special reference to quadriceps muscle strength and morphology. clinical Physiology, 1:87-98.

Aniansson, A. , Ljungberg, P., Rundgren, A., Wetterqvist, H. (1984) Effect of a training porgramme for pensioners on condition and muscular strength. Arch. Gerontol. Geriatr.. 3:229-241.

Atha, J. (1981) strengthening Muscle. Exercise and Sports Science Review, $9: 1-73$.

Belanger, A.Y., Mccomas, A.J. (1981) Extent of motor unit activation during effort. J.Appl. Physiol., 51:1131-1135.

Bick, E.M. (1961) Aging in connective tissue of human musculoskeletal system. GERIA,448-453.

Borkan,G.A., Hults, D.E., Gerzof,S.G., Robbins, A.H., Silbert, C.K. (1983) Age changes in body composition revealed by computed tomography. J. of Gerontol., 38:673-677.

Campbell, M.J., McComas, A.J., Petito, F. Physiological changes in ageing muscles. J. Neurol. Neurosurg. Psychiatry, 36:174-182.

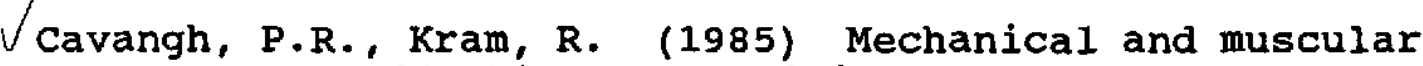
factors affecting the efficiency of human movement. Med. Sci. Sports Exercise, 17:326-331.

n Chapman, E.A., devries,H.A., Swezey,R. (1972) Joint stiffness: effects of exercise on young and old men. J. Gerontol., 27:218-221. 
Cureton, K.J., Collins, M.A., Hill, D.W., Mcelhannon jr. F.M. (1988) Muscle hypertrophy in men and women. Med. Sci. Sports Exercise,20:338-344.

Davies, C.T.M., White, M.J. (1983) Contractile properties of elderly human triceps surae. Gerontol.. 29:19-25.

Davies, C.T.M., White, M.J. (1983) Effects of dynamic exercise on muscle function in elderly men, aged 70 years. Gerontol.,29:26-31.

Davies, C.T.M., White, M.J., Young, K. (1983) Muscle function in children. Eur. J. Appl. Physiol. $52: 11-114$.

Drahota, Z., Gutmann, E. (1962) The effects of age on compensatory and "postfunctional hypertrophy" in cross-striated muscle. Gerontologia, 6:81-90.

Edstrom,L., Nystrom B. (1969) Histochemical types and sizes of fibres in normal human muscles. A biopsy study. Acta. Neurol. Scand., 45(3):

Edstrom, L., Larsson,L. (1987) Effects of age on contractractile and enzyme-histochemical properties of fast- and slow-twitch single motor units in the rat. J.Physiol. $392: 129-145$.

Enoka, R.M. (1988) Muscle Strength and Its Development: New Perspectives. Sports Med..,6:146168 .

Essen-Gustavsson,B., Borges, 0 . (1986) Histochemical and metabolic characteristics of human skeletal muscle in relation to age. Acta. Physiol. Scand. $126: 107-114$.

Falkel, M.S. (1978) Human flexor strength testing using the cybex isokinetic dynamometer. Phys. Ther.. 58:847-850.

Fitch,S., McComas,A.J. (1985) Influence of human muscle length on fatigue. I. Physiol.4362:205213 . 
Frontear,W.R., Meredith, C.N., Knuttgen, H.G., Evans, W.J. conditioning in older men: hypertrophy and improved function. O'Reilly, K.P., physiol., 64:1038-1044.

Fugl-Meyer, A.R., Gerdle,B., Langstrom,M. Characteristics of related isokinetic plantar flexions in middle-aged and elderly subjects with special regard to muscular work. Acta Physiol Scand, $124: 213-222$.

(Gerdle,B., Fugl-Meyer,A.,R. (1985) Mechanical output and iEMG of isokinetic plantar flexion in 40-64year-old subjects. Acta. Physiol. Scand. 124:201211.

Gibson,M.C., Schultz,E..

Age-related differences in absolute numbers of skeletal muscle satellites cells. Muscle \& Nerve, 6:574-580.

Goldberg,A.L., Etlinger,J.D., Goldspink,D.F., Jablecki,c. (1975) Mechanism of work-induced hypertrophy of skeletal muscle. Med. Sci, sports Exercise, 7:248-261.

Goldspink, G., Howells, K.F. (1974) Work-induced hypertrophy in exercised normal muscles of different ages and the reversibility of hypertrophy after cessation of exercise. I.Physiol.,239:179193 .

Gollnick,P.D., Parsons,D., Riedy,M., Moore,R.I. , (1983) Fiber number and size in overloaded chicken anterior latissimus dorsi muscle. J. Appl. Physiol.:Respirat. Environ. Exercise Physiol.. 54:1292-1297.

Gollnick, P.D., Armstrong, R.B.,

Shepherd,R.E., Saltin B.

Sembrowich, W.L., (1973) Glycogen depletion pattern in human skeletal muscle fibers after heavy exercise. J.App 1. Physiol...34:615618 .

Gollnick, P.D., Timson,B.F., Moore,R.L., Riedy,M. (1981) Muscular enlargement and number of fibers in skeletal muscles of rats. J. Appl. Physiol.: Respirat. Environ. Exercise Physiol. 50:936-943. 
Gonyea,W.J. (1980) Role of exercise in inducing increases in skeletal muscle fiber number. $\mathrm{J}$. Appl. Physiol. Respirat. Environ. Exercise physiol., 48:421-426.

Gonyea,W., Ericson,G.C., Bonde-Petersen, F. skeletal muscle fiber splitting induced by weightlifting exercise in cats. Acta. Physiol. Scand., 99:105-109.

Gonyea,W.J., Ericson,G.C. (1976) An experimental model for the study of exercise-induced skeletal muscle hypertrophy. J.Appl. Physiol.,40:630-633.

Gonyea,W.J., Sale,D.G., Gonyea,F.B., Mikesky,A. (1986) Exercise induced increases in muscle fiber number. Eur. J. Appl. Physiol., 55:137-141.

Gonyea,w.J., Sale,D. (1982) Physiology of weight lifting exercise. Arch. Phys. Med. Rehabil. $63: 235-237$.

Gordon, A.M. , Huxley, A.F., Julian, F.J. (1966) The variation in isometric tension with sarcomere length in vertebrate fibres. I. Physiol., 184:170192 .

Grimby,G., Saltin,B., (1983) Mini-review: the ageing muscle. Clin. Physiol., 3:209-218.

Grimby,G., Danneskiold-Samsoe,B., Hvid, K., Saltin, B. (1982) Morphology and enzymatic capacity in arm and leg muscles in 78-81 year old men and women. Acta. Physiol. Scand. . 115:125-134.

Gutmann, E. (1970) Nervous and hormonal mechanisms in the aging process. Exp. Geront., 5:357-366.

Gutmann, E., Hanzlikova,V., Jakoubek,B. (1968) Changes in the neuromuscular system during old age. Exp. Geront. 3 : 141-146.

Hasan, Z., Enoka,R.M. (1985) Isometric torque-angle relationship and movement-related activity of human elbow flexors: implications for the equilibriumpoint hypothesis. Exp. Brain Res, 59:441-450. 
Henry,F.M. (1959) Factorial structure of speed and static strength in a lateral arm movement. Res. Quart... 31:440-447.

Henry,F.M., Whitley,J.D. (1959) Relationships between individual differences in strength, speed, and mass in an arm movement. Res. Quart., 31:24-33.

Ikai,M., Fukunaga,T. (1968) Calculation of muscle strength per unit cross-sectional area of human muscle by means of ultrasonic measurement. Int, $Z$. angew. Physiol. einschl. Arbeitsphysiol, 26:26-32.

Ikai,M., Fukunaga,T. (1970) A study on training effect on strength per unit cross-sectional area of muscle by means of ultrasonic measurement. Int. $z$. angew. physiol. 28:173-180.

Imamura,K., Ashida,H., Ishikawa,T., Fujii,M. (1983) Human major psoas muscle and sacrospinalis muscle in relation to age: a study by computed tomography. J.Gerontol. $38: 678-681$.

Ismail,H.M., Ranatunga,K.W. (1978) Isometric tension development in a human skeletal muscle in relation to its working range of movement: the lengthtension relation of biceps brachii muscle. Exp. Neuro1.,62:595-604.

Johnson, M.A., Polgar,J., Weightman, D., Appleton, D. (1973) Data on the distribution of fibre types in thirty-six human muscles: an autopsy study. JNSCA $18: 111-129$

Jones, D.A., Rutherford, O.M. (1987) Human muscle strength training: the effects of three different regimes and the nature of the resultant changes. J. Physiol., 391:1-11.

Jones, D.A., Rutherford,O.M. , Parker, D.F.

(1989) Physiological changes in skeletal muscle as a result of strength training. 0.J. Exp. Physiol. $74: 233-256$.

Joyce,G.C., Rack,P.M.H. (1969) Isotonic lengthening and shortening movements of cat soleus muscle. J. Physiol., 204:475-491. 
Klitgaard,H., Clausen, T. (1989) Increased total concentration of $\mathrm{Na}-\mathrm{K}$ pumps in vastus lateralis muscle of old trained human subjects. J. Appl. physiol., 67:2491-2494.

Kauffman,T.L. (1985) strength training effect in young and aged women. Arch. Phys. Med. Rehabil., $65: 223-226$

Larsson,L. (1983) Histochemical characteristics of human skeletal muscle during aging. Acta. Physiol. Scand. $117: 469-471$.

Larsson, L., sjodin, B., Karlsson, J.

(1978) Histochemical and biochemical changes in human skeletal muscle with age in sedentary males, ages 22-65 years. Acta. Physiol. Scand. 103:31-39.

Larsson, L., Grimby,G., Karlsson,J.

(1979)

Muscle strength and speed of movement in relation to age and muscle morphology. J. Appl. Physiol. Respirat. Environ. Exercise Physiol., 46:451-456.

Lexell,J., Downham, D., Sjostrom,M. (1986) Distribution of different fibre types in human skeletal muscles: fibre type arrangement in $\mathrm{m}$. vastus lateralis from three groups of healthy men between 15 and 83 years. INSCA, 72:211-222.

MacDougall,J.D., Sale,D.G., Moroz,J.R., Howald,H., Elder,G., Sutton,J.R. (1980) Effects of strength training and immobilization and human muscle fibres. Eur. J. Appl. Physiol. 43:25-34.

MacDougall,J.D., Sale,D.G., Edler,G.C.B., Sutton,J.R. (1982) Muscle ultrastructural characteristics of elite powerlifters and bodybuilders. Eur. J. Appl. Physiol., 48:117-126.

MacDougall,J.D., Sale,D.G., Alway, S.E., Sutton,J.R. (1984) Muscle fibre number in biceps brachii in bodybuilders and control subjects. J. Appl. Physiol.: Respirat Environ. Ex. Physiol. 57:13991403 .

MacDougall, J.D., (1986) Adaptability of muscle to strength training. In - saltin, B.(ed) Biochemistry of exercise VI. International series on sport sciences, vol 16. Human Kinetics, Champaign, Ill,pp 501-514. 
Maughan,R.J. (1984) Relationship between muscle strength and muscle cross-sectional area. Spor. Med. 1:263-269.

McComas, A.J., Upton, A.R.M., Sica,R.E.P. Motoneurone disease and ageing. Lancet, 1477-1480.

McComas,A.J., Kereshi,S., Quinlan,J. (1983) A method of detecting functional weakness. J. Neurol. Neurosurg. Psychiatry, 46:280-282.

MCDonagh,M.J.N., Hayward, C.M., Davies, C.T.M. (1983) Isometric training in human elbow muscles. J. Bone Jt. Surg. $65: 355-358$.

McDonagh,M.J.N., Davies, C.T.M. 1984) Adaptive response of mammalian skeletal muscle to exercise with high loads. Eur. J. Appl. Physiol, . 52:139-155.

Miyashita,M., Kanehisa,H. (1979) Dynamic peak torque related to age, sex and perofrmance. Res. Quart. 50:249-255.

Moller, P., Alvestrand, A., Bergstrom, J., Furst, P., Hellstrom, K. (1983) Electrolytes and free amino acids in leg skeletal muscle of young and elderly women. Gerontol. 29:1-8.

Montoye,H.J., Lamphiear,D.E. (1977) Grip and arm strength in males and females, age 10-69. The Res. Quart., $48: 109-120$.

Moritani,T., devries,H.A. (1979) Neural factors versus hypertrophy in the time course of muscle strength gain. Am. J. Phys. Med. , 58:115-129.

Moritani,T., devries,H.A. (1980) Potential for gross muscle hypertrophy in older men. J. Gerontol.. $35: 672-682$.

Murray,P.M., Gardner,G.M., Mollinger, L.A., Sepic,S.B. (1980) strength of isometric and isokinetic contractions: Knee muscles of men aged 20 to 86 . Phys. Ther., 60:412-419.

Murray,P.M., Duthie,E.H.Jr., Gambert,S.R., Sepic,s.B., Mollinger,L.A. (1985) Age-related differences in knee muscle strength in normal women. $J$. Gerontol.. 40:275-280. 
Narici,M.V., Roi,G.S., Landoni,L., Minetti,A.E., Cerretelli,P. (1989) Changes in force, crosssectional area and neural activation during strength training and detraining of the human quadriceps. Eur. J. Physiol.e 59:310-319.

Nygaard, E. , Houston, M., Suzuki, Y., Jorgensen, K., Saltin, B. (1983) Morphology of the brachial biceps muscle and elbow flexion in man. Acta. Physiol. Scand., 117:287-292.

Orlander,J., Kiessling,K.H., Larsson, L., Karlsson, J., Aniansson, A. (1978) skeletal muscle metabolism andultrastructure in relation to age in sedentary men. Acta. Physiol. Scand, 104:249-261.

Pearson,M.B., Bassey,E.J., Bendall,M.J. (1985) Muscle strength and anthropometric indices in elderly men and women. Age and Ageing. 14:49-54.

Penman,K.A. Ultrastructural changes in human striated muscle using three methods of training. Res. Quart.e $40(4): 764-772$.

Perrine,J.J., Edgerton,V.R. (1978) Muscle forcevelocity and power-velocity relationships under isokinetic loading. Med. Sci. Sports, 10:159-166.

Petrofsky,J.S., Lind, A.R. (1975) Aging, isometric strength and endurance, and cardiovascular responses to static effort. J. Appl.Physiol. $38: 91-95$.

Petrofsky,J.S., Phillips,C.A., Sawka,M.N., Hanpeter,D., Lind,A.R., stafford,D. (1981) Muscle fiber recruitment and blood pressure response to isometric exercise. J. App1. Physiol., 50:32-37.

Purifoy,F.E., Koopmans,L.H., Mayes,D.M. (1981) Age differences in serum androgen levels in normal adult males. Hum. Biol., 53:499-511.

Rack,P.M.H., Westbury,D.R. (1969) The effects of length and stimulus rate on tension in the isometric cat soleus muscle. J. Physiol.e 204:443460 . 
Reaven,G.M., Reaven,E.P. (1981) Prevention of agerelated hypertriglyceridemia by caloric restriction and exercise training in the rat. Metabolism, $30: 982-986$.

Roedde,S., MacDougall,J.D., Sutton,J.R., Green,H.J. (1986) Super compensation of muscle glycogen in trained and untrained subjects. Can. J. Appli. Spt. Sci.., 11:42-46.

Rosenheimer,J.L. (1985) Effects of chronic stress and exercise on age-related changes in end-plate architecture. J. Neurophysiol., 53:1582-1589.

Rowe,R.W.D. (1969) The effect of hypertrophy on the properties of skeletal muscle. Comp. Biochem. Physiol., 28:1449-1453.

Rutherford, O.M., Jones, D.A. (1986) The role of learning and coordination in strength training. Eur. J. Appl. Physiol., 55: 100-105.

Sale,D.G.

Neural Adaption

to resistance $/ 1 / 3$ training. Med. Sci. Sports Exercise. 20:S135-S145.

Sale,D.G., MacDougall,J.D. (1981) specificity in strength training: a review for the coach and athlete. Can. J.App1. Sports Sci, 6:87-92.

Sale,D.G., MacDougall, J.D., Upton,A.R.M., Mccomas,A.J. (1983) Effect of strength training upon motorneuron excitability in man. Med. Sci. Sports Exerc. 15: 57-62.

Sale,D.G., MacDougall,J.D., (1984) Isokinetic Strength In Weight Trainers. Eur. J.Appl. Physiol. 53:128-132

Sale,D.G., MacDougall,J.D., Alway,S.E., Sutton,J.R. (1987) Voluntary strength and muscle characteristics in untrained men and women and male bodybuilders. J. App1. Physiol., 62:1786-1795.

Sale,D.G. (1988) Neural adaption to resistance training. Med. Sci. Sports Exerc., 20:S135-S145.

Sale,D.G., Upton,A.R.M., McComas,A.J., MacDougall,J.D. (1983) Neuromuscular function in weight-trainers. Exp. Neurol.1.82:521-531. 
Sale,D.G., MacDougall, J.D., Jacobs, I., Garner,S. (1990) Interaction between concurrent strength and endurance training. J. Appl. Physiol. 68:260-270.

Salmons, S., Henriksson, J. (1981) The adaptive reponse of skeletal muscle to increased use. Muscle \& Nerve, $4: 94-105$.

Schantz, P., Randall-Fox, E., Hutchison, w. , Tyden, A., Astrand,P.O. (1983) Muscle fibre type distribution, muscle cross-sectional area and maximal voluntary strength in humans. Acta. Physiol. Scand. $117: 219-226$.

Sica,R.E.P., McComas,A.J. (1971) Fast and slow twitch units in a human muscle. J. Neurol. Neurosurg. Psychiat. $34: 113-120$.

Silbermann, M., Finkelbrand, S., Weiss, A., Gershon, D., Reznick,A,.. (1983) Morphometric analysis of ageing skeletal muscle following endurance training. Muscle \& Nerve, 6:136-142.

Stalberg,E., Fawcett,P.R.W. (1982) Macro EMG in healthy subjects of different ages. I. Neurol. Neurosurg. Psychiatry, $45: 870-878$.

Staron,R.S., Hikida,R.S., Hagerman,F.C., Dudley,G.A., Murray,T.F. (1984) Human skeletal muscle fiber type adaptability to various workloads. J. Histochem. Cytochemistry_ 32:146-152.

Tanaka,M., McDonagh,M.J.N., Davies, C.T.M. (1984) A comparison of the mechanical properties of the first dorsal interosseous in the dominant and nondominant hand. Eur. J. Physiol. 53:17-20.

Tesch,P. A., Karlsson,J. (1985) Muscle fiber types and size in trained and untrained muscles of elite athletes. J. Appli. Physiol., 59:1716-1720.

Thorstensson, A. (1976) Muscle Strength, Fiber Types, and Enzyme Activities in Man. Acta. Physiol. Scand. Supplement, 443:7-44.

Thorstensson, A., Hulten, B., Von Dobeln, W., Karlsson, J. (1976) Effects of strength training on enzyme activities and fibre characteristics in human skeletal muscle. Acta physiol scand., 96:392-398. 
Tzankoff,S.P., Norris,A.H. (1978) Longitudinal changes in basal metabolism in man. J. Appl. Physiol., $45: 536-539$.

Tzankoff,S.P., Norris,A.H. (1977) Effect of muscle mass decrease on age-related BMR changes. I. Appl. Physiol.: Respirat. Environ. Exercise Physiol., 43:1001-1006.

Vailas, A.C., Pedrini,V.A., Pedrini-Mille, A., Holloszy,J.O. (1985) Patellar tendon matrix changes associated with aging and voluntary exercise. I. Appl. Physiol.. 58:1572-1576.

van der Gon J.J. Denier, ter Haar Romeny,B.M., van Zuylen,E.J. (1985) Behaviour of motor units of human arm muscles: differences between slow isometric contraction and relaxation. J. Physiol.. 359: 107-118.

Vandervoort, A.A. McComas, A.J. (1986) Contracile changes in opposing muscles of the human ankle joint with aging. J. Appl. Physiol. 661:361-367.

wilmore,J.H. (1974) Alterations in strength, body composition and anthropometric measurements consequent to a 10-week weight training program. Med.Scj.Sports, 6:133-138.

Wilmore, J.H. , Parr,R.R., Girandola,R.N. , Ward,P., Vodak,P.A., Barstow,T.J., Pipes,T.V., Romero,G.T., Leslie, P. (1978) Physiological alterations consequent to circuit weight training. Med. sci. Sports, 10:79-84. 
APPENDIX A 


\title{
Positive adaptations to weight-lifting training in the elderly
}

\author{
ALLAN B. BROWN, NEIL McCARTNEY, AND DIGBY G. SALE \\ Department of Physical Education, McMaster University, Hamilton, Ontario L8S 4K1, Canada
}

Brown, Allan B., Neil McCartney, and Digby G. Sale. Positive adaptations to weight-lifting training in the elderly. J. Appl. Physiol, 69(5): 1725-1733, 1990.-Maximal weight-lifting performance, isometric strength, isokinetic torque, whole muscle and individual fiber cross-sectional areas, and muscle evoked contractile properties were assessed in 14 elderly males before and after $12 \mathrm{wk}$ of weight-lifing training. Dynamic elbow flexion training of one arm resulted in a significant $48 \%$ mean increase in the maximal load that could be lifted once (1 RM) and a smaller improvement in isokinetic torque $(8.8 \%)$ but no change in isometric strength. In the contralateral control arm, $1 \mathrm{RM}$ and isokinetic torque increased by 12.7 and $6.5 \%$, respectively, but isometric strength did not change. The interpolated twitch technique confirmed complete motor unit activation during a maximal isometric contraction of the elbow flexors before and after the training. Bilateral leg press training effected mean increases of 17 and $23 \%$ in isokinetic torque and dynamic lifting capacity, respectively. The mean maximal cross-sectional area of the elbow flexors (biceps brachii and brachialis) increased by $17.4 \%$ in the trained arm but did not change the control arm. The increase in the mean area of type II fibers in the biceps brachii muscle in the trained arm (30.2\%) was greater than the corresponding change in the control arm $(10.7 \%, P<0.05)$. The most significant change in the evoked contractile properties of the trained elbow flexors was the increase in twitch half-relaxation time. It is concluded that older individuals retain the potential for significant increases in strength performance and upper limb muscle hypertrophy in response to overload training.

strength training; contractile properties; hypertrophy

SKELETAL MUSCLE STRENGTH has been found to increase up to $30 \mathrm{yr}$ of age, to plateau until $\sim 50 \mathrm{yr}$, and to decline slowly thereafter (19). In older individuals, peripheral muscle weakness may compromise common activities of daily living, such as rising from a low chair or lavatory seat (38), and may lead to dependency on others. The relative contributions of changes in the neuromuscular system and progressive inactivity to the reduction in strength with aging are unclear.

The maximal cross-sectional area of the quadriceps muscles may be $25 \%$ lower in the eighth decade than in the third decade (39). This decrease has been attributed to small reductions in the size of type II fibers (13) and to a progressive loss in the total number of muscle fibers $(21,22)$, particularly the type II moiety $(19,20)$. Evidence from electrophysiological studies indicates that the loss of the type II fibers is secondary to motoneuron cell death (6); the fiber type grouping and enclosed fibers that are seen in histological sections of older muscles lend support to this finding (13). Based on the similar reductions in muscle mass and strength with aging and evidence for the preservation of specific tension in muscle, Grimby and Saltin (14) have suggested that quantitative rather than qualitative changes within muscles account for most of the strength loss.

The extent to which reductions in strength with aging may be overcome by appropriate physical training is uncertain. There are relatively few published studies on the effects of strength training in the elderly, and in most of these isometric training of very small muscle groups (17) or calisthenics and elastic bands $(2,3)$ have been used rather than progressive resistance training. Variable increases in strength have occurred after all forms of training, but the greatest gains were reported recently by Frontera and colleagues (11). These investigators noted increases of $>100 \%$ in the strength of the knee extensors and flexors after $12 \mathrm{wk}$ of weight-lifting training, along with evidence of considerable muscle hypertrophy. This is in contrast to other short-term studies of strength training in the elderly, which have demonstrated gains in the strength of knee extensors (3) and elbow flexors (28) with little or no evidence of muscle hypertrophy, suggesting that the improvements were due to neural adaptations.

The present work was designed to extend previous observations by investigating the effects of strength training on muscle strength, whole muscle and muscle fiber cross-sectional areas, muscle contractile properties, and the completeness of motor unit activation in older men.

\section{METHODS}

Subjects. Fourteen healthy $60-$ to 70 -yr-old male volunteers took part in this study (means \pm SD: age $63 \pm$ $2.7 \mathrm{yr}$, height $174 \pm 5.5 \mathrm{~cm}$, weight $79 \pm 7.7 \mathrm{~kg}$ ). None had prior experience with weight-lifting training. All subjects gave their informed consent, and the study was approved by the appropriate Institutional Review Committee. Before acceptance into the study subjects performed a progressive incremental cycle ergometer test (15) to detect any signs of latent heart disease or severe pulmonary impairment; such individuals were excluded from the study.

Study design. The study was designed so that the subjects would specifically train the elbow flexors of one arm only ("trained" arm), affording a within-subject control and thus reducing the need for a control group of subjects. It should be emphasized, however, that although the "untrained" control arm did not receive specific elbow flexion training on the device to be described below, it was involved in two other exercises (bench press 
and seated dead lift) that would have provided a mild training stimulus to the elbow flexors. The training regimen incorporated additional arm, leg, and trunk exercises to provide an overall conditioning stimulus. Posttraining, changes in weight-lifting capacity were evaluated in all the arm and leg exercises but not in movements primarily involving the trunk.

Training. Training was done on 3 alternate days each week for $12 \mathrm{wk}$. Bilateral leg press, supine bench press, and seated dead lift exercises were done on a multistation weight-lifting machine (Global Gym, Downsview, Ontario, Canada); bent-leg abdominal curls were performed on a padded station on the floor. One arm was selected at random, and the elbow flexors were trained on a custom-built weight-lifting apparatus (Rubicon Industries, Stoney Creek, Ontario). Exercises were done in a circuit set system, with 2-min pauses between sets. Each set comprised 10 repetitions in bench press and arm curl exercise, 15 repetitions in leg press, and 12-20 repetitions in the seated dead lift and abdominal curl exercises. The bench press was performed supine as a repeated bilateral arm press exercise from an initial position close to the chest. For the arm curl exercise the subjects were seated and began the movement with the arm in a fully extended position with the palm facing up. The elbow was flexed through a full range of movement to lift the weight before being returned to full extension. The bilateral leg press exercise was performed in a seated position with the back fully supported and the feet resting on a footplate. The exercise consisted of simultaneous hip and knee extension and ankle plantar flexion. Subjects began the movement with the knees flexed at $90^{\circ}$ and then lifted the weight by straightening the legs before resuming the starting position. Training progressed from two sets of each exercise at $50 \%$ of the initial one-repetition maximum (1 RM) to four sets at 70-90\% of 1 RM over the course of the study. Throughout the training program the weights were adjusted to restrict the number of repetitions in each set to the required number.

Measurement of voluntary strength, torque, and weightlifting capacity. Weight-lifting capacity was measured as the heaviest weight that could be lifted once throughout the complete range of movement (1 RM). Testing took place on 2 separate days, and the heaviest weight lifted was recorded as the pretraining value. The movements tested were unilateral arm curl, bilateral leg press, and supine bench press. After the training program, the 1 RM was again determined, and in addition each subject did as many repetitions as possible with the pretraining $1 \mathrm{RM}$ to provide a measure of endurance. In this endurance test, repetitions were done at a rate of $10 / \mathrm{min}$, the same rate used in the training.

Maximal concentric contraction torque of the elbow flexors was measured on a Cybex isokinetic dynamometer (Lumex, Ronkonkoma, NY) before and after the training period. Unilateral elbow flexion was performed at angular velocities of $0.52,2.09,3.14,4.19$, and 5.24 $\mathrm{rad} / \mathrm{s}\left(30,120,180,240\right.$, and $\left.300^{\circ} / \mathrm{s}\right)$ in random sequence. For each contraction, peak torque was taken as the highest value attained regardless of where it occurred in the range of movement. The best performance of three trials at each velocity was recorded as the maximal value.
Bilateral leg press (simultaneous hip and knee extension and ankle plantar flexion) torque was measured as described in detail previously (37). Briefly, a leg press apparatus was coupled to a Cybex dynamometer, and the resulting 4:1 gear reduction enabled the Cybex to accommodate the large torques that can be generated in a bilateral leg press maneuver. However, because this arrangement also restricts the maximal angular velocity of the instrument's lever arm to $1.31 \mathrm{rad} / \mathrm{s}\left(75^{\circ} / \mathrm{s}\right)$ compared with the usual $5.24 \mathrm{rad} / \mathrm{s}\left(300^{\circ} / \mathrm{s}\right)$, measurements were recorded during three trials at lever arm angular velocities of 0.26 and $1.31 \mathrm{rad} / \mathrm{s}$. The maximal voluntary isometric strength of the elbow flexors of each arm was measured on a custom-built apparatus as described in detail elsewhere (25). Subjects did two maximal voluntary contractions (MVCs) separated by 2 min of rest at joint angles of $1.31,2.09$, and $2.88 \mathrm{rad}\left(75,120\right.$, and $\left.165^{\circ}\right)$; the order of testing was selected at random, and the highest torque in the two trials was recorded as the maximal value.

Motor unit activation. The extent of motor unit activation during the MVCs was assessed using the interpolated twitch technique as described by Belanger and McComas (4). A supramaximal electrical stimulus was delivered to the involved muscles during the MVCs. If an increment occurred on the MVC torque recording, the magnitude of the increment, expressed as a percentage of the maximal twitch magnitude evoked at rest, represented that portion of the muscle mass not activated by the voluntary effort. The method cannot distinguish between incomplete recruitment or insufficient motor unit firing rate as being responsible for the increment on the torque recording; hence the term activation is used (4). Therefore complete activation, as indicated by no increment on the torque recording, implies that all motor units have been recruited and are firing at rates sufficient to produce maximal tetanic force.

Measurement of evoked muscle contractile properties. The evoked contractile properties of the elbow flexors were determined in each arm by use of the same apparatus and joint angles previously employed for the measurement of isometric MVC. The assessment of evoked twitch torque always preceded the testing of isometric MVC to obviate the potentiation of the twitch by a maximal effort (36). Twitch contractions were evoked by percutaneous nerve stimulation as described in detail previously (25). Briefly, the contractions were evoked by percutaneous electrical stimulation via two lead plate electrodes, which were encased in moistened gauze impregnated with conducting medium. One electrode was placed on the motor point of the biceps, and the other was placed on the ventral surface of the forearm just below the elbow. The latter placement ensured stimulation of brachioradialis and brachialis as well as biceps. Stimuli were rectangular voltage pulses of 50 - or $100-\mu \mathrm{S}$ duration, delivered by a Devices stimulator (Medical Systems). When no further increases in torque could be produced by additional increases in the stimulus intensity, the twitch contraction was considered to be maximal. The data were displayed on a storage oscilloscope (Hewlett-Packard 120 1B) and analyzed on-line by use of a laboratory computer (PDP 11-03, Digital Equip- 
ment). Measurements included maximal twitch torque, contraction time, half-relaxation time, maximal rates of torque development and relaxation, and torque-time integral.

Measurement of muscle size. The cross-sectional areas of the flexors and extensors of the elbows and knees were measured from computerized tomography scans as reported previously (24). Included in the flexor compartment of the arm were biceps brachii and brachialis but not brachioradialis; the arm extensors were triceps brachii. The knee extensor compartment comprised the four quadriceps heads, and the knee flexor compartment also included the adductor muscles. The legs were scanned simultaneously at a point corresponding to $50 \%$ of the upper leg length as measured from the head of the fibula up to the lateral point of the greater trochanter. The arms were scanned individually at a point corresponding to $40 \%$ of the upper arm length up from the lateral epicondyle of the humerus to the acromium process.

Measurement of the muscle fiber characteristics. Muscle fiber characteristics of the biceps brachii muscle (long head) in both the trained and untrained arms were determined from percutaneous needle biopsy samples using established procedures (24). Measurements comprised fiber type distribution and the mean cross-sectional areas of type I (or slow-twitch, ST) and II (or fasttwitch, FT) fibers.

Statistical analyses. Descriptive statistics included means \pm SE. Overall training effects were evaluated by analysis of variance techniques; specific differences were tested using the Tukey $A$ method. The critical level for statistical significance was established at $P=0.05$.

\section{RESULTS}

All subjects were able to successfully complete the training without injury.

Weight-lifting capacity. The $1 \mathrm{RM}$ loads in all three weight-lifting exercises increased significantly $(P<$ 0.001 ) after the training (Figs. 1 and 2). The single arm curl $1 \mathrm{RM}$ was higher in both arms after the training $(P$ $<0.05$ ), but the mean increase in the trained arm $(48.4 \%)$ was greater $(P<0.05)$ than the increase in the control $\operatorname{arm}(12.7 \%$; Fig. 2$)$. In addition, the absolute endurance was substantially increased after the training, inasmuch as subjects were able to lift their pretraining $1 \mathrm{RM}$ an average of 7-19 times in the trained limbs and 7 times in the control arm (Table 1).

Isokinetic torque. The maximum isokinetic torque in bilateral leg press exercise performed at 0.26 and 1.31 $\mathrm{rad} / \mathrm{s}$ increased by 17 and $18 \%$, respectively, after the training (Fig. 1). During elbow flexion at the five angular velocities, the mean gains in the trained arm $(8.8 \%, P<$ $0.01)$ were similar to those in the control arm $(6.5 \%, P$ $<0.01$; Fig. 3).

Isometric strength. During maximal isometric contractions of the elbow flexors, torque measurements demonstrated the well-established variation with joint angle, but there was no significant change in the maximum torque in either arm after the intervention period (Fig. 3 ). The failure of an interpolated stimulus to produce additional isometric torque confirmed that the subjects
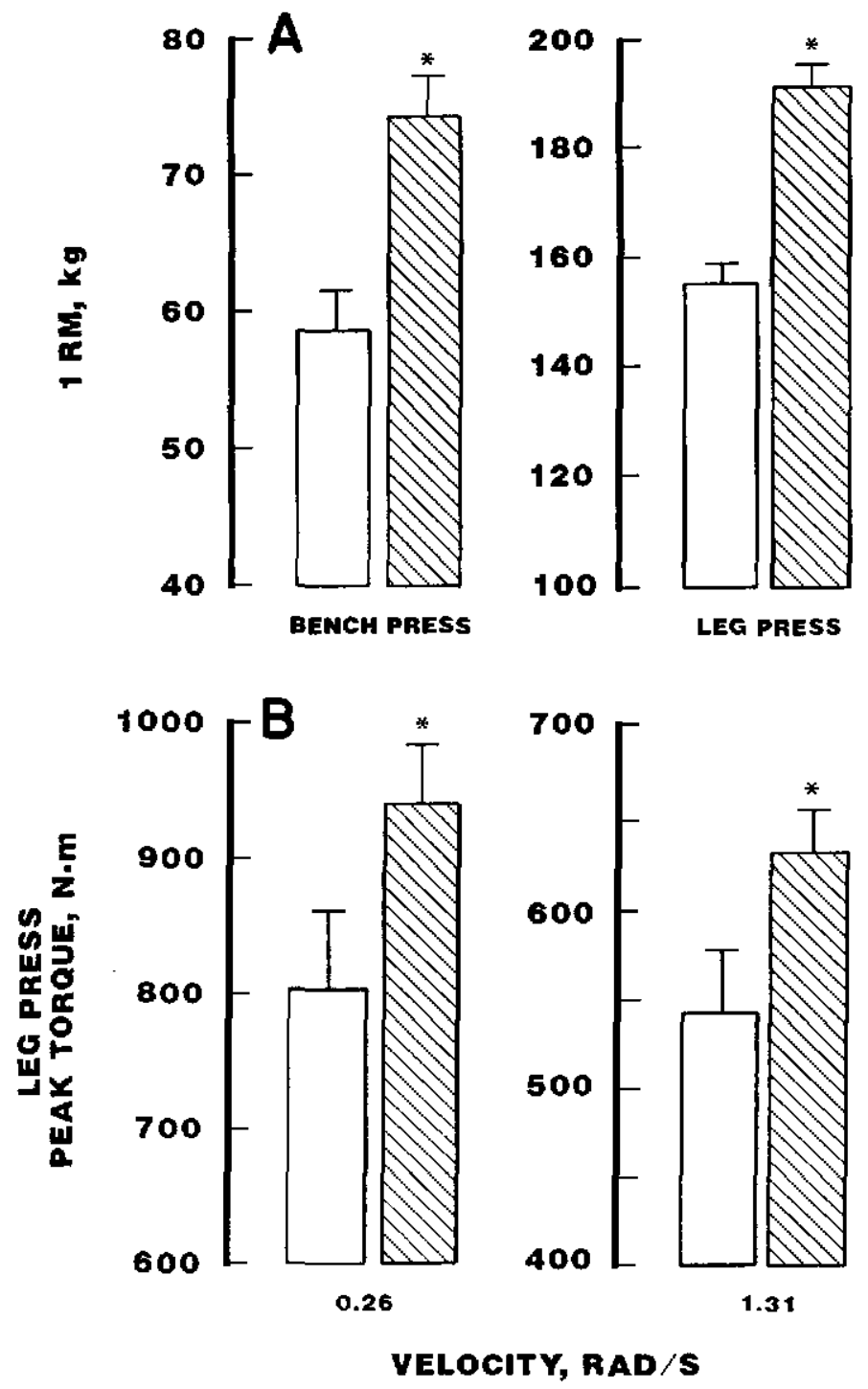

FIG. 1. A: maximal (means $\pm \mathrm{SE}$ ) weight-lifting capacity (1-repetition maximum, $1 \mathrm{RM}$ ) in bench press and bilateral leg press exercises, measured before (open bars) and after (hatched bars) 12 wk of training. $B$ : maximal (means $\pm \mathrm{SE}$ ) isokinetic leg press torque at 2 angular velocities before and after training. ${ }^{*} P<0.001$, increase with training.

were able to achieve complete motor unit activation (98\%) both before and after the training.

Evoked muscle contractile properties. After training, increases in the maximal evoked twitch torque were recorded at elbow joint angles of $2.09(9.1 \%)$ and 2.88 $\mathrm{rad}(11.6 \%)$ in the trained arm and at $2.88 \mathrm{rad}(11.9 \%)$ in the untrained arm $(P<0.05$; Fig. 4$)$; there was also a significant decrease $(P<0.05)$ in evoked twitch torque in the untrained arm at $2.09 \mathrm{rad}(11.2 \%)$. The twitch torque-time integral increased significantly $(P=0.007)$ in the trained arm after training at elbow joint angles of 2.09 and $2.88 \mathrm{rad}$, but there was no change in the control arm (Fig. 4). The maximal rate of torque development decreased $(P<0.05)$ in the untrained elbow flexors at the 2.09-rad angle and increased significantly $(P<0.05)$ in both arms at the 2.88-rad position, but there was no change at the other joint positions (Fig. 5). The times to attain peak twitch torque (Fig. 6) and the maximal rates of torque relaxation (Fig. 5) were similar in both arms 

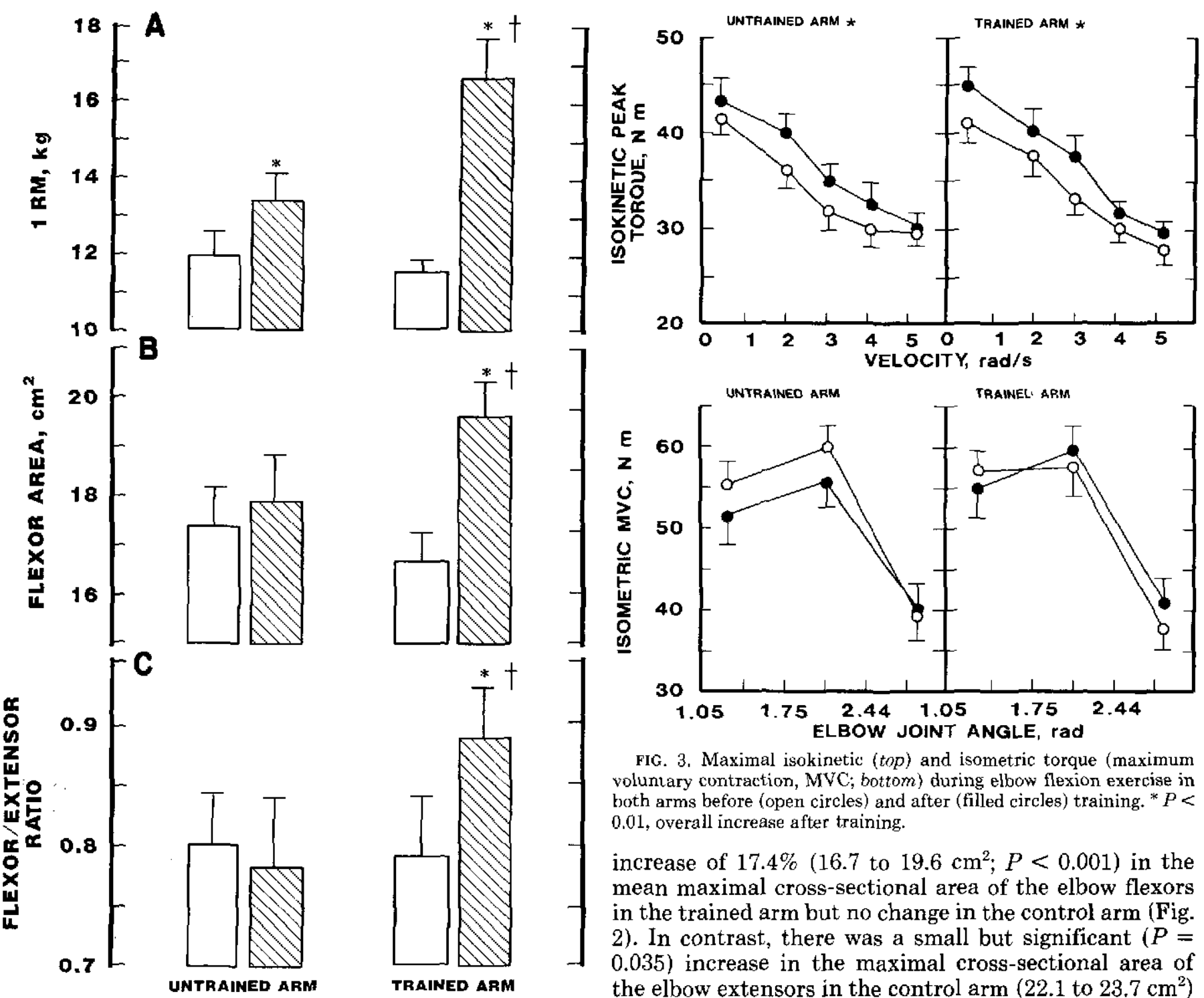

FIG. 3. Maximal isokinetic (top) and isometric torque (maximum voluntary contraction, MVC; bottom) during elbow flexion exercise in both arms before (open circles) and after (filled circles) training. ${ }^{*} P<$ 0.01 , overall increase after training.

increase of $17.4 \%\left(16.7\right.$ to $\left.19.6 \mathrm{~cm}^{2} ; P<0.001\right)$ in the mean maximal cross-sectional area of the elbow flexors in the trained arm but no change in the control arm (Fig. $2)$. In contrast, there was a small but significant $(P=$ 0.035 ) increase in the maximal cross-sectional area of the elbow extensors in the control arm $\left(22.1\right.$ to $\left.23.7 \mathrm{~cm}^{2}\right)$

FIG. 2. Maximal weight-lifting capacity (1-repetition maximum, 1 $\mathrm{RM}, A$ ), maximal cross-sectional area of elbow flexors ( $B)$, and flexorto-extensor area ratio $(C)$ in trained and untrained arms before (open bars) and after (hatched bars) training. ${ }^{*} P<0.05$, change after training ( $A$ and $C) ;{ }^{*} P<0.001(B)$ and $+P<0.05(A-C)$, difference between arms.

TABLE 1. Number of repetitions that could be completed by subjects after training with a load corresponding to their pretraining $1 R M$

\begin{tabular}{ccc} 
Exercise & & No. of Repetitions \\
\cline { 2 - 3 } & Range & Mean \\
Bench press & $5-10$ & 7.0 \\
Leg press & $10-34$ & 19.0 \\
Arm curl & & \\
Trained & $4-22$ & 14.0 \\
Untrained & $1-16$ & 7.0 \\
\hline
\end{tabular}

before and after the training. The half-relaxation times were greater in the trained arm at all joint angles after training $(P<0.05)$ and remained unchanged in the control arm (Fig. 6).

Muscle cross-sectional area. Training resulted in an that the term "trained" refers only to the elbow flexors, because the elbow extensors of both arms received a training stimulus from the bench press exercise.

Before training the flexor-to-extensor area ratio was similar in both arms $(0.79$ and 0.80$)$, but after training the ratio was higher $(P=0.042)$ in the trained arm $(0.89)$ than in the control arm (0.76; Fig. 2).

There were significant $(P<0.01)$ increases after training in the mean maximal cross-sectional areas of the knee flexors $\left(3.6 \mathrm{~cm}^{2}, 4.4 \%\right)$ and extensors $\left(6.9 \mathrm{~cm}^{2}, 9.9 \%\right)$ in the right leg only despite the fact that both legs were trained simultaneously in bilateral movements.

Muscle fiber characteristics. After training, there was a significant $(P<0.005)$ increase in the mean cross-sectional areas of both type I (ST) and II (FT) fibers from the biceps brachii muscle of each arm (Fig. 7). However, mean type II fiber area increased more in the arm that received the more direct training stimulus (trained arm, $30.2 \%, P<0.05)$ than in the less directly trained arm (untrained arm, 10.7\%; Fig. 7). Type II fiber area in the trained arm increased more than type I area; consequently, there was a significant $(P<0.05)$ increase in 

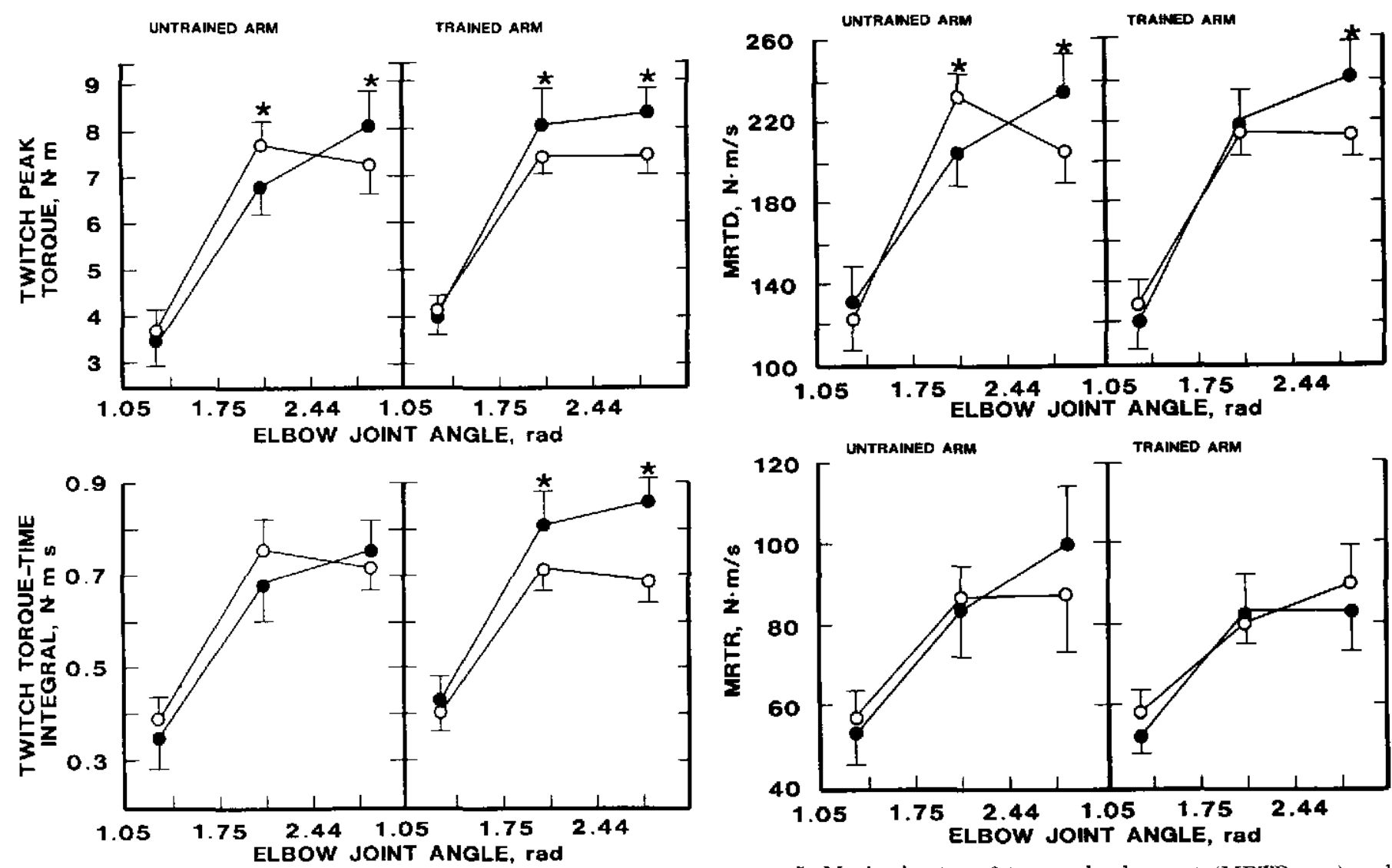

FIG. 4. Maximal twitch torque (top) and torque-time integral (bottom) during electrically evoked contractions of elbow flexors of both arms before (open circles) and after (filled circles) training. ${ }^{*} P<0.05$ (top) and ${ }^{*} P=0.007$ (bottom), change after training-

the type II-to-I (FS-to-ST) area ratio (1.13 to 1.29). In contrast, the FS-to-ST area ratio did not increase significantly in the untrained arm (Fig. 7). The percent distribution of type I fibers in the biceps muscles of both the trained (40\%) and untrained arm (45\%) remained constant.

\section{DISCUSSION}

Changes in muscle performance and muscle size. The major finding in the present study was that the older men responded to weight-lifting training in a qualitatively similar manner as young men, with large increases in the maximal load that could be lifted and accompanying enlargement of whole muscle and muscle fiber areas.

Previous studies of strength training in the elderly have produced conflicting results. Moritani and deVries (28) reported an increase in weight-lifting capactiy of the trained elbow flexors of $23 \%$ but no change in upper arm girth after 8 wk of progressive weight-lifting exercise. Aniansson and Gustafsson (2) found a similar increase in isokinetic torque of the knee extensors and no significant increment in the cross-sectional areas of individual muscle fibers after $12 \mathrm{wk}$ of training with body weight as resistance. In contrast, a recent study by Frontera et al. (11) was the first to show that older leg muscles could respond to intense resistance training with significant increases in muscle and muscle fiber size. Now the pres-

FIG. 5. Maximal rates of torque development (MR'TD; top) and relaxation (MRTR; bottom) during electrically evoked twitch contractions of elbow flexors of both arms before (open circles) and after (filled circles) training. ${ }^{*} P<0.05$, change after training.

ent study has shown that older arm muscles can also hypertrophy in response to strength training.

The latter two studies showed a similar general pattern of results. There was a very large increase in weightlifting performance, a much smaller and sometimes insignificant increase in less specific isometric and isokinetic tests, and increases in muscle and muscle fiber size that were considerably smaller than the increases in weight-lifting performance but were similar to or moderately greater than the increases in the less specific performance measures.

However, there were notable differences between the two studies. Frontera et al. (11) found a much larger increase (107 vs. $48 \%$ ) in weight-lifting performance, but we found a slightly greater increase $(17.4 \mathrm{vs} .11 .9 \%)$ in muscle cross-sectional area. Whereas a similar increase in type II fiber area was found in both studies (our study $30 \%$, Frontera et al. $27.6 \%$ ), a larger increase in type I fiber area was found by Frontera et al. (33.5\%) than by us (13.7\%). Thus our data gave the commonly observed pattern of greater hypertrophy of type II fibers and consequently an increase in the type II-to-I area ratio (7, 23,34 ), whereas Frontera et al. (11) found equal enlargement of type I and II fibers.

There was a high degree of specificity in the training response. Strength performance measured on the training device (weight lifting) increased far more than in the less familiar isometric and isokinetic tests. Indeed, isometric and isokinetic performance failed to increase sig- 

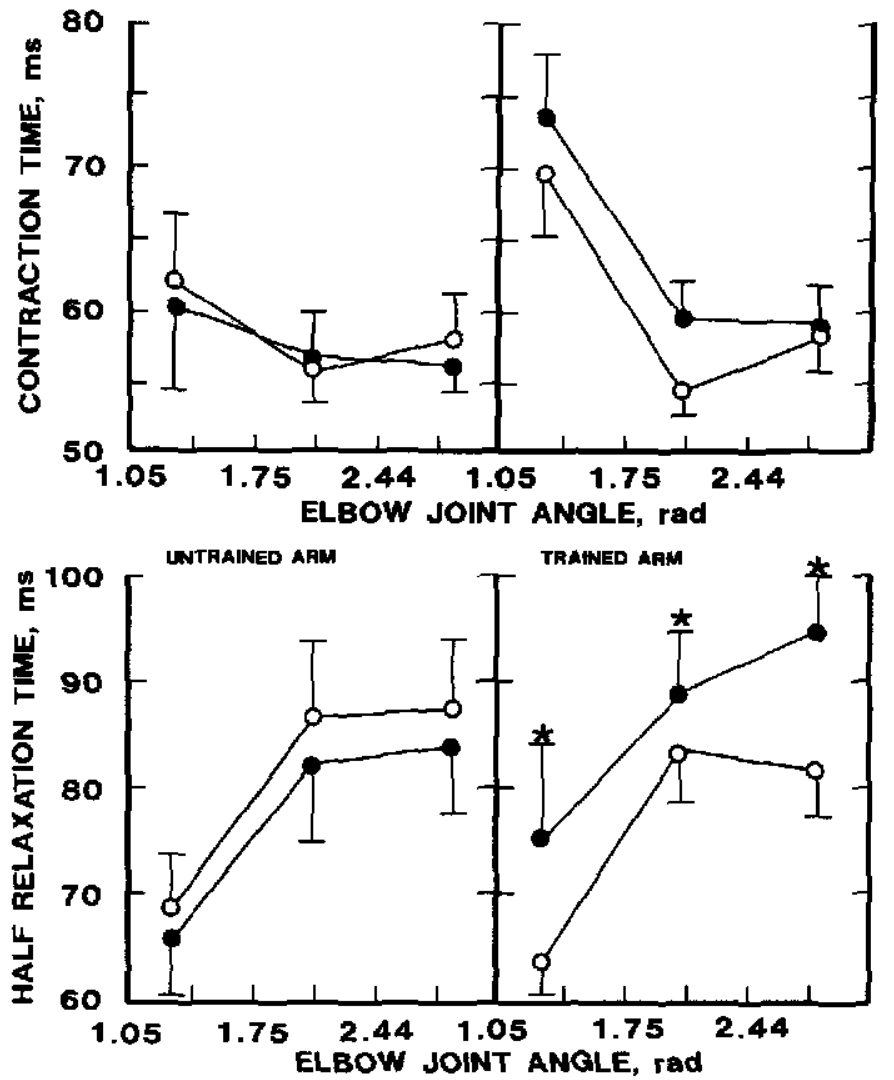

FIG. 6. Contraction times (top) and half-relaxation times (bottom) during electrically evoked twitch contractions of elbow flexors of both arms before (open circles) and after (filled circles) training. ${ }^{*} P<0.05$, change after training.

nificantly despite a large (48\%) increase in weight-lifting performance and a substantial amount of hypertrophy (17\%). The observed specificity points to the important role of nervous system adaptations in the response to strength training, in particular the role of learning and coordination (30). The implication for the design of strength-training programs for the elderly is that the training exercises should simulate as closely as possible the most common strength-requiring tasks likely to be encountered by this population. Such an approach will ensure the best possible return on the training investment.

A puzzling finding was the lack of a significantly greater increase in isometric and isokinetic performance in the trained vs. untrained arm, because the trained arm underwent a greater increase in muscle and muscle fiber cross-sectional area. A greater increase in strength would be expected to accompany a greater increase in muscle mass. Such a finding is not unique to our study. In the study of Frontera et al. (11), the right knee extensors failed to increase isometric strength despite an $11.9 \%$ increase in muscle cross-sectional area. In the left knee extensors the increase in isometric strength $(7.7 \%)$ was slightly less than the increase in muscle size $(9.3 \%)$. Weight training in young men caused a greater increase in muscle cross-sectional area (10-17\%) than isometric strength $(4-5 \%)$; weight-lifting performance increased $24-42 \%(9)$. In a recent study in our laboratory (unpublished observations) we did not find a significant increase
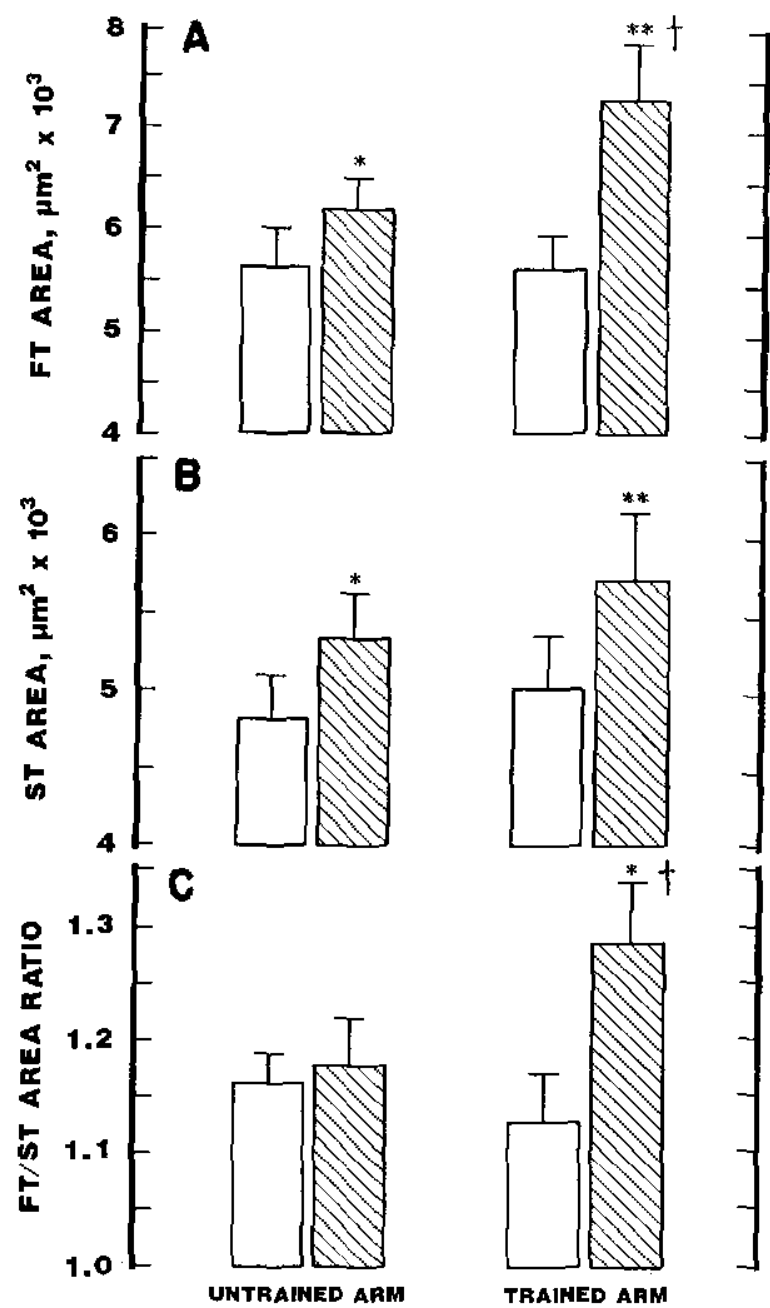

FIG. 7. Mean cross-sectional areas of type II (fast-twitch, FT; $A$ ) and I (slow-twitch, ST; $B$ ) fibers and FT-to-ST area ratios (C) in biceps brachii muscles of both arms before (open bars) and after (hatched bars) training. ${ }^{*} P<0.05$, change after training $(A-C){ }^{* *} P$ $<0.001$ and $+P<0.001$, greater increase in FT vo. ST fibers in trained arm $(A)$; ${ }^{* * *} P<0.01$, change after training $(B) ; \dagger P<0.05$, difference between arms $(C)$.

in isometric strength after 5 mo of weight training by young men despite significant increases in weight-lifting performance and muscle cross-sectional area. Finally, in a recent study no increase was found in the peak isometric force of overloaded rat soleus despite significant increases in muscle mass and muscle fiber area (16).

It is difficult to explain why any measure of strength would not increase if muscle size increased. Perhaps in the present study training caused a "negative" neural adaptation, which took the form of inhibition of the elbow flexors during isometric contractions, thereby preventing increased force despite hypertrophy. This explanation can be excluded because motor unit activation in the flexors was near maximal and similar before and after training. A counterproductive neural adaptation might have taken the form of increased cocontraction of antagonists; thus increased cocontraction of triceps in the less familiar isometric task may have offset the increased contractile force of the agonists (elbow flexors). We have no data related to this possibility, although there is one report of greater cocontraction in the leg 
muscles of trained power athletes than endurance athletes (29). In view of the many complex ways in which the muscles acting at the elbow joint can be activated and coordinated (5), such seemingly counterproductive adaptations cannot be ruled out.

Perhaps the observed hypertrophy did not increase the intrinsic force-generating capacity of the muscle. It cannot be argued that hypertrophy in these older muscles was entirely the result of connective tissue proliferation, because the increase in fiber size was at least equivalent to that of the whole muscle. Furthermore the greatly hypertrophied muscles of bodybuilders show no evidence of connective tissue proliferation (32). In the previously cited study of rat soleus (16), hypertrophy after 30 days of overload was not associated with connective tissue proliferation, an increase in interstitial fluid volume, or a decrease in protein content. These authors suggested that ultrastructural examination of myofibrils and cytoarchitecture and assessment of possible alterations in excitation-contraction coupling might help uncover the mechanisms responsible for the decrease in specific tension (i.e., the force developed per unit muscle crosssectional area) that can accompany hypertrophy. Whatever the mechanisms, they may account for the pattern of results found in the present study.

A notable observation was that muscle size increased significantly only in the right knee extensors and flexors even though both legs were trained simultaneously in a bilateral leg press movement. Perhaps most of the subjects were right limb dominant and unintentionally favored this limb during training.

In addition to the substantial gains in maximal weightlifting capacity in this study, there was a notable improvement in muscular endurance during repeated lifting. After the training, subjects were able to lift their pretraining $1 \mathrm{RM}$ from (range) 4 to 34 times in the trained limbs but only from 1 to 16 times in the untrained arm. By the seventh decade of life, losses in strength and power often interfere with many common activities of daily living, such as lifting and carrying, raising and lowering body weight, and walking. It seems likely that increases in muscular endurance of the type reported here might enable seniors to accomplish certain tasks that may otherwise prove to be impossible or extremely fatiguing.

Evoked twitch contractile properties. In the present study twitch torque increased in the trained arm at two of the three joint angles tested; however, a similar increase occurred at one of the joint angles in the untrained arm. Therefore there was no convincing evidence of a greater increase in twitch torque in the trained arm. These results are consistent with the lack of a greater voluntary isometric strength increase in the trained arm. Of the previously discussed mechanisms that might account for the failure of voluntary isometric strength to increase despite hypertrophy, only the possible decrease in specific tension can be offered to explain the failure of twitch torque to increase more in the more hypertrophied trained arm. Bodybuilders and weight lifters do have greater evoked twitch force than untrained men (33); however, these athletes had trained for many years and possessed greatly hypertrophied muscles. A greater degree of hypertrophy than we observed in the present study may be necessary before absolute muscle force begins to increase. Thus previous short-term longitudinal strength-training studies $(1,8,26)$ in young subjects have mainly not shown increases in the evoked twitch and tetanic tension (Ref. 10 is an exception).

We elected not to use tetanic stimulation because of the extreme discomfort associated with the procedure. A limitation of using twitch torque as a measure of forcegenerating capacity is that the twitch response would be very sensitive to any alteration in excitation-contraction coupling; indeed, some investigators (10) use the twitch response as a measure of excitation-contraction coupling and the tetanic response as the measure of intrinsic force. It is possible that twitch and tetanic force could change independently. In a sense this happened in the present study. There was an increase in twitch but not tetanic (MVC with full activation) torque in both arms. If the increase in twitch torque was an adaptation to training, we cannot explain why the response was not greater in the more intensely trained arm.

Time to peak twitch torque did not change significantly in the trained arm, but there was a significant increase in half-relaxation time, in agreement with similar observations in young adults after strength training (18). The increase in half-relaxation time contributed to the increase in the twitch torque-time integral. The prolongation of the twitch contraction would shift the force-frequency relationship to the left, thereby allowing maximal tetanic tension to be achieved at a lower motor unit firing frequency. This adaptation coupled with the already observed slowing of older muscles even without training (35) should allow strength-trained seniors to achieve maximal muscle force at lower motor unit firing rates than their younger counterparts. Lower firing rates might also increase resistance to fatigue.

There was an apparent joint angle specificity in the changes in some of the twitch properties. At the smallest joint angle where the elbow flexors were at their shortest length, there were no changes in twitch torque, torquetime integral, or maximum rate of torque development. In contrast, at the largest joint angle and longest muscle length, these measures increased significantly but similarly in both untrained (actually received a mild training stimulus) and trained arms. The lack of change at the short muscle length may have resulted from the large inseries compliance at this length, which prevented all but a small part of the developed tension from being registered externally. The potential torque would already have been small because of the short muscle length. We are not able to explain why the untrained arm showed a decrease in twitch torque at the intermediate joint angle and muscle length after training while the trained arm showed an increase. Although the changes in MVC were not significant, the pattern of results was similar to that for twitch torque, namely, at the intermediate joint angle a decrease in the untrained arm but an increase in the trained arm. This pattern of results may have been influenced by the resistance pattern of the arm-training device because only the trained arm used it.

Motor unit activation. The elderly men in this study were able to fully activate their elbow flexors in maximal 
isometric contractions even before the training began. This observation confirms a previous report that the elderly are not impaired in the ability to activate muscles in voluntary isometric contractions (35). Both studies used the interpolated twitch method of assessing motor unit activation (4).

The method assumes that if no increment in torque occurs on a voluntary contraction recording when a supramaximal stimulus is superimposed, then the involved muscles have been fully activated. One possible criticism of the method might be that if the stimulus failed to fully activate the muscle and if the part not activated by stimulation was the same part not activated by voluntary effort, then it would be falsely concluded that voluntary activation was complete. However, such a happening is quite unlikely. Moreover, whereas the method is most sensitive when all motor axons have been stimulated, failure to do so does not invalidate the method $(27,31)$. The procedure that we and others have used to ensure the greatest possible activation by stimulation has been to use a stimulus intensity well in excess of that needed to evoke a maximal twitch response, the assumption being that no further increases in torque despite increases in stimulus intensity provide evidence that all motor fibers have been stimulated. Another indication that our stimulation maximally activated the elbow flexors was that the evoked twitch torque at rest $(\sim 8 \mathrm{~N} \cdot \mathrm{m})$ was what you would expect for a tetanic (or MVC with full activation) torque of $\sim 60 \mathrm{~N} \cdot \mathrm{m}$, i.e., a twitch-to-tetanus ratio of $\sim 0.15$ for the elbow flexors ( 12 , 26).

It must be emphasized that we determined motor unit activation only for isometric contractions, the contraction mode in which no improvement occurred after training. It is possible that before training the subjects were not able to fully activate their muscles in the weightlifting and isokinetic tasks in which performance improved.

In summary, we have demonstrated that older males can respond to progressive weight-lifting training with increases in dynamic muscle performance and whole muscle and muscle fiber size that compare favorably with responses seen in young men. These observations raise the encouraging prospect that the rate of decline in strength and muscle mass in old age and the accompanying loss of independent functional capacity can be reduced or even reversed by appropriate resistance training programs.

We are indebted to Dianne Moroz for invaluable assistance in the organization and administration of the study.

This work was supported by grants from the Ontario Ministry of Tourism and Recreation and from the Natural Sciences and Engineering Research Council of Canada.

Address for reprint requests: N. McCartney, Dept. of Physical Education, McMaster University, 1280 Main St. West, Hamilton, Ontario L8S $4 \mathrm{~K} 1$, Canada.

Received 1 June 1989; accepted in final form 25 June 1990.

\section{REFERENCES}

1. Alway, S. E., J. D. MacDougall, and D. G. Sale. Contractile adaptations in the human triceps surae after isometric exercise. $J$. Appl. Physiol. 66: 2725-2732, 1989.
2. ANIANSSON, A., AND E. GUSTAFsson. Physical training in elderly men with special reference to quadriceps muscle strength and morphology. Clin. Physiol. Oxf. 1: 87-98, 1981.

3. Aniansson, A., P. LuUngberg, A. Rundgren, and H. WetTERQVIST. Effect of a training programme for pensioners on condition and muscular strength. Arch. Gerontol. Geriatr. 3: 229-241, 1984.

4. Belanger, A. Y., And A. J. MCComas. Extent of motor unit activation during effort. J. Appl. Physiol. 51: 160-167, 1981.

5. Buchanan, T. S., G. P. Roval, AND W. Z. Rymer. Strategies for muscle activation during isometric torque generation at the human elbow. J. Neurophysiol. 62: 1201-1212, 1989.

6. Camprell, M. J., A. J. McComas, and F. Petrto. Physiological changes in ageing muscles. J. Neurol. Neurosurg. Psychiatry 36: 174-182, 1973.

7. Costill, D. L., E. F. Coyle, W. F. Fink, G. R. Lesmes, and F. A. Witzman. Adaptation in skeletal muscle following strength training. J. Appl. Physiol. 46: 96-99, 1979.

8. DAvies, C. T. M., AND K. Young. Effects of training at $30 \%$ and $100 \%$ maximal isometric force (MVC) on the contractile properties of the triceps surae in man (Abstract). J. Physiol. Lond. 336: 31P, 1983.

9. Dons, B., K. Bollerup, F. Bonde-Petersen, and S. Hancke. The effect of weight-lifting exercise related to muscle fibre composition and muscle cross-sectional area in humans. Eur. J. Appl. Physiol. Occup. Physiol. 40: 95-106, 1979.

10. Duchateau, J., and K. HainaUt. Isometric or dynamic training: differential effects on mechanical properties of human muscle. $J$. Appl. Physiol. 56: 296-301, 1984.

11. Frontera, W. R., C. N. Meredith, K. P. O'Reilly, H. G. KNUTTGEN, AND W. J. EvaNS. Strength conditioning in older men, skeletal muscle hypertrophy, and improved function. J. Appl. Physiol. 64 : $1038-1044,1988$.

12. Gandevia, S. C., AND D. K. McKenzif. Activation of human muscles at short muscle lengths during maximal static efforts. $J$. Physiol. Lond. 407: 599-613, 1988.

13. Grimby, G., B. Danneskiold-Samsoe, K. Hvid, and B. Saltin. Morphology and enzymatic capacity in arm and leg muscles in 7882 year old men and women. Acta Physiol. Scand. 115: 124-134, 1982.

14. Grimby, G., ano B. Saltin. The ageing muscle. Clin. Physiol. Oxf. 3: $209-218,1983$.

15. Jones, N. L., And E. J. M. CAMPBell. Clinical Exercise Testing (2nd ed.). Philadelphia, PA: Saunders, 1982.

16. Kandarian, S. C., AND T. P. White. Force deficit during the onset of muscle hypertrophy. J. Appl. Physiol. 67: 2600-2607, 1989.

17. KAUFMAN, T. L. Strength training effect in young and aged women. Arch. Phys. Med. Rehabil 65: 223-226, 1985.

18. Kitai, T. A., AND D. G. SalE. Specificity of joint angle in isometric training. Eur. J. Appl. Physiol. Occup. Physiol. 58: 744-748, 1989.

19. Larsson, L., G. GRImBY, AND J. KarLsson. Muscle strength and speed of movement in relation to age and muscle morphology. $J$. Appl. Physiol. 46: 451-456, 1979.

20. Larsson, L., B. Siódin, and J. KarLsson. Histochemical and biochemical changes in human skeletal muscle with age in sedentary males, age 22-65 years. Acta Physiol. Scand. 103: 31-39, 1978.

21. LeXell, J., D. Downham, AND M. SJöstrom. Distribution of different fibre types in human skeletal muscles. Fibre type arrangement in $\mathrm{m}$. vastus lateralis from three groups of healthy men between 15 and 83 years. J. Neurol. Sci. 72: 211-222, 1986.

22. LeXell, J., K. HenrtKsson-I arsson, B. Winblad, and M. SJÖsTRÖ. Distribution of different fibre types in human skeletal muscles: effects of aging studied in whole muscle cross-sections. Muscle Nerve 6: 588-595, 1983.

23. MacDougall, J. D., G. C. B. Elder, D. G. Sale, J. R. Moroz, AND J. R. SUTTON. Effects of strength training and immobilization on human muscle fibres. Eur. J. Appl. Physiol. Occup. Physiol. 43: $25-34,1980$.

24. MacDovgall, J. D., D. G. Sale, S. E. Alway, and J. R. Sutton, Muscle fiber number in biceps brachii in body builders and control subjects. J. Appl. Physiol. 57; 1399-1403, 1984.

25. McCartnex, N., D. Moroz, S. H. Garner, and A. J. McComas. The effects of strength training in patients with selected neuromuscular disorders. Med. Sci. Sports Exercise 20: 362-368, 1988.

26. McDonagh, M. J. N., C. M. Hayward, and C. T. M. Davies. 
Isometric training in human elbow flexor muscles. $J$. Bone Jt. Surg. 65: $355-358,1983$

27. Merton, P. A. Voluntary strength and fatigue. J. Physiol. Lond. 123: $553-564,1954$

28. Moritani, T., AND H. A. DeVries. Potential for gross muscle hypertrophy in older men. J. Gerontol. 35: 672-682, 1980.

29. Osternig, L. R., J. Hamill, J. E. Lander, and R. Robertson. Coactivation of sprinter and distance runner muscles in isokinetic exercise. Med. Sci. Sports Exercise 18: 431-435, 1986.

30. Rutherford, O. M., AND D. A. Jones. The role of learning and coordination in strength training. Eur. J. Appl. Physiol. Occup. Physiol. 55̃: 100-105, 1986.

31. Rutherford, O. M., D. A. Jones, and D. J. Newham. Clinical and experimental application of the percutaneous twitch superimposition technique for the study of human muscle activation. $J$. Neurol. Neurosurg. Psychiatry 49: 1288-1291, 1986.

32. Sale, D. G., J. D. MacDougall, S. E. Alway, and J. R. Sutton. Voluntary strength and muscle characteristics in untrained men and women and male body builders. J. Appl. Physiol. 62: 1786$1793,1987$.

33. Sale, D. G., A. R. M. Upton. A. J. McComas, And J. D. MaC-
Dougall. Neuromuscular function in weight-trainers. Exp. Neurol. 82: 521-531, 1983.

34. Thorstensson, A., B. Hulten, W, Von Doblem, and J. KarlssoN. Effect of strength training on enzyme activities and fibre characteristics in human skeletal muscle. Acta Physiol. Scand. 96: 392-398, 1976.

35. VANDERvoonT, A. A., AND A. J. MCComas. Contractile changes in opposing muscles of the human ankle joint with aging. $J$. Appl. Physiol. 61: 361-367, 1986.

36. VandervookT, A. A., J. Quinlan, ANd A. J. McComas. Twitch potentiation after voluntary contraction. Exp. Neurol. 81: 141-152, 1983.

37. VANDERvoort, A. A., D. G. Sale, AND J. Mokoz. Comparison of motor unit activation during unilateral and bilateral leg extension. J. Appl. Physiol. 56: 46-51, 1984.

38. YounG, A. Exercise physiology in geriatric practice. Acta Med. Scand. Suppl 711: 227-232, 1986.

39. Young, A., M. Stokes, AND M. Crowe. The size and strength of the quadriceps muscles of old and young men, Clin. Physiol. Oxf. 5: 145-154, 1985. 
APPENDIX B 
B) i) The number of repetitions that could be completed by the subjects after the training with a load that corresponded to their pre-training $1 \mathrm{RM}$.

EXERCISE

NUMBER OF REPETITIONS

(RANGE)

(MEAN)

BENCH PRESS

$5-10$

7.0

LEG PRESS

$10-34$

19.0

ARM CURL (TRAINED)

$4-22$

14.0

ARM CURL (UNTRAINED)

$1-16$

7.0 
APPENDIX C 
(c) i) The maximum weight lifting strength of various muscle groups measured before and after 12 weeks of training.

MEASURE

BENCH PRESS 1RM

$(\mathrm{kg})$

LEG PRESS 1RM (kg)

ARM CURL 1RM $(\mathrm{kg})$

(TRAINED ARM)

ARM CURL 1RM (kg)

(UNTRAINED ARM)
PRE

POST

MEAN

SD

58.6

9.5

155.7

11.4

11.2

1.7

$16.7 *+$

3.2

11.9

2.3

13.4 *

2.6

(* - P<.001)

$(+-$ denotes a significant difference $(P<.001)$ between the trained and untrained arms post training.) 
(c) ii)

The maximal isokinetic torque of the legs (upper panel) and the arms (lower panel) before and after training.

\section{BILATERAL LEG PRESS (N.m)}

PRE

POST

VELOCITY $(\% / 5)$

15 MEAN

201.3

53.0

237.0

SD

135.4

32.2

158.4

75

32.2

$\star$

ARM FLEXION (N.M)

30 MEAN

SD

120

180

240

300

$(*-\mathbf{P}<.001)$

$(* *-\mathrm{P}<.01)$
TRAINED ARM

PRE POST

UNTRAINED ARM

PRE POST

41.4

6.5

43.4

8.5

36.2

6.5

39.7

8.5

8.5

37.3
6.2

37.4

8.8

31.6

5.5

34.7

5.0

31.9

3.7

30.1

6.7

32.3

4.2

8.9

27.7
29.7

30.1

$4.8 \ldots \quad 4.8$

30.4
6.4

4.9 
(c) iii)

The evoked contractile properties of the elbow flexors of both arms recorded at joint angles of 75,120 and 165 degrees, before and after training.

PEAK TORQUE (N.m)

JOINT ANGLE

(DEGREES)

75 MEAN

SD

120

165

75

120

165

75

120

165

$\begin{array}{cl}\text { TRAINED } & \text { ARM } \\ \text { PRE } & \text { POST }\end{array}$

4.2

1.0

7.5

1.4

7.5

1.2
4.1

1.3

8.2 *

2.3

8.4 *

1.9
UNTRAINED ARM

PRE

POST

3.8

1.5

3.5

1.7

7.7

1.6

6.8 *

1.9

7.3

2.0

8.2 *

2.3

MAX. RATE OF TORQUE DEVELOPMENT ( $\mathrm{N.m} / \mathrm{s}$ )

$\begin{array}{rcrc}129.8 & 120.5 & 122.9 & 131.2 \\ 44.4 & 41.8 & 50.3 & 57.1 \\ 213.5 & 218.65 & 229.6 & 204.8 * \\ 41.3 & 48.3 & 42.6 & 60.3 \\ 211.9 & 237.8 * & 202.7 & 232.5 * \\ 32.4 & 63.4 & 44.5 & 63.7\end{array}$

HALF RELAXATION TIME (ms)

64.2

14.1

84.0

17.4

81.8

12.6
75.8

29.4

89.5

18.5

95.2

17.1
69.0

18.0

86.8

24.6

87.8

$\underline{22.6}$
66.3

20.4

82.7

25.4

84.3

$\underline{21.5}$

* $P<0.01$, difference between arms, upper two panels

$P<0.05$, change after training, bottom panel 
(c) iv)

The maximum isometric strength of the elbow flexors before and after 12 weeks of training.

$$
\begin{gathered}
\text { JOINT ANGLE } \\
\text { (degrees) }
\end{gathered}
$$

MVC TRAINED ARM (N.m)

75

120

165

MVC UNTRAINED ARM $(N \cdot m)$
75

120

165
MEAN

SD

10.4

37.6

7.5

55.5

7.6

59.9

9.6

39.3

9.6
54.9

12.0

59.7

10.4

41.1

10.0

51.3

11.1

55.8

10.2

40.2

10.5 
(c) v)

MEAN CROSS-SECTIONAL AREA OF THE

FLEXOR AND EXTENSOR COMPARTMENTS OF THE ARMS

BEFORE AND AFTER TRAINING

\begin{tabular}{|c|c|c|c|c|c|}
\hline & \multicolumn{5}{|c|}{ TRAINED ARM } \\
\hline & PRE & POST & DIFF & \&DIFF & $\mathbf{P}$ \\
\hline $\begin{array}{l}\text { FLEXOR AREA } \\
\left(\mathrm{cm}^{2}\right)\end{array}$ & $\begin{array}{r}16.73 \\
2.02\end{array}$ & $\begin{array}{r}19.61 \\
2.31\end{array}$ & 2.88 & 17.21 & $<.001$ \\
\hline $\begin{array}{l}\text { EXTENSOR AREA } \\
\left(\mathrm{cm}^{2}\right)\end{array}$ & $\begin{array}{r}21.82 \\
3.68\end{array}$ & $\begin{array}{r}22.43 \\
3.16\end{array}$ & .61 & 2.8 & - \\
\hline $\begin{array}{l}\text { BONE AREA } \\
\left(\mathrm{cm}^{2}\right)\end{array}$ & $\begin{array}{r}4.92 \\
.52\end{array}$ & $\begin{array}{r}5.02 \\
.41\end{array}$ & .1 & 2.03 & - \\
\hline & \multicolumn{5}{|c|}{ UNTRAINED ARM } \\
\hline $\begin{array}{l}\text { FLEXOR AREA } \\
\left(\mathrm{cm}^{2}\right)\end{array}$ & $\begin{array}{r}17.41 \\
2.53\end{array}$ & $\begin{array}{r}17.91 \\
3.51\end{array}$ & .5 & 2.9 & - \\
\hline $\begin{array}{l}\text { EXTENSOR AREA } \\
\left(\mathrm{cm}^{2}\right)\end{array}$ & $\begin{array}{r}22.11 \\
2.54\end{array}$ & $\begin{array}{r}23.74 \\
3.63\end{array}$ & 1.63 & 7.37 & .035 \\
\hline $\begin{array}{l}\text { BONE AREA } \\
\left(\mathrm{cm}^{2}\right)\end{array}$ & $\begin{array}{c}4.98 \\
.4\end{array}$ & $\begin{array}{r}5.22 \\
.37\end{array}$ & .24 & 4.82 & - \\
\hline
\end{tabular}


(c) vi)

$$
\begin{aligned}
& \text { MEAN CROSS-SECTIONAL AREA OF THE FLEXOR } \\
& \text { AND EXTENSOR COMPARTMENTS OF THE LEGS } \\
& \text { BEFORE AND AFTER TRAINING }
\end{aligned}
$$

(This chart displays $z$ as the mean of the sum of the individualo)

$$
\text { RIGHT LEG LEFT LEG }
$$

$\begin{array}{lccccrr} & \text { PRE } & \text { POST } & \text { 8DIFF } & \text { PRE } & \text { POST } & \text { 8DIFF } \\ \text { FLEXOR } & 77.55 & 81.17 & 4.4 & 76.13 & 74.91 & -1.76 \\ & 10.67 & 14.24 & 14.24 & 11.04 & 13.46 & 5.75 \\ \text { EXTENSOR } & 68.84 & 75.74 & 9.87 & 66.63 & 67.44 & 1.48 \\ & 7.34 & 10.34 & 6.33 & 5.90 & 6.78 & 8.79 \\ \text { BONE } & 8.82 & 9.63 & 9.41 & 8.55 & 8.55 & 1.06 \\ & .96 & .99 & 8.71 & .82 & .72 & 8.43\end{array}$


(c) vii)

MEAN CROSS-SECTIONAL AREA OF THE

FLEXOR AND EXTENSOR COMPARTMENTS OF THE LEGS

BEFORE AND AFTER TRAINING

(This chart displays difference as calculated from the mean of the pre and post scores.)

\begin{tabular}{lcccccc} 
& \multicolumn{3}{c}{ RIGHT LEG } & \multicolumn{3}{c}{ LEFT LEG } \\
& PRE & POST & \&DIFF & PRE & POST & 8DIFF \\
FLEXOR & 77.55 & 81.17 & 4.67 & 76.13 & 74.91 & -1.6 \\
& 10.67 & 14.24 & & 11.04 & 13.46 & \\
EXTENSOR & 68.84 & 75.74 & 10.02 & 66.63 & 67.44 & 1.22 \\
& 7.34 & 10.34 & & 5.90 & 6.78 & \\
BONE & 8.82 & 9.63 & 9.18 & 8.55 & 8.55 & 0 \\
& .96 & .99 & & .82 & .72 &
\end{tabular}


(c) viii)

\author{
MEAN CROSS-SECTIONAL AREAS \\ OF TYPE I AND TYPE II FIBRES \\ IN TRAINED AND UNTRAINED ARMS \\ BEFORE AND AFTER TRAINING
}

\begin{tabular}{cccccc} 
& \multicolumn{5}{c}{ TRAINED ARM } \\
& PRE & POST & Diff & \& Diff & P \\
TYPE I & 5034.13 & 5724.02 & 689.89 & 13.7 & .005 \\
FIBRE AREA & 1190.64 & 1574.05 & & & \\
TYPE II & 5616.92 & 7310.91 & 1693.99 & 30.16 & .005 \\
FIBRE AREA & 1153.61 & 1972.14 & & &
\end{tabular}

TYPE I

FIBRE AREA

TYPE II

FIBRE AREA

\subsection{1}

\section{UNTRAINED ARM}

4820.24

1082.21

5345.4

1002.14

525.16

10.89

.005

5608.62

1404.7

6209.16

1031.17

600.54

$10.71 \quad .005$ 
(c) ix)

THE MEAN \# OF TYPE I AND TYPE II

FIBRES DIGITIZED IN BOTH TRAINED AND UNTRAINED ARMS

BEFORE AND AFTER TRAINING

$\begin{array}{ccccc} & & & & \text { TYPE II } \\ \text { PRE } & \text { POST } & \text { PRE } & \text { POST } \\ \text { UNTRAINED } & 99 & 82 & 100 & 90.2 \\ \text { TRAINED } & 100 & 29 & & 14 \\ & & 76 & 100 & 86 \\ & & 23.5 & & 22\end{array}$


(c) $x)$

UPPER PANEL- The maximum cross-sectional areas of the elbow flexors and extensors determined by computed tomography in the trained and control arm, before and after training.

LOWER PANEL- The mean fibre area of the Type 1 and Type 11 muscle fibres in the elbow flexors of both arms, before and after the training period.

FLEXOR AREA

PRE POST

TRAINED MEAN

ARM $\left(\mathrm{Cm}^{2}\right) \quad S D$

UNTRAINED

ARM $\left(\mathrm{cm}^{2}\right)$

$$
16.7
$$

2.0

17.4

2.5
$19.6 *$

2.3

17.9

3.5
EXTENSOR AREA

PRE POST

$$
21.8 \quad 22.4
$$

3.7

3.2

22.1

$23.7 * *$

2.5

3.6

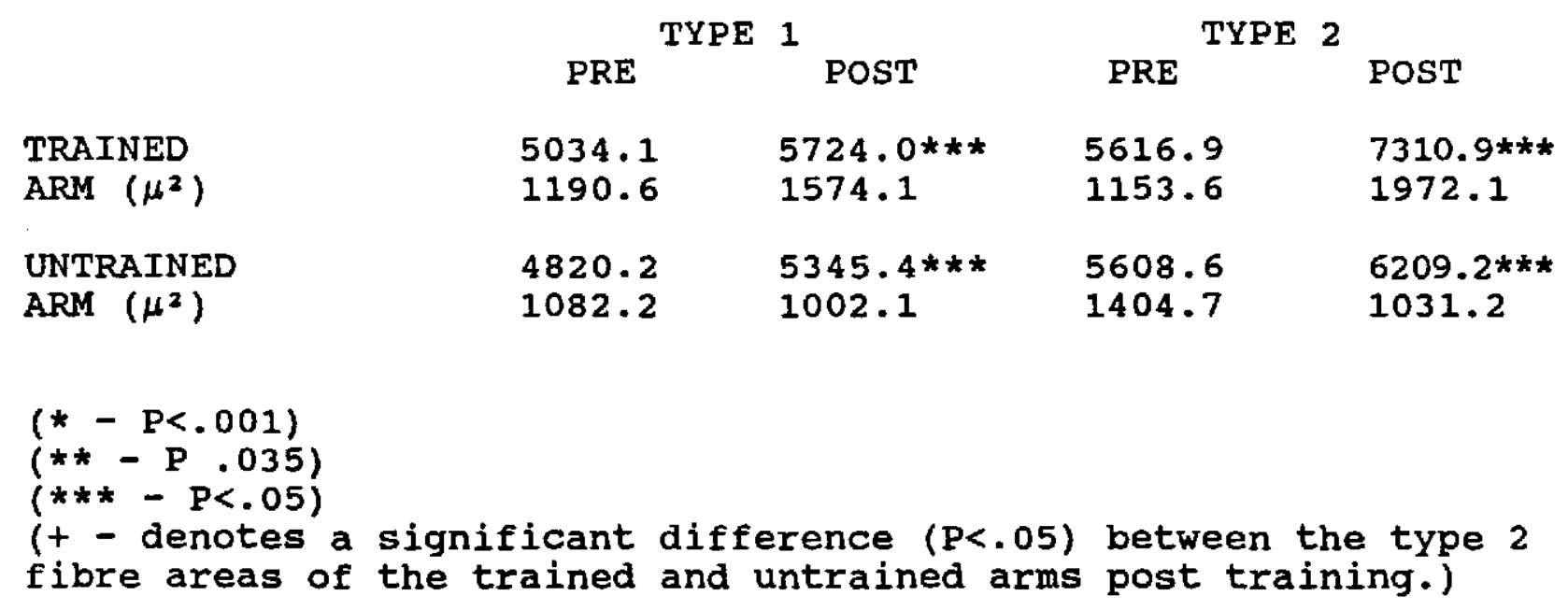


(c) $x i)$

\& TYPE I FIBRES

\begin{tabular}{rrrrr} 
& \multicolumn{2}{c}{ UNTRAINED ARM } & \multicolumn{2}{c}{ TRAINED ARM } \\
& & PRE & & \\
& & & & \\
$\bar{X}$ & 45.07 & 45.14 & 39.36 & 39.71 \\
SD & 6.59 & 9.62 & 8.89 & 6.73
\end{tabular}


(c) xii)

FT/ST AREA RATIO OF

THE TRAINED AND UNTRAINED ARMS

BEFORE AND AFTER TRAINING

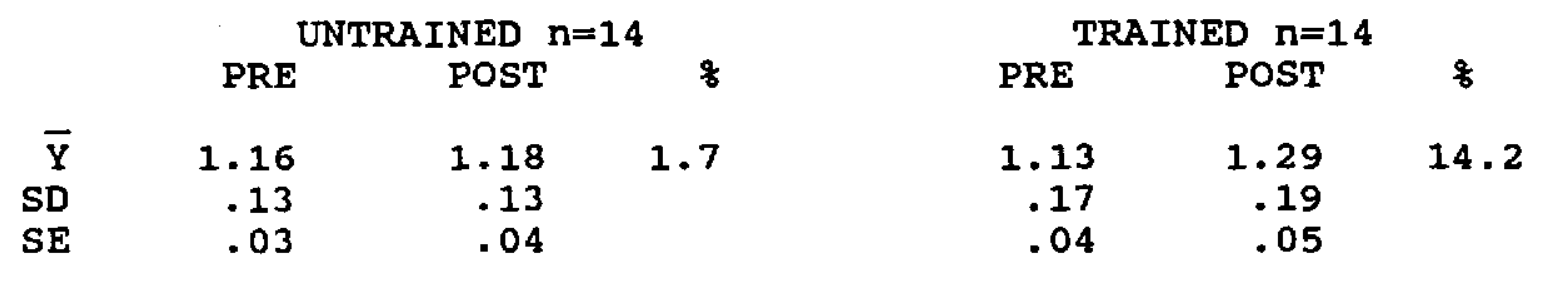


APPENDIX D 


\begin{tabular}{|c|c|c|c|c|c|c|}
\hline \multicolumn{7}{|c|}{$\begin{array}{c}\text { PEAK TORQUE (N.m) } \\
\text { Untrained Arm }\end{array}$} \\
\hline \multirow[b]{2}{*}{ Subject } & \multicolumn{2}{|c|}{75} & \multicolumn{2}{|c|}{120} & \multicolumn{2}{|c|}{165} \\
\hline & Pre & Post & Pre & Post & Pre & Post \\
\hline$A B$ & 8.54 & 8.85 & 8.91 & 11.7 & 9.74 & - \\
\hline $\mathrm{HB}$ & 4.31 & 3.74 & 10.65 & 9.98 & 9.22 & 10.59 \\
\hline JB & 2.61 & 2.68 & 7.02 & 4.86 & 7.33 & 7.46 \\
\hline $\mathrm{CB}$ & 3.82 & 2.24 & 6.99 & 6.01 & 5.37 & 7.87 \\
\hline $\mathrm{HC}$ & 7.51 & 7.48 & 9.06 & 9.47 & 11.27 & 13.52 \\
\hline $\mathrm{JC}$ & 3.8 & 1.1 & 8.16 & 7.2 & 7.69 & 8.38 \\
\hline $\mathrm{AF}$ & 2.36 & 2.77 & 8.35 & 7.22 & 7.03 & 7.28 \\
\hline FF & 3.16 & 2.13 & 5.03 & 4.04 & 4.43 & 4.43 \\
\hline $\mathrm{HH}$ & 2.3 & 2.5 & 5.03 & 5.29 & 5.42 & 7.01 \\
\hline$L H$ & 5.83 & 2.85 & 11.55 & 8.53 & - &. \\
\hline $\mathrm{JK}$ & 5.28 & 4.04 & 7.33 & 6.27 & 5.33 & 5.8 \\
\hline$R P$ & 3.39 & 3.44 & 8.99 & 5.34 & 9.97 & 7.78 \\
\hline FR & 2.55 & 5.24 & 8 & 7.88 & 6.63 & 9.17 \\
\hline MS & 4.39 & 4.24 & 7.73 & 8.51 & 7.56 & 8.59 \\
\hline$x$ & 3.79 & 3.47 & 7.7 & 6.84 & 7.29 & 8.16 \\
\hline S.D. & 1.49 & 1.68 & 1.6 & 1.87 & 2.04 & 2.3 \\
\hline
\end{tabular}




\begin{tabular}{|c|c|c|c|c|c|c|}
\hline \multicolumn{7}{|c|}{$\begin{array}{c}\text { PEAK TORQUE (N.m) } \\
\text { Trained Arm }\end{array}$} \\
\hline \multirow[b]{2}{*}{ Subject } & \multicolumn{2}{|c|}{75} & \multicolumn{2}{|c|}{120} & \multicolumn{2}{|c|}{165} \\
\hline & Pre & Post & Pre & Post & Pre & Post \\
\hline $\mathrm{AB}$ & 6.7 & 9.04 & 8.09 & 11.11 & 9.27 & 9.48 \\
\hline $\mathrm{HB}$ & 5.61 & 4.72 & 8.36 & 12.19 & 8.4 & 9.67 \\
\hline $\mathrm{JB}$ & 3.35 & 4.53 & 6.36 & 7.53 & 7.29 & 7.81 \\
\hline $\mathrm{CB}$ & 4.26 & 5.8 & 10.81 & 12.18 & 9.05 & 12.31 \\
\hline $\mathrm{HC}$ & 5.73 & 3.96 & 7.54 & 8.09 & 9.7 & 9.6 \\
\hline JC & 4.56 & 2.94 & 7.42 & 6.65 & 6.61 & 6.86 \\
\hline $\mathrm{AF}$ & 5.27 & 4.46 & 7.68 & 8.43 & 8.13 & 8.79 \\
\hline $\mathrm{FF}$ & 2.91 & 2.09 & 5.55 & 4.8 & 5.86 & 5.19 \\
\hline $\mathrm{HH}$ & 2.69 & 3.14 & 5.75 & 6.39 & 6.84 & 7.34 \\
\hline LH & 4.26 & 2.61 & 8.96 & 8.51 & 7.44 & 9.56 \\
\hline JK & 4.36 & 6.4 & 7.97 & 7.33 & 6.63 & 6.59 \\
\hline$R P$ & 3.48 & 2.65 & 7.56 & 6.13 & 8.37 & 9.7 \\
\hline FR & 4.32 & 4.95 & 6.76 & 10.25 & 6.85 & 9.67 \\
\hline MS & 3.77 & 3.9 & 7.86 & 7.84 & 6.63 & 7.32 \\
\hline$x$ & 4.19 & 4.13 & 7.47 & 8.15 & 7.53 & 8.4 \\
\hline S.D. & 1 & 1.28 & 1.37 & 2.31 & 1.17 & 1.92 \\
\hline
\end{tabular}




\begin{tabular}{|c|c|c|c|c|c|c|}
\hline \multicolumn{7}{|c|}{$\begin{array}{c}\text { MAX RATE OF TORQUE DEVELOPMENT (N.m./s) } \\
\text { Untrained Arm }\end{array}$} \\
\hline \multirow[b]{2}{*}{ Subject } & \multicolumn{2}{|c|}{75} & \multicolumn{2}{|c|}{120} & \multicolumn{2}{|c|}{165} \\
\hline & Pre & Post & Pre & Post & Pre & Post \\
\hline $\mathrm{AB}$ & 248.6 & 221 & 276.2 & 303.8 & 276.2 & \\
\hline $\mathrm{HB}$ & 119.7 & 138.1 & 313 & 267 & 221 & - \\
\hline JB & 73.7 & 119.7 & 211.7 & 165.7 & 211.7 & 257.8 \\
\hline $\mathrm{CB}$ & 156.5 & 128.9 & 239.4 & 184.1 & 147.3 & 193.3 \\
\hline $\mathrm{HC}$ & 257.8 & 230.2 & 211.7 & 276.2 & 267 & 221 \\
\hline $\mathrm{JC}$ & 101.3 & 46 & 248.6 & 211.7 & 239.4 & 386.7 \\
\hline $\mathrm{AF}$ & 82.9 & 92.1 & 221 & 211.7 & 184.1 & 239.4 \\
\hline $\mathrm{FF}$ & 111.2 & 64.4 & 176 & 128.9 & 148.2 & 221 \\
\hline $\mathrm{HH}$ & 92.1 & 147.3 & 156.5 & 165.7 & 147.3 & 147.3 \\
\hline LH & 193.3 & 101.3 & 432.7 & 267 & . & 174.9 \\
\hline $\mathrm{JK}$ & 148.2 & 119.7 & 240.9 & 156.5 & 222.4 & - \\
\hline $\mathbf{R P}$ & 138.1 & 138.1 & 267 & 147.3 & 276.2 & 165.7 \\
\hline FR & 82.9 & 239.4 & 267 & 331.4 & 184.1 & 285.4 \\
\hline MS & 110.5 & 110.5 & 202.5 & 211.7 & 184.1 & 248.6 \\
\hline$x$ & 122.91 & 131.2 & 229.61 & 204.83 & 202.73 & 232.48 \\
\hline S.D. & 50.03 & 57.06 & 42.64 & 60.32 & 49.55 & 63.69 \\
\hline
\end{tabular}




\begin{tabular}{|c|c|c|c|c|c|c|}
\hline \multicolumn{7}{|c|}{$\begin{array}{c}\text { MAX RATE OF TORQUE DEVELOPMENT (N.m /s) } \\
\text { Trained Arm }\end{array}$} \\
\hline \multirow[b]{2}{*}{ Subject } & \multicolumn{2}{|c|}{75} & \multicolumn{2}{|c|}{120} & \multicolumn{2}{|c|}{165} \\
\hline & Pre & Post & Pre & Post & Pre & Post \\
\hline $\mathrm{AB}$ & 184.1 & 2025 & 230.2 & 276.2 & 257.8 & 257.8 \\
\hline HB & 221 & 119.7 & 276.2 & 239.4 & 221 & 211.7 \\
\hline JB & 92.1 & 119.7 & 174.9 & 230.2 & 230.2 & 202.5 \\
\hline $\mathrm{CB}$ & 110.5 & 138.1 & 285.4 & 313 & 239.4 & 359.1 \\
\hline $\mathrm{HC}$ & 202.5 & 156.5 & 211.7 & 230.2 & 267 & 322.2 \\
\hline JC & 119.7 & 82.9 & 211.7 & 184.1 & 184.1 & 202.5 \\
\hline $\mathrm{AF}$ & 138.1 & 119.7 & 257.8 & 257.8 & 211.7 & 248.6 \\
\hline FF & 111.2 & 55.2 & 203.8 & 147.3 & 148.2 & 128.4 \\
\hline $\mathrm{HH}$ & 82.9 & 92.1 & 165.7 & 193.3 & 211.7 & 202.5 \\
\hline LH & 184.1 & 82.9 & 313 & 276.2 & 248.6 & 239.4 \\
\hline JK & 92.7 & 193.3 & 194.6 & 202.5 & 203.8 & 221 \\
\hline $\mathbf{R P}$ & 165.7 & 101.3 & 230.2 & 165.7 & 248.6 & 276.2 \\
\hline FR & 119.7 & 184.1 & 165.7 & 276.2 & 184.1 & 285.4 \\
\hline MS & 101.3 & 82.9 & 184.1 & 184.1 & 193.3 & 193.3 \\
\hline$x$ & 129.78 & 120.46 & 213.48 & 218.65 & 211.93 & 237.83 \\
\hline S.D. & 44.41 & 41.8 & 41.26 & 48.27 & 32.43 & 63.41 \\
\hline
\end{tabular}




\begin{tabular}{|c|c|c|c|c|c|c|}
\hline \multicolumn{7}{|c|}{ HALF RELAXATION TIME (ms) } \\
\hline \multicolumn{7}{|c|}{ Untrained Arm } \\
\hline & \multicolumn{2}{|c|}{75} & \multicolumn{2}{|c|}{120} & \multicolumn{2}{|c|}{165} \\
\hline Subject & Pre & Post & Pre & Post & Pre & Post \\
\hline $\mathrm{AB}$ & 66 & 64 & 80 & 100 & 102 & - \\
\hline $\mathrm{HB}$ & 52 & 48 & 92 & 66 & 90 & 86 \\
\hline $\mathrm{JB}$ & 78 & 26 & 72 & 90 & 64 & 68 \\
\hline $\mathrm{CB}$ & 94 & 58 & 76 & 64 & 94 & 90 \\
\hline $\mathrm{HC}$ & 44 & 88 & 50 & 48 & 38 & 40 \\
\hline JC & 60 & 42 & 112 & 124 & 100 & 112 \\
\hline $\mathrm{AF}$ & 82 & 70 & 120 & 52 & 74 & 56 \\
\hline $\mathrm{FF}$ & 100 & 82 & 102 & 106 & 112 & 100 \\
\hline $\mathrm{HH}$ & 80 & 96 & 44 & 62 & 82 & 70 \\
\hline LH & 40 & 86 & 34 & 96 & - & - \\
\hline JK & 72 & 82 & 100 & 106 & 120 & 102 \\
\hline$R P$ & 56 & 66 & 70 & 114 & 76 & 92 \\
\hline FR & 60 & 62 & 92 & 84 & 104 & 94 \\
\hline MS & 50 & 76 & 112 & 76 & 100 & 102 \\
\hline$x$ & 69 & 66.33 & 86.83 & 82.67 & 87.83 & 84.33 \\
\hline S.D. & 18.02 & 20.43 & 24.56 & 25.36 & 22.63 & 21.45 \\
\hline
\end{tabular}




\begin{tabular}{|c|c|c|c|c|c|c|}
\hline \multicolumn{7}{|c|}{$\begin{array}{c}\text { HALF RELAXATION TIME (ms) } \\
\text { Trained Arm }\end{array}$} \\
\hline \multirow[b]{2}{*}{ Subject } & \multicolumn{2}{|c|}{75} & \multicolumn{2}{|c|}{120} & \multicolumn{2}{|c|}{165} \\
\hline & Pre & Post & Pre & Post & Pre & Post \\
\hline$A B$ & 76 & 56 & 104 & 104 & 108 & 112 \\
\hline $\mathrm{HB}$ & 60 & 64 & 114 & 84 & 88 & 96 \\
\hline JB & 42 & 162 & 78 & 86 & 70 & 104 \\
\hline $\mathrm{CB}$ & 84 & 62 & 90 & 66 & 74 & 60 \\
\hline HC & 50 & 84 & 54 & 58 & 68 & 72 \\
\hline JC & 76 & 64 & 66 & 116 & 96 & 120 \\
\hline $\mathrm{AF}$ & 62 & 58 & 70 & 72 & 86 & 92 \\
\hline FF & 76 & 80 & 78 & 118 & 70 & 94 \\
\hline $\mathrm{HH}$ & 48 & 62 & 90 & 94 & 68 & 82 \\
\hline LH & 66 & 118 & 62 & 98 & 90 & 98 \\
\hline $\mathrm{JK}$ & 70 & 68 & 76 & 104 & 78 & 104 \\
\hline $\mathbf{R P}$ & 50 & 46 & 94 & 100 & 82 & 106 \\
\hline FR & 78 & 80 & 110 & 90 & 102 & 98 \\
\hline MS & 74 & 80 & 88 & 86 & 100 & 95.17 \\
\hline$x$ & 64.17 & 75.83 & 84 & 18.49 & 81.83 & 17.09 \\
\hline S.D. & 14.05 & 29.35 & 17.37 & & 12.55 & \\
\hline
\end{tabular}


TIME TO PEAK TORQUE (ms)

Untrained Arm

\begin{tabular}{|l|l|l|l|l|l|l||}
\hline & \multicolumn{2}{|c|}{75} & \multicolumn{3}{c|}{120} & \multicolumn{2}{c|}{165} \\
\hline Subject & Pre & Post & Pre & Post & Pre & Post \\
\hline AB & 64 & 66 & 52 & 72 & 64 & - \\
\hline HB & 84 & 66 & 56 & 76 & 68 & 68 \\
\hline JB & 54 & 32 & 62 & 54 & 56 & 58 \\
\hline CB & 62 & 104 & 60 & 58 & 74 & 48 \\
\hline HC & 52 & 52 & 60 & 46 & 62 & 58 \\
\hline JC & 86 & 80 & 44 & 50 & 48 & 58 \\
\hline AF & 46 & 64 & 52 & 56 & 58 & 52 \\
\hline FF & 40 & 54 & 46 & 48 & 52 & 54 \\
\hline HH & 38 & 26 & 50 & 60 & 58 & 54 \\
\hline LH & 56 & 64 & 48 & 50 & - & - \\
\hline JK & 76 & 60 & 64 & 56 & 36 & 50 \\
\hline RP & 64 & 52 & 56 & 52 & 58 & 64 \\
\hline FR & 74 & 60 & 56 & 48 & 60 & 52 \\
\hline MS & 68 & 74 & 64 & 78 & 70 & 58 \\
\hline X & 62 & 60.33 & 55.83 & 56.83 & 58.33 & 56.17 \\
\hline S.D. & 16.29 & 20.64 & 6.69 & 10.36 & 10.19 & 5.75 \\
\hline
\end{tabular}




\begin{tabular}{|c|c|c|c|c|c|c|}
\hline \multicolumn{7}{|c|}{$\begin{array}{c}\text { IMPULSE TO } / 2 \text { RELAXATION TIME } \\
\text { Untrained Arm }\end{array}$} \\
\hline & \multicolumn{2}{|c|}{75} & \multicolumn{2}{|c|}{120} & \multicolumn{2}{|c|}{165} \\
\hline Subject & Pre & Post & Pre & Post & Pre & Post \\
\hline MS & .364 & .411 & .98 & .854 & .902 & .885 \\
\hline FR & .26 & .468 & .799 & .716 & .755 & .884 \\
\hline RP & .301 & .301 & .723 & .632 & .808 & .789 \\
\hline JK & .552 & .395 & .863 & .72 & .593 & .543 \\
\hline $\mathrm{HH}$ & .203 & .203 & .323 & .452 & .478 & .584 \\
\hline FF & .316 & .194 & 521 & .425 & .52 & .485 \\
\hline AF & .225 & .275 & .942 & .535 & .618 & .532 \\
\hline $\mathrm{JC}$ & .4 & .107 & .836 & .792 & .756 & .874 \\
\hline $\mathrm{HC}$ & .487 & .665 & .639 & .615 & .709 & .798 \\
\hline $\mathrm{CB}$ & .439 & .298 & .667 & .520 & .617 & .74 \\
\hline JB & .249 & .1 & .66 & .465 & .569 & .572 \\
\hline $\mathrm{BB}$ & .414 & .292 & 1.084 & .933 & .902 & 1.005 \\
\hline $\mathrm{AB}$ & .813 & .787 & .816 & 1.37 & 1.14 & 1.199 \\
\hline
\end{tabular}




\begin{tabular}{|c|c|c|c|c|c|c|}
\hline \multicolumn{7}{|c|}{$\begin{array}{c}\text { IMPULSE TO } h_{2} \text { RELAXATION TIME } \\
\text { Trained Arm }\end{array}$} \\
\hline & \multicolumn{2}{|c|}{75} & \multicolumn{2}{|c|}{120} & \multicolumn{2}{|c|}{165} \\
\hline Subject & Pre & Post & Pre & Post & Pre & Post \\
\hline MS & .345 & .494 & .841 & .857 & .686 & .861 \\
\hline FR & .455 & .494 & .799 & 1.03 & .836 & 1.062 \\
\hline $\mathbf{R P}$ & .308 & .26 & .705 & .706 & .712 & 1.047 \\
\hline JK & .389 & .67 & .659 & .891 & .507 & .74 \\
\hline $\mathrm{HH}$ & .257 & .278 & .59 & .615 & .598 & .708 \\
\hline FF & .309 & .274 & .513 & .599 & .494 & .532 \\
\hline $\mathrm{AF}$ & .379 & .348 & .546 & .673 & .783 & .865 \\
\hline JC & .482 & .322 & .609 & .75 & .664 & .813 \\
\hline $\mathrm{HC}$ & .427 & .387 & .565 & 546 & .735 & .75 \\
\hline $\mathrm{CB}$ & .546 & .456 & 1.13 & 1.024 & .885 & 1.001 \\
\hline $\mathrm{JB}$ & .329 & .777 & .603 & .741 & .576 & .88 \\
\hline BB & .623 & .418 & 1.009 & 1.325 & .801 & 1.082 \\
\hline
\end{tabular}




\begin{tabular}{|c|c|c|c|c|c|c|}
\hline \multicolumn{7}{|c|}{$\begin{array}{l}\text { MVC (N.m) } \\
\text { Trained Arm }\end{array}$} \\
\hline & \multicolumn{2}{|c|}{75} & \multicolumn{2}{|c|}{120} & \multicolumn{2}{|c|}{165} \\
\hline Subject & Pre & Post & Pre & Post & Pre & Post \\
\hline $\mathrm{AB}$ & 42.49 & 38.83 & 52.76 & 52.37 & 28.6 & 38 \\
\hline $\mathrm{HB}$ & 61.44 & 58.82 & 57.82 & 70.75 & 34.29 & 36.03 \\
\hline JB & 56.77 & 49.25 & 53.79 & 57.79 & 34.02 & 35.87 \\
\hline $\mathrm{CB}$ & 72.08 & 73.32 & 77.06 & 71.61 & 42.5 & 63.86 \\
\hline $\mathrm{HC}$ & 49.86 & 50.12 & 50.05 & 51.2 & 33.24 & 37.98 \\
\hline JC & 50.09 & 29.47 & 52.5 & 55.38 & 33.02 & 37.39 \\
\hline $\mathrm{AF}$ & 56.2 & 62.96 & 68.03 & 70.62 & 46.96 & 53.02 \\
\hline FF & 50.83 & 43.07 & 46.15 & 48.25 & 28.32 & 29.75 \\
\hline $\mathrm{HH}$ & 68.8 & 72.16 & 71.22 & 72.35 & 54.24 & 47.45 \\
\hline LH & 64.01 & 58.07 & 70.46 & 66.38 & 36.46 & 38.05 \\
\hline JK & 59.96 & 55.12 & 49.44 & 51.96 & 34.35 & 34.59 \\
\hline RP & 47.91 & 49.61 & 47.11 & 43.25 & 35.48 & 32.42 \\
\hline FR & 46.55 & 59.27 & 52.44 & 54.89 & 31.52 & 36.3 \\
\hline MS & 63.32 & 55.29 & 67.25 & 68.45 & 43.42 & 47.89 \\
\hline$x$ & 56.98 & 54.87 & 57.74 & 59.71 & 37.61 & 41.05 \\
\hline S.D. & 8.34 & 12.08 & 10.44 & 10.44 & 7.53 & 9.97 \\
\hline
\end{tabular}


MAXIMUM RATE OF TORQUE RELAX (N.m/s)

Trained Arm

\begin{tabular}{|c|c|c|c|c|c|c|}
\hline & \multicolumn{2}{|c|}{75} & \multicolumn{2}{|c|}{120} & \multicolumn{2}{|c|}{165} \\
\hline Subject & Pre & Post & Pre & Post & Pre & Post \\
\hline$A B$ & -92.1 & -110.5 & -82.9 & -119.7 & -82.9 & -101.3 \\
\hline $\mathrm{HB}$ & -93.7 & -64.4 & -69.4 & -101.3 & -92.1 & -110.5 \\
\hline JB & -55.2 & -46 & -64.4 & -82.9 & -128.9 & -73.7 \\
\hline$C B$ & -55.2 & -76.7 & -110.5 & -147.3 & -92.1 & -165.7 \\
\hline $\mathrm{HC}$ & -82.9 & -55.2 & -110.5 & -119.7 & -147.3 & -110.5 \\
\hline $\mathrm{JC}$ & -55.2 & -36.8 & -82.9 & -55.2 & -64.4 & -46 \\
\hline $\mathrm{AF}$ & -92.1 & -55.2 & -101.3 & -92.1 & -92.1 & -73.7 \\
\hline FF & -37.1 & -27.6 & -64.9 & -36.8 & -55.6 & -46 \\
\hline $\mathrm{HH}$ & -55.2 & -55.2 & -64.4 & -64.4 & -82.9 & -73.7 \\
\hline LH & -55.2 & -27.6 & -92.1 & -73.7 & -64.4 & -101.3 \\
\hline JK & -55.6 & -73.7 & -92.7 & -73.7 & -101.9 & -73.7 \\
\hline RP & -55.2 & -46 & -82.9 & -55.2 & -110.5 & -73.7 \\
\hline FR & -36.8 & -46 & -55.2 & -92.1 & -55.2 & -82.9 \\
\hline MS & -46 & -55.2 & -73.7 & -73.7 & -55.2 & -64.4 \\
\hline$x$ & -58.35 & -52.92 & -80.65 & -82.87 & -89.85 & -82.88 \\
\hline S.D. & 16.8 & 13.69 & 19.31 & 30.42 & 29.67 & 32.85 \\
\hline
\end{tabular}




\begin{tabular}{|c|c|c|c|c|c|c|}
\hline \multicolumn{7}{|c|}{ MAXIMUM } \\
\hline \multirow[b]{2}{*}{ Subject } & \multicolumn{2}{|c|}{75} & \multicolumn{2}{|c|}{120} & \multicolumn{2}{|c|}{165} \\
\hline & Pre & Post & Pre & Post & Pre & Post \\
\hline $\mathrm{AB}$ & -128.9 & -101.3 & -138.1 & -110.5 & -119.7 & - \\
\hline $\mathrm{HB}$ & -64.4 & -55.2 & -101.3 & -119.7 & -128.9 & -138.1 \\
\hline JB & -36.8 & -82.9 & -73.7 & -46 & -92.1 & -92.1 \\
\hline $\mathrm{CB}$ & -55.2 & -27.6 & -82.9 & -64.4 & -55.3 & -110.5 \\
\hline $\mathrm{HC}$ & -119.7 & -110.5 & -128.9 & -174.9 & -184.1 & -230.2 \\
\hline JC & -55.2 & -27.6 & -110.5 & -110.5 & -92.1 & -101.3 \\
\hline $\mathrm{AF}$ & -55.2 & -36.8 & -101.3 & -92.1 & -33.7 & -101.3 \\
\hline $\mathrm{FF}$ & -37.1 & -27.6 & -46.3 & -36.8 & -37.1 & -46 \\
\hline $\mathrm{HH}$ & -46 & 64.4 & -73.7 & -69.4 & -55.3 & -92.1 \\
\hline LH & -119.7 & -46 & -221 & -110.5 & - & - \\
\hline JK & -55.6 & -36.8 & 64.9 & -64.4 & -55.6 & -46 \\
\hline $\mathbf{R P}$ & -55.2 & -55.2 & -119. & -36.8 & -65.7 & -64.4 \\
\hline FR & -36.8 & -64.4 & -73.7 & -82.9 & -55.2 & -82.9 \\
\hline MS & -64.4 & -46 & 64.4 & -110.5 & -55.2 & -92.1 \\
\hline$\underline{x}$ & -56.8 & -52.92 & -86.77 & -83.62 & -87.52 & -99.75 \\
\hline S.D. & 22.13 & 25.19 & -25.21 & 40.52 & 47.78 & 48.71 \\
\hline
\end{tabular}


TIME TO PEAK TORQUE (ms)

Trained Arm

\begin{tabular}{||l|l|l|l|l|l|l||}
\hline & \multicolumn{2}{|c|}{75} & \multicolumn{2}{c|}{120} & \multicolumn{2}{c||}{165} \\
\hline & Pre & Post & Pre & Post & Pre & Post \\
\hline AB & 68 & 78 & 60 & 68 & 58 & 60 \\
\hline HB & 86 & 74 & 50 & 78 & 56 & 74 \\
\hline JB & 88 & 86 & 58 & 64 & 58 & 70 \\
\hline CB & 86 & 56 & 62 & 58 & 74 & 62 \\
\hline HC & 56 & 54 & 60 & 46 & 56 & 52 \\
\hline JC & 70 & 86 & 56 & 56 & 54 & 54 \\
\hline AF & 50 & 60 & 46 & 52 & 58 & 52 \\
\hline FF & 74 & 92 & 52 & 56 & 60 & 58 \\
\hline HH & 84 & 62 & 52 & 50 & 66 & 60 \\
\hline LH & 50 & 64 & 56 & 54 & 56 & 60 \\
\hline JK & 64 & 82 & 50 & 64 & 42 & 48 \\
\hline RP & 56 & 92 & 46 & 62 & 48 & 56 \\
\hline FR & 68 & 58 & 56 & 56 & 68 & 54 \\
\hline MS & 52 & 82 & 66 & 72 & 60 & 72 \\
\hline X & 69.5 & 73.67 & 54.5 & 59.5 & 58.38 & 59.33 \\
\hline S.D. & 14.15 & 14.72 & 6.27 & 9.11 & 8.56 & 8.54 \\
\hline
\end{tabular}


TIME TO PEAK TORQUE (ms)

Untrained Arm

\begin{tabular}{||l|l|l|l|l|l|l||}
\hline & \multicolumn{2}{|c|}{75} & \multicolumn{3}{c|}{120} & \multicolumn{2}{c|}{165} \\
\hline Subject & Pre & Post & Pre & Post & Pre & Post \\
\hline AB & 64 & 66 & 52 & 72 & 64 & - \\
\hline HB & 84 & 66 & 56 & 76 & 68 & 68 \\
\hline JB & 54 & 32 & 62 & 54 & 56 & 58 \\
\hline CB & 62 & 104 & 60 & 58 & 74 & 48 \\
\hline HC & 52 & 52 & 60 & 46 & 62 & 58 \\
\hline JC & 86 & 80 & 44 & 50 & 48 & 58 \\
\hline AF & 46 & 64 & 52 & 56 & 58 & 52 \\
\hline FF & 40 & 54 & 46 & 48 & 52 & 54 \\
\hline HH & 38 & 26 & 50 & 60 & 58 & 54 \\
\hline LH & 56 & 64 & 48 & 50 & - & - \\
\hline IK & 76 & 60 & 64 & 56 & 36 & 50 \\
\hline RP & 64 & 52 & 56 & 52 & 58 & 64 \\
\hline FR & 74 & 60 & 56 & 48 & 60 & 52 \\
\hline MS & 68 & 74 & 64 & 78 & 70 & 58 \\
\hline X & 62 & 60.33 & 55.83 & 56.83 & 58.33 & 56.17 \\
\hline S.D. & 16.29 & 20.64 & 6.69 & 10.36 & 10.19 & 5.75 \\
\hline \hline
\end{tabular}




\begin{tabular}{|c|c|c|c|c|c|c|}
\hline \multicolumn{7}{|c|}{$\begin{array}{c}\text { MVC (N.m) } \\
\text { Untrained Arm }\end{array}$} \\
\hline \multirow[b]{2}{*}{ Subject } & \multicolumn{2}{|c|}{75} & \multicolumn{2}{|c|}{120} & \multicolumn{2}{|c|}{165} \\
\hline & Pre & Post & Pre & Post & Pre & Post \\
\hline$A B$ & 54.55 & 40.48 & 55.38 & 54 & 33.72 &. \\
\hline $\mathrm{HB}$ & 61.36 & 67.37 & 65.72 & 65.64 & 38.82 & 40.56 \\
\hline $\mathrm{JB}$ & 55.31 & 46.55 & 55.33 & 56.17 & 35.28 & 32.48 \\
\hline $\mathrm{CB}$ & 67.35 & 55.24 & 75.14 & 66.29 & 38.34 & 51.75 \\
\hline $\mathrm{HC}$ & 51.08 & 42.3 & 66.27 & 51.73 & 40.06 & 39.24 \\
\hline $\mathrm{JC}$ & 55.63 & 41.27 & 54.8 & 56.15 & 36.68 & 36.17 \\
\hline $\mathrm{AF}$ & 63.93 & 60.2 & 64.61 & 64.55 & 35.5 & 42.33 \\
\hline $\mathrm{FF}$ & 46.94 & 38.65 & 45.5 & 38.88 & 28.7 & 24.76 \\
\hline $\mathrm{HH}$ & 66.22 & 52.74 & 68.29 & 59.98 & 55.48 & 48.8 \\
\hline $\mathrm{LH}$ & 75 & 60.79 & 77.48 & 70.1 & - & - \\
\hline JK & 47.74 & 40.14 & 47.95 & 41.78 & 25.37 & 23.88 \\
\hline $\mathrm{RP}$ & 54.58 & 47.45 & 65.22 & 52.2 & 47.88 & 36.69 \\
\hline $\mathrm{FR}$ & 46.23 & 49.65 & 46.55 & 45.88 & 32.96 & 45.85 \\
\hline MS & 49.25 & 73.68 & 63.63 & 70.65 & 56.46 & 59.6 \\
\hline$x$ & 55.47 & 51.27 & 59.92 & 55.82 & 39.29 & 40.18 \\
\hline S.D. & 7.63 & 11.13 & 9.61 & 10.16 & 9.61 & 10.51 \\
\hline
\end{tabular}


085070027 